Supporting Information

\title{
Photoorganocatalyzed Reversible-Deactivation Alternating Copolymerization of Chlorotrifluoroethylene and Vinyl Ethers under Ambient Conditions: Facile Access to Main-Chain Fluorinated Copolymers
}

Kunming Jiang, Shantao Han, Mingyu Ma, Lu Zhang, Yucheng Zhao and Mao Chen*

State Key Laboratory of Molecular Engineering of Polymers, Department of Macromolecular Science, Fudan University, Shanghai, 200433, China

*E-mail: chenmao@fudan.edu.cn 


\section{Table of Contents}

1. General information of materials and analytical methods

2. Synthesis and characterizations of F-PTH

3. Condition optimizations for the alternating copolymerization

4. Kinetic investigations for the alternating copolymerization in Figure 2

5. Experimental procedures and results for experiments in Table 1

6. UV-vis analysis and ${ }^{1} \mathrm{H}$ NMR spectra for alternating copolymers

7. Light controlled "ON/OFF" experiments in Figures 4 and 5

8. Experiments and characterizations for Figure 6

9. Synthesis and characterizations of CTAs

10. Information of global CTFE Market 


\section{General information of materials and analytical methods}

Ethyl vinyl ether (EVE), isobutyl vinyl ether (IBVE), nbutyl vinyl ether (BVE), 2chloroethyl vinyl ether (CEVE), hydroxybutyl vinyl ether (HBVE), di(ethylene glycol) vinyl ether (DEGVE), tbutyldimethylsilyl chloride, tris(2-phenylpyridinato)iridium(III) (Ir(ppy)3), diethyl carbonate (DEC), polyethylene oxide (PEO or PEG, $M_{\mathrm{n}}=10000 \mathrm{~g} / \mathrm{mol}$ ), lithium bis(trifluoromethanesulfone)imide (LiTFSI), other reagents and solvents were purchased from Sigma-Aldrich, TCI or Adamas. All monomers were redistilled before use. Tetrahydrofuran (THF) and 1,4-dioxane were freshly distilled from sodium before use. Dichloromethane (DCM) was freshly distilled from $\mathrm{CaH}_{2}$ before use. $\mathrm{DEC}$ were freshly distilled from anhydrous $\mathrm{CaCl}_{2}$ before use. For the synthesis and characterization of photoredox catalsyt and chain-transfer agents, see sections 2 and 10, respectively.

Nuclear magnetic resonance (NMR) was recorded with an Avanced III $400 \mathrm{MHz}$ Bruker spectrometer at $25{ }^{\circ} \mathrm{C}$. ${ }^{1} \mathrm{H}$ NMR signals were measured relative to the signal for residual chloroform $(7.26 \mathrm{ppm})$ in deuterochloroform $\left(\mathrm{CDCl}_{3}\right)$, are reported in $\delta$ units, parts per million (ppm). ${ }^{19} \mathrm{~F}$ NMR signals were obtained are reported in ppm units. ${ }^{13} \mathrm{C}$ NMR signals were obtained with ${ }^{1} \mathrm{H}$ decoupling, and are reported in ppm units relative to $\mathrm{CDCl}_{3}$ (77.16 ppm). Size-exclusion chromatography (SEC) measurements were performed in THF at $35^{\circ} \mathrm{C}$ with an elution rate of $1.0 \mathrm{~mL} / \mathrm{min}$ on an Agilent 1100 equipped with a G1310A pump, a G1362A refractive index detector. Three columns were employed including one $5 \mu \mathrm{m}$ LP gel column (molecular range 500 2×10 $\mathrm{g} \mathrm{mol}^{-1}$ ) and two $5 \mu \mathrm{m}$ LP gel mixed bed columns (molecular range $\left.200 \sim 3 \times 10^{6} \mathrm{~g} \mathrm{~mol}^{-1}\right)$. The calibration was performed with PS standards. The UV-vis absorption was obtained using a Perkin-Elmer Lambda750 UV-visible spectrophotometer. The emission and excitation spectra were obtained using an PTI Instruments QM40 SteadyState/Transient Fluorescence Spectrometer. Column chromatography was carried out using silica gel (300-400 mesh).

\section{Synthesis and characterization of F-PTH}

A $10 \mathrm{~mL}$ vial equipped with a magnetic stir bar was charged with $\mathrm{NaO} t \mathrm{Bu}(240.0 \mathrm{mg}, 2.5$ mmol), 3,7-diphenyl-10H-phenothiazine ${ }^{[1]}$ (351.1 mg, $1.0 \mathrm{mmol}$ ), RuPhos Precat ${ }^{[2]}$ (14.0 mg, $0.02 \mathrm{mmol}, 2 \mathrm{~mol} \%$ ) and RuPhos ( $8.2 \mathrm{mg}, 0.02 \mathrm{mmol}, 2 \mathrm{~mol} \%$ ) under $\mathrm{N}_{2}$ atmosphere. A solution of 3-bromobenzoic acid $(1.05 \mathrm{mmol})$ in anhydrous dioxane $(1 \mathrm{~mL})$ was added via a syringe into this vial under $\mathrm{N}_{2}$. Then, the mixture was heated at $90^{\circ} \mathrm{C}$ with stirring for $5 \mathrm{~h}$. After 
reaction, the mixture was cooled to room temperature. The $\mathrm{pH}$ value was adjusted to $\sim 2$ by adding $\mathrm{HCl}$ ( $1 \mathrm{M}$ in water). The mixture was diluted with EtOAc. The organic layer was washed with water, brine, dried with $\mathrm{Na}_{2} \mathrm{SO}_{4}$ and concentrated. The collected residue was recrystallized with a pre-mixed solution of hexanes and EtOAc to give 3-(3,7-diphenyl-10H-phenothiazin10-yl) benzoic acid (PTH-acid) as green solid (438.2 mg, 93\% yield). The crude PTH-acid was directly used in the further step of synthesis without further purification.

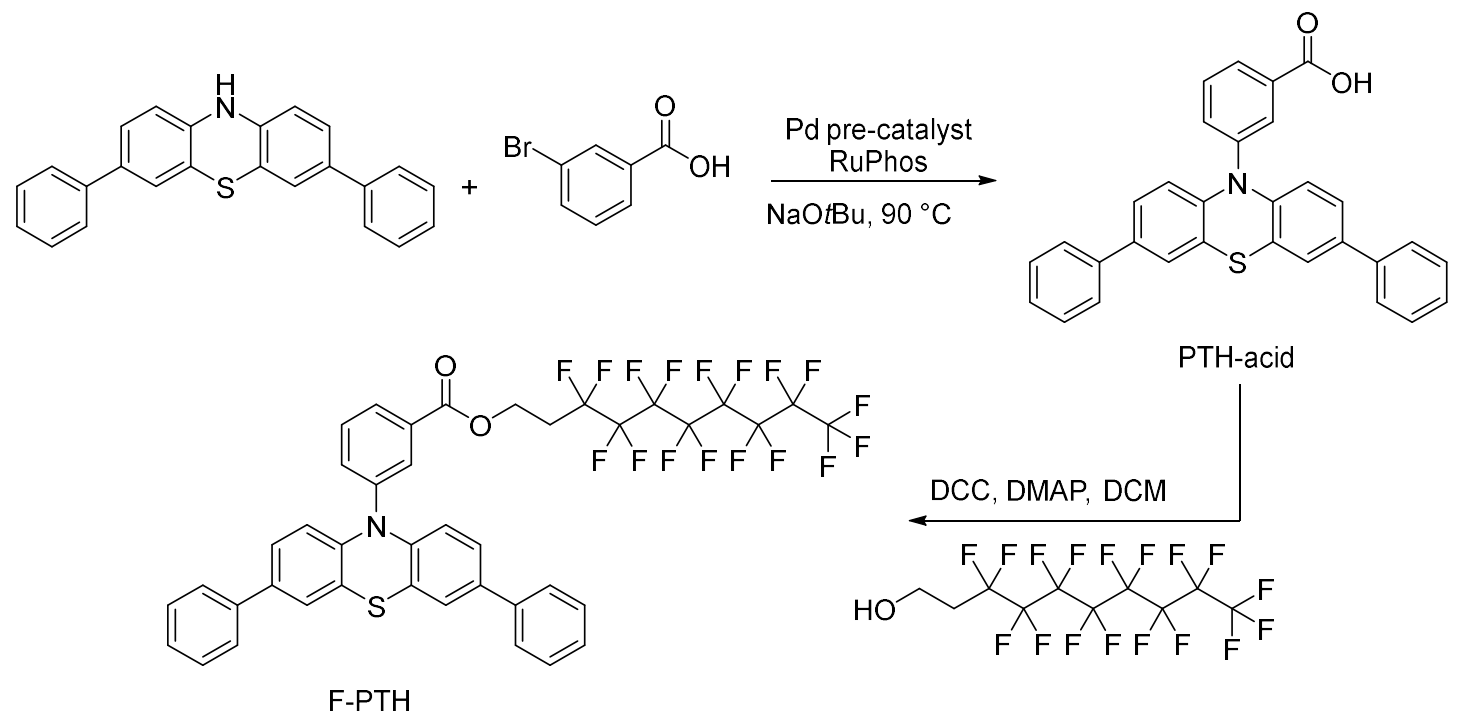

Scheme S1. Synthetic route for F-PTH.

A $25 \mathrm{~mL}$ flask equipped with a magnetic stir bar was charged with PTH-acid (377.0 $\mathrm{mg}$, $0.8 \mathrm{mmol}), 1 \mathrm{H}, 1 \mathrm{H}, 2 \mathrm{H}, 2 \mathrm{H}$-heptadecafluorodecanol (464.0 mg, $1.0 \mathrm{mmol})$ and anhydrous dichloromethane (3 mL). Dicyclohexylcarbodiimide (DCC, $216.2 \mathrm{mg} 1.05 \mathrm{mmol}$ ) and 4dimethylaminopyridine (DMAP, $2.4 \mathrm{mg}, 0.02 \mathrm{mmol}$ ) were dissolved in $2 \mathrm{~mL}$ anhydrous dichloromethane, and the solution was dropped into the flask at $0{ }^{\circ} \mathrm{C}$. The reaction mixture was stirred at room temperature for $12 \mathrm{~h}$. After reaction, the mixture was filtered. The filtrate was concentrated and treated with cold ethyl ether. After further filtration to remove solid impurities and concentration of obtained filtrate, the residue was purified by column chromatography (eluting with $0-10 \%$ EtOAc in hexanes) to afford F-PTH as a light-yellow solid (676.2 $\mathrm{mg}$, $74 \%$ yield). ${ }^{1} \mathrm{H}$ NMR (400 MHz, CDCl3) $\delta: 8.24$ - 8.19 (m, 2H), 7.79 - 7.70 (m, 2H), $7.54-$ $7.52(\mathrm{~m}, 4 \mathrm{H}), 7.45-7.42(\mathrm{~m}, 4 \mathrm{H}), 7.37-7.32,7.16(\mathrm{~m}, 4 \mathrm{H}), 7.15(\mathrm{dd}, J=8.4 \mathrm{~Hz}, 2.4 \mathrm{~Hz}, 2 \mathrm{H})$, $6.29(\mathrm{~d}, J=8.8 \mathrm{~Hz}, 2 \mathrm{H}), 4.71(\mathrm{t}, J=6.8 \mathrm{~Hz}, 2 \mathrm{H}), 2.74-2.61(\mathrm{~m}, 2 \mathrm{H}) \mathrm{ppm} ;{ }^{13} \mathrm{C} \mathrm{NMR}(100$ $\left.\mathrm{MHz}, \mathrm{CDCl}_{3}\right) \delta: 165.2,142.8,141.5,139.7,136.1,135.6,132.5,131.7,131.2,129.4,128.8$, 127.2 , 126.4, 125.6, 125.5, 121.2, 116.7, 118.6 - $106.8(\mathrm{~m}, 8 \mathrm{C}), 57.3,30.6(\mathrm{t}, J=22.0 \mathrm{~Hz})$ ppm; ${ }^{19} \mathrm{~F}$ NMR $\left(376 \mathrm{MHz}, \mathrm{CDCl}_{3}\right) \delta:-80.75$ (t, $\left.J=10.2 \mathrm{~Hz}, 3 \mathrm{~F}\right),-113.47--113.55$ (m, 2F), $121.60--121.63(\mathrm{~m}, 2 \mathrm{~F}),-121.86--121.96(\mathrm{~m}, 4 \mathrm{~F}),-122.71--122.75(\mathrm{~m}, 2 \mathrm{~F}),-123.41--$ 
123.46 (m, 2F), -126.11 - -126.15 (m, 2F); IR (KBr, cm $\left.{ }^{-1}\right)$ : 3060, 2920, 1728, 1600, 1466, 1242, 1148, 1110; HRMS (TOF ES ${ }^{+}$): $m / z$ calcd for $\mathrm{C}_{41} \mathrm{H}_{24} \mathrm{~F}_{17} \mathrm{NO}_{2} \mathrm{SNa}^{+}[\mathrm{M}+\mathrm{Na}]^{+}, 940.1149$; found, 940.1154 .

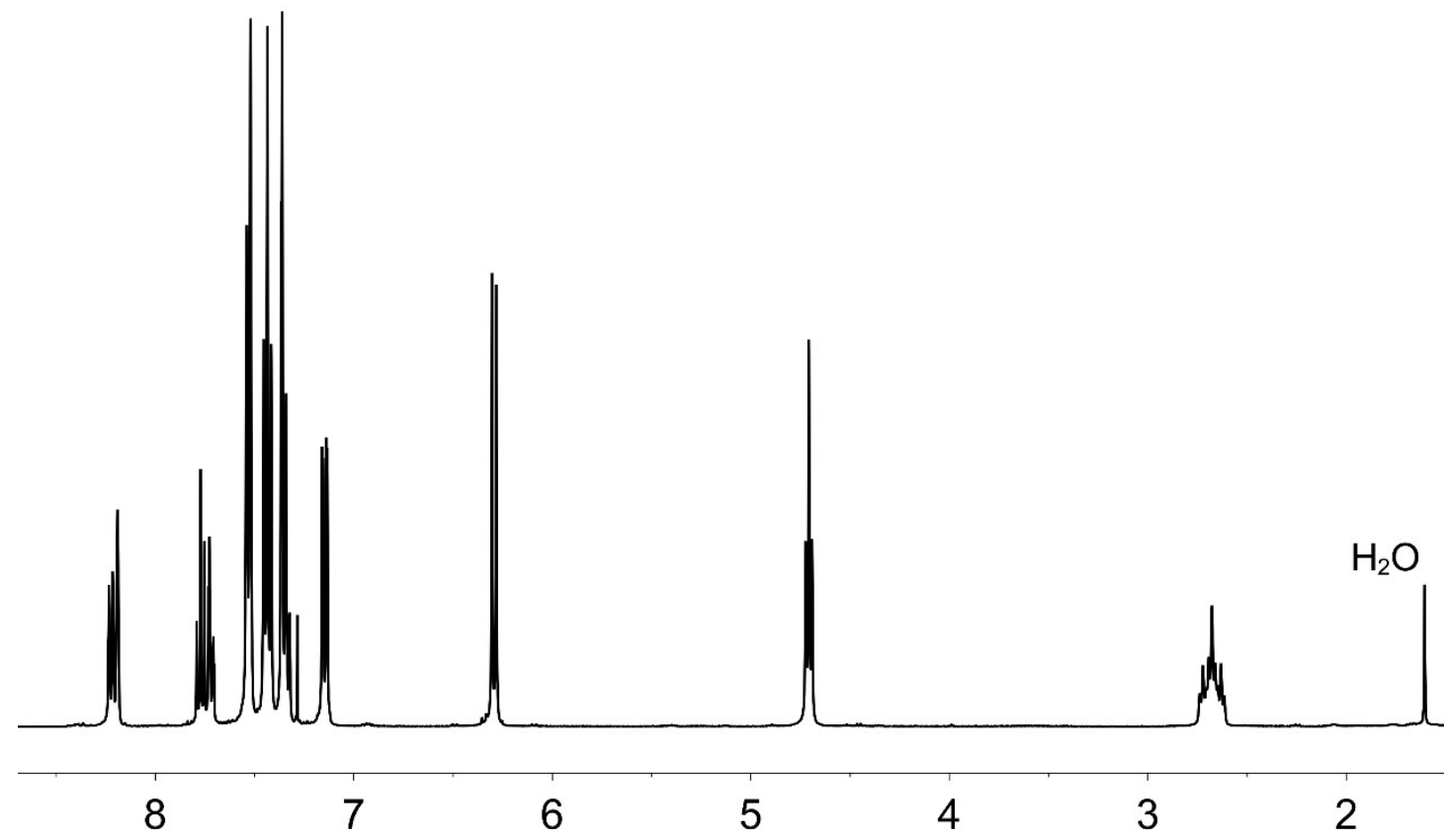

Figure S1. ${ }^{1} \mathrm{H}$ NMR spectrum of F-PTH.

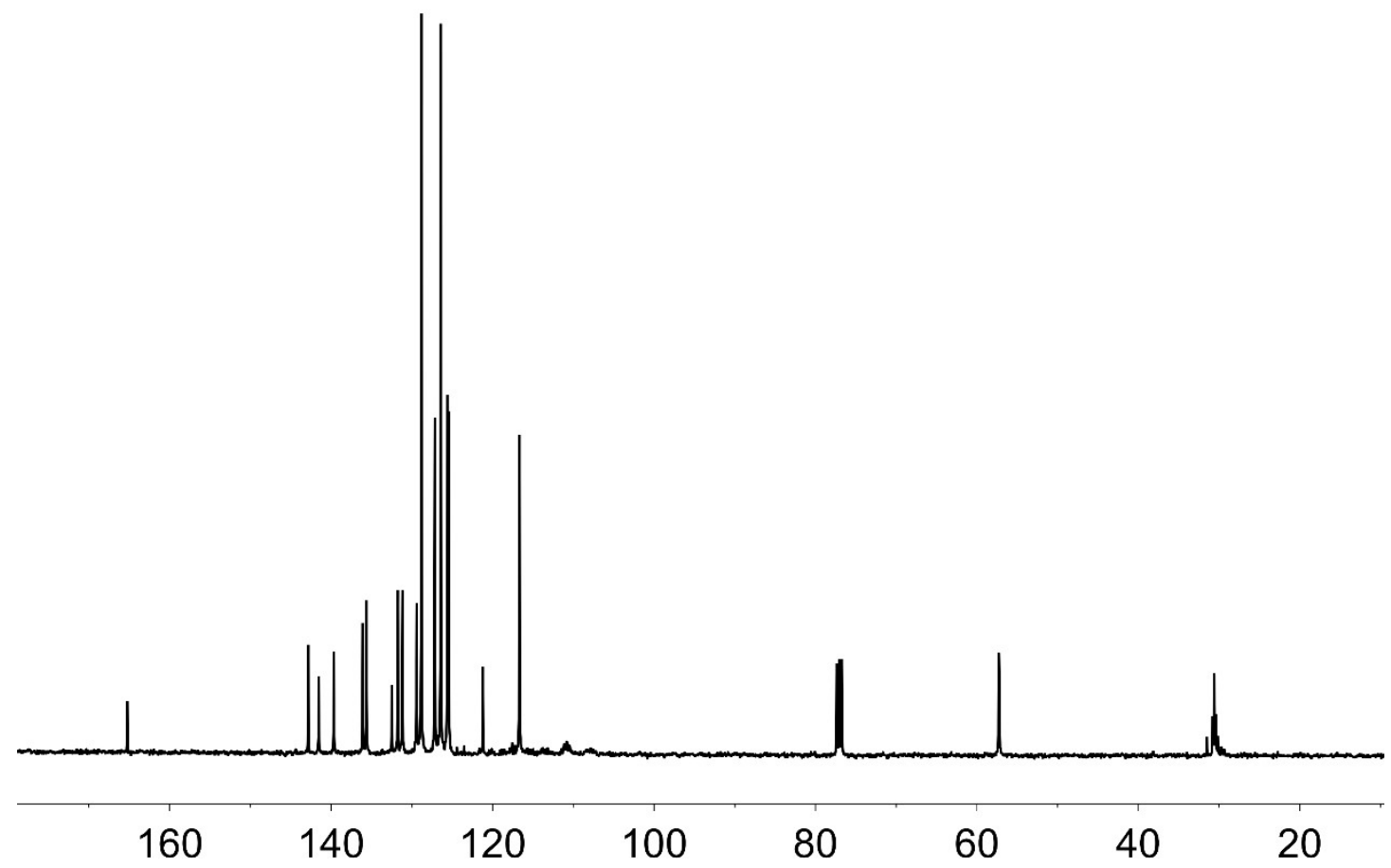

Figure S2. ${ }^{13} \mathrm{C}$ NMR spectrum of F-PTH. 


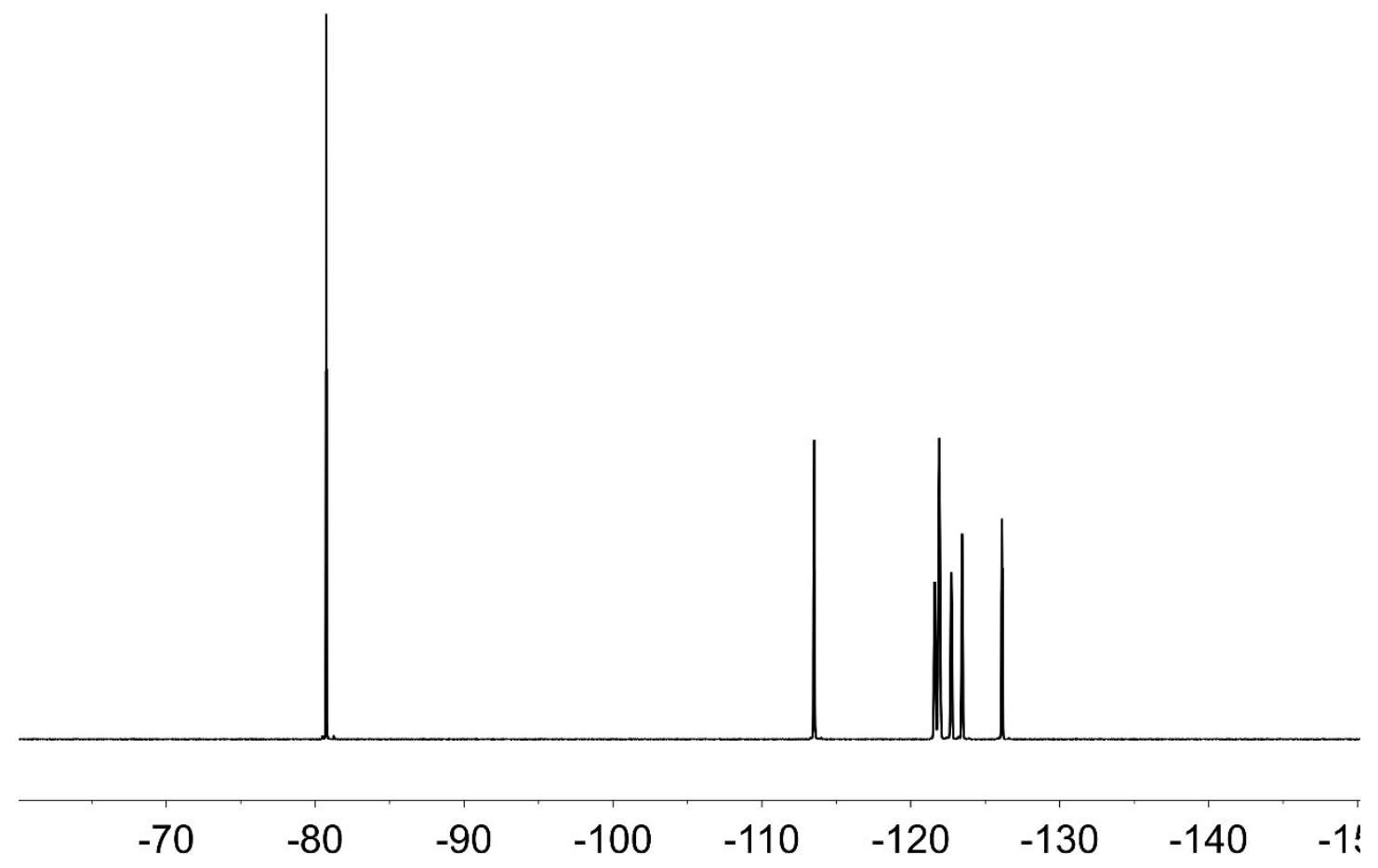

Figure S3. ${ }^{19} \mathrm{~F}$ NMR spectrum of F-PTH.
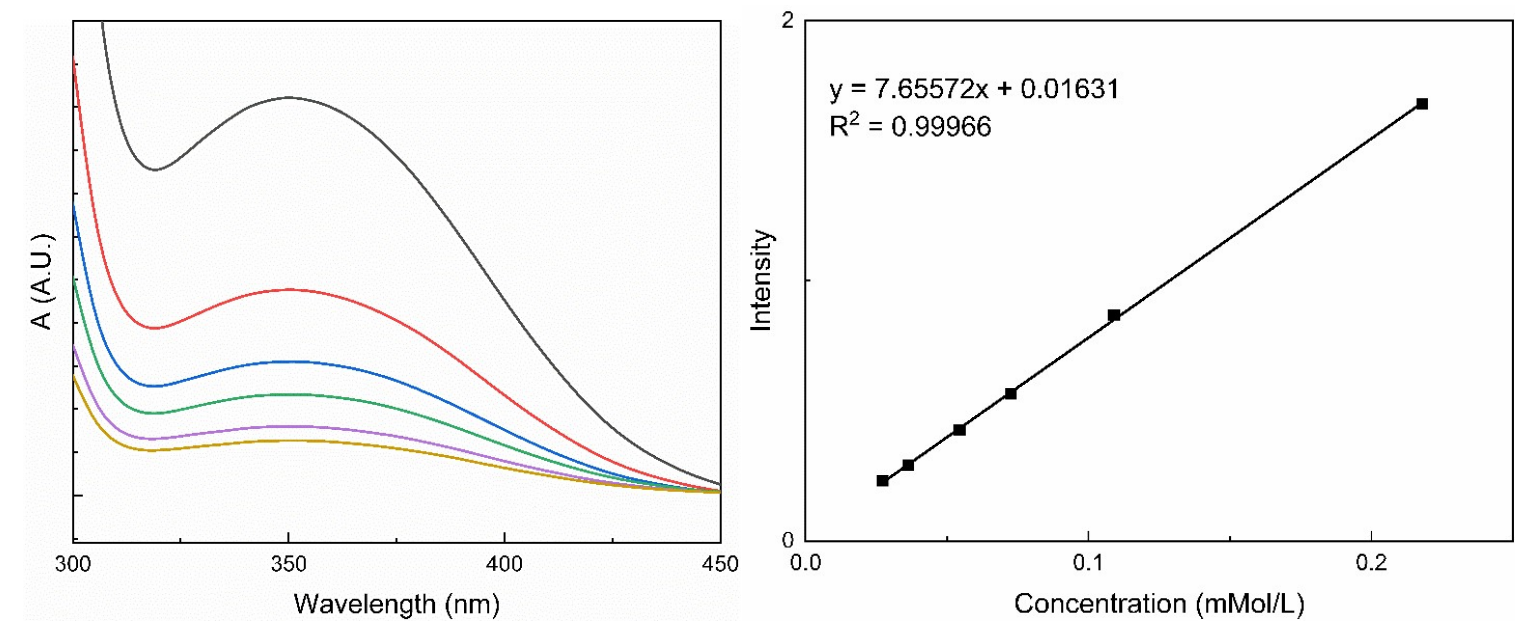

Figure S4. UV-vis profile of F-PTH in $\mathrm{MeCN}\left(5 \times 10^{-5} \mathrm{M}\right)$. 


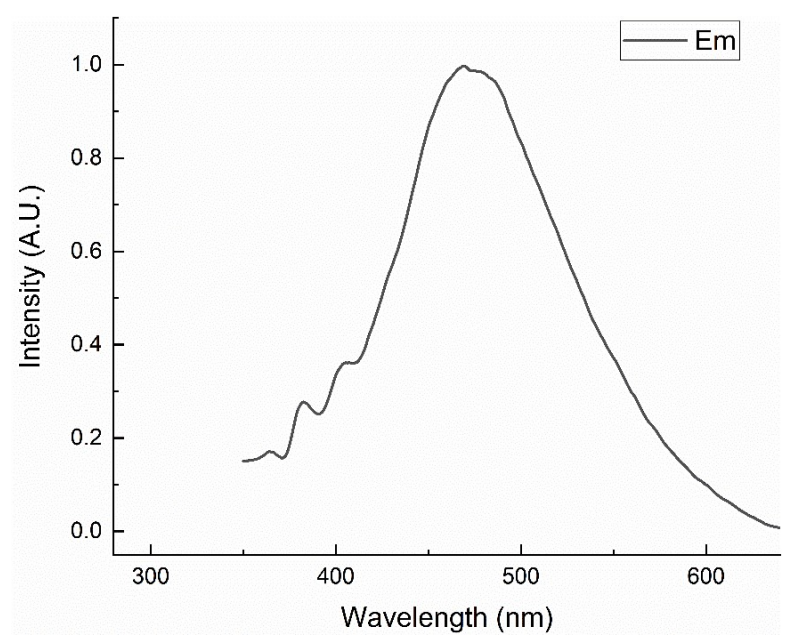

Figure S5. Emission spectra of F-PTH in $\mathrm{MeCN}\left(2 \times 10^{-5} \mathrm{M}\right)$.

Cyclic voltammetry $(\mathrm{CV})$ analysis of the photocatalysis were conducted with $0.1 \mathrm{M}$ $n \mathrm{Bu}_{4} \mathrm{NBF}_{4}$ (Energy Chemical, Electrochemical grade) in MeCN. CV measurements were recorded on a CHI605E potentiostat using a three electrode cell with a glassy carbon working electrode, which was cleaned by polishing with a $0.25 \mu \mathrm{m}$ diamond paste and rinsed in an ultrasound bath for 5 minutes prior to each analysis. The counter electrode was a Pt wire, and the reference electrode was $\mathrm{Ag} / \mathrm{AgCl}$. The working solution was degassed with $\mathrm{N}_{2}$ for $15 \mathrm{~min}$ and then kept under a positive $\mathrm{N}_{2}$ pressure.

Within the electrochemical potential window as shown in Figure S6, the oxidation of FPTH is highly reversible, indicating the resulted $\mathrm{PC}^{\cdot+}$ species is stable in the catalytic cycle of photopolymerization.
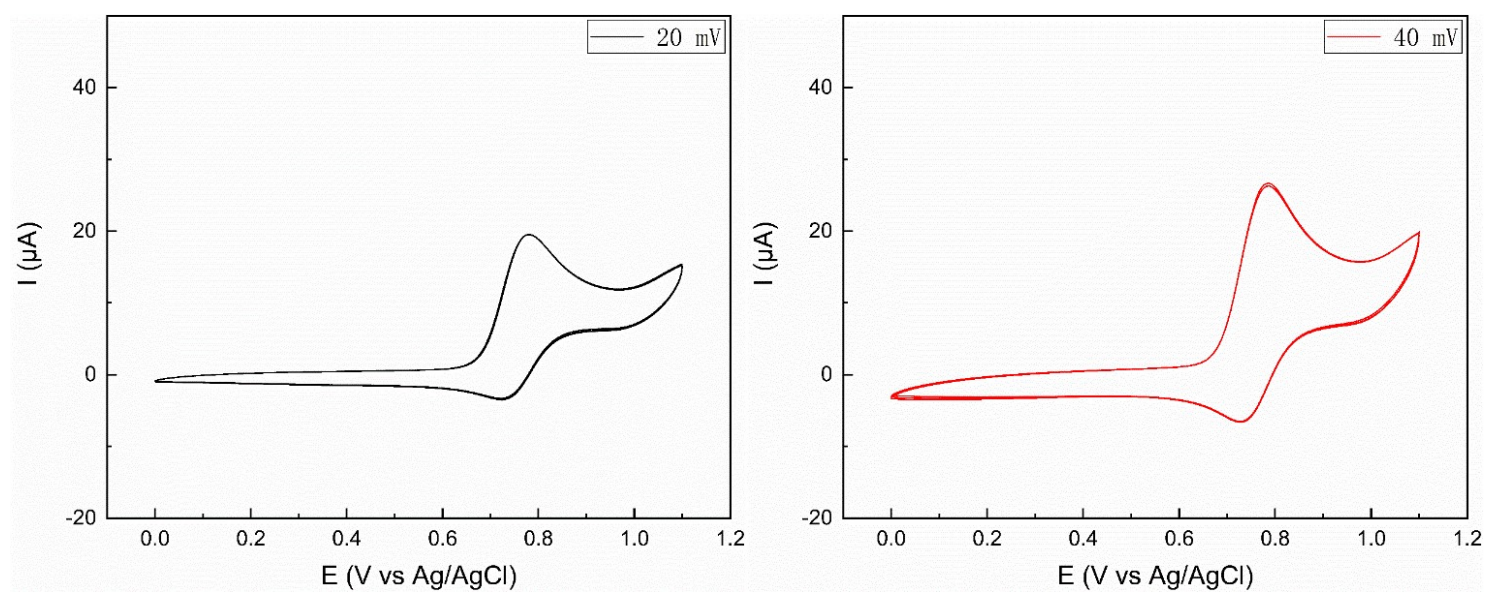

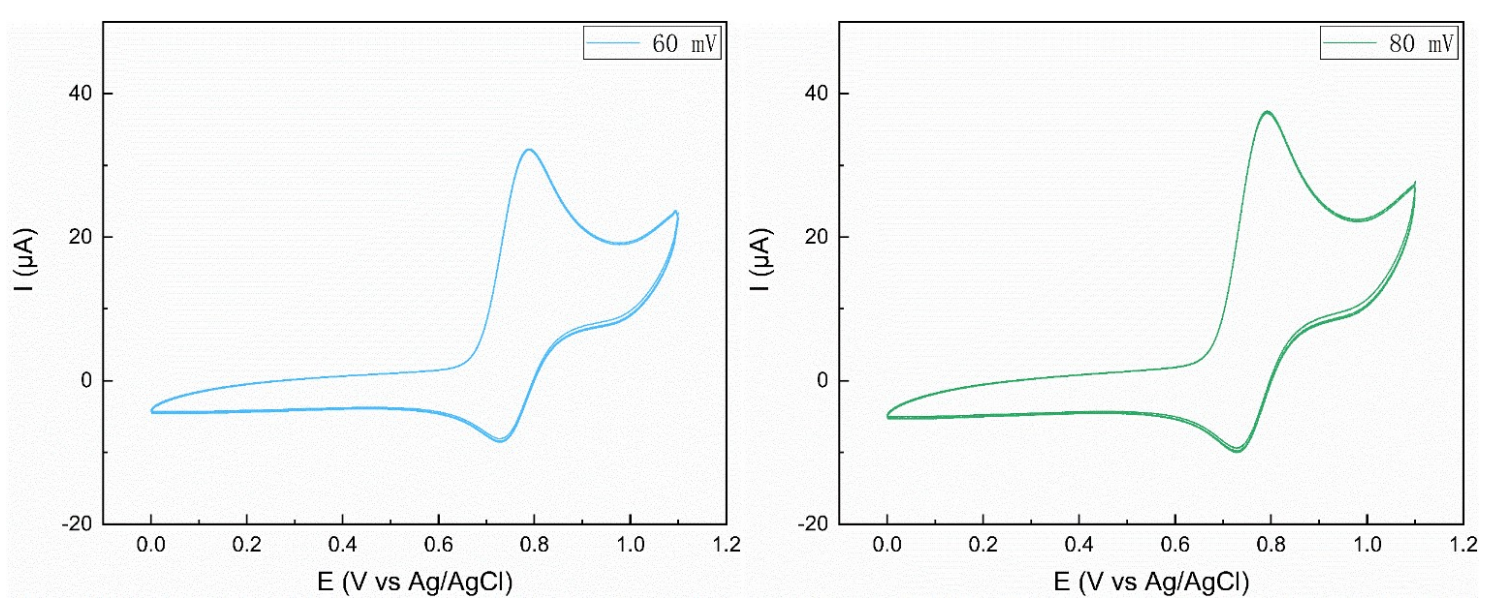

\section{Combined}
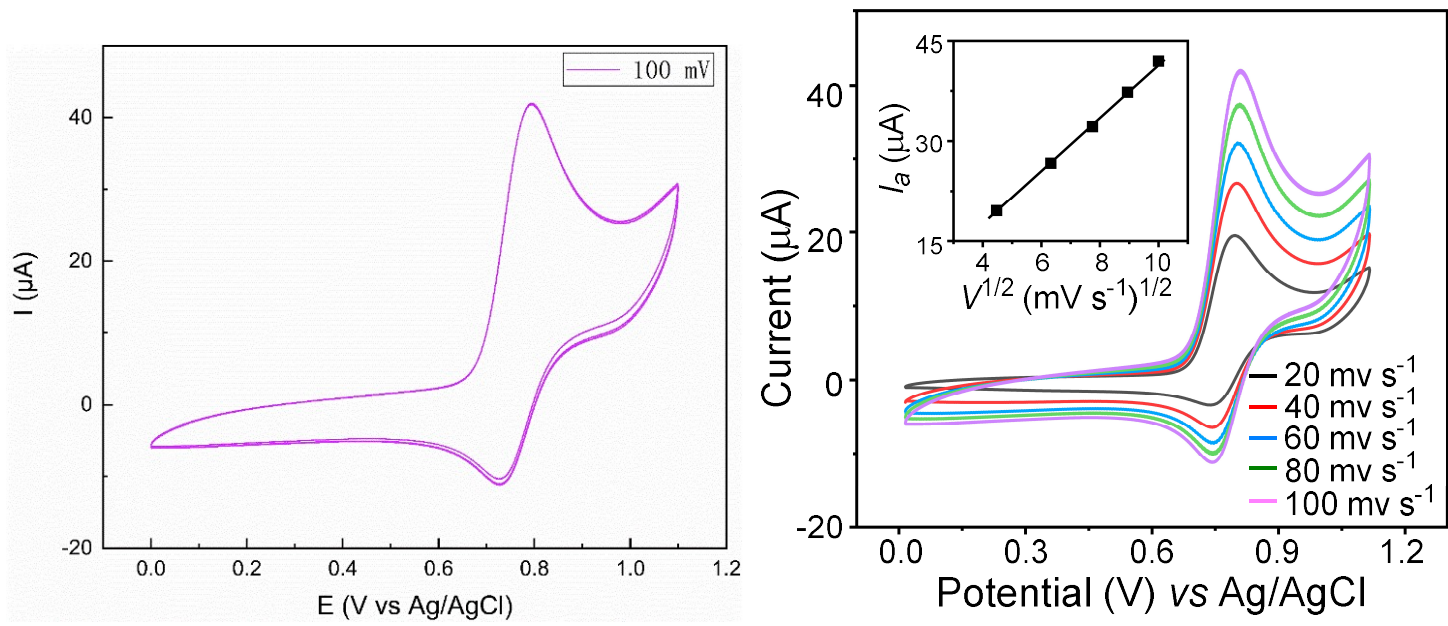

Figure S6. CV curves of F-PTH at different scan rates in $\mathrm{MeCN}\left(5 \times 10^{-4} \mathrm{M}\right)$. Three cycles of scan were conducted at each rate. In the combined CV curves, the anodic current $\left(I_{\mathrm{a}}\right)$ increased linearly along with the square root of the scan rate $\left(V^{1 / 2}\right)$, revealing that the electron transfer between F-PTH and electrode should be faster than the diffusion limit.

\section{Condition optimizations for the alternating copolymerization}



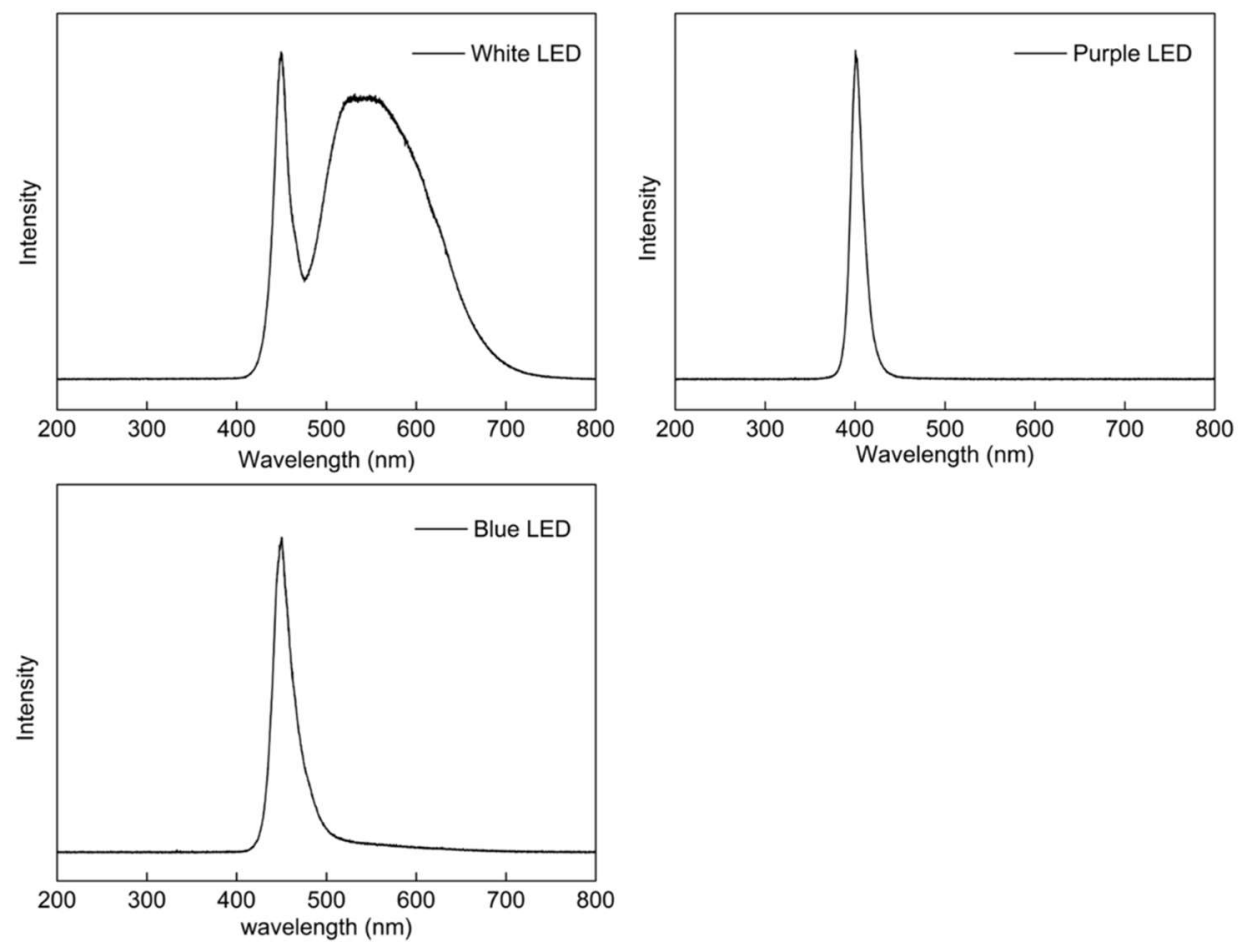

Figure S7. The emission spectra of LEDs used in condition optimization. The dosage of light for purple LED is about $13 \mathrm{~mW} / \mathrm{cm}^{2}$, for blue LED is about $2 \mathrm{~mW} / \mathrm{cm}^{2}$, for white LED is about $33 \mathrm{~mW} / \mathrm{cm}^{2}$.

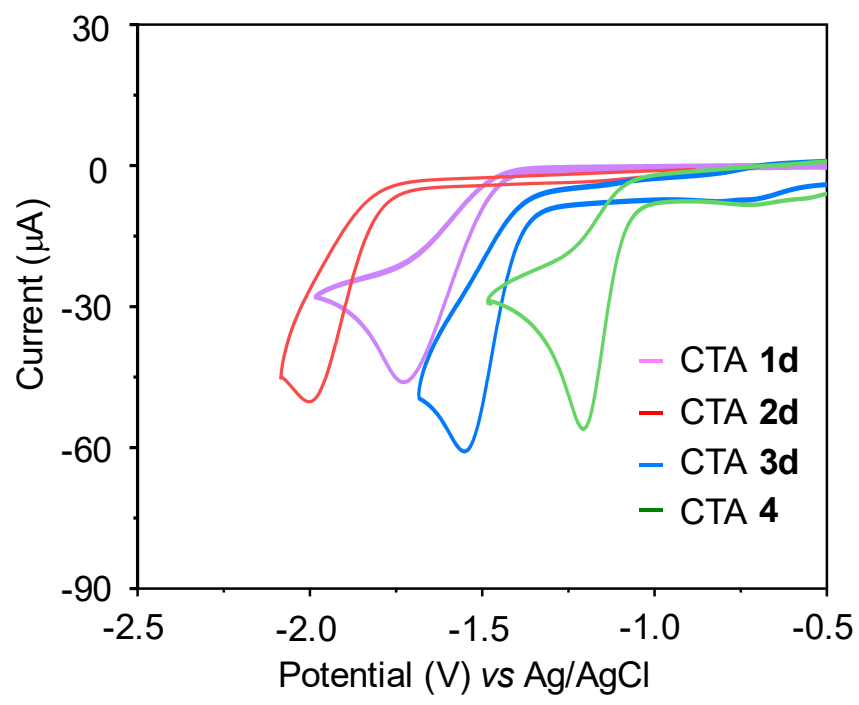

Figure S8. Cyclic voltammetry (CV) of CTAs conducted using $0.1 \mathrm{M} n \mathrm{Bu}_{4} \mathrm{NBF}_{4}$ as electrolyte in acetonitrile at $25^{\circ} \mathrm{C}$.

Preparation of solutions containing CTFE and VE:

A $200 \mathrm{~mL}$ Schlenk flask was charged with anhydrous DEC under $\mathrm{N}_{2}$ atmosphere at $-40{ }^{\circ} \mathrm{C}$. 
CTFE gas was bubbled into the solutioin at $-40{ }^{\circ} \mathrm{C}$. The amount of CTFE contained in DEC was calculated by the weight change before and after adding CTFE. Then, EVE was added into the solution via a syringe at a molar ratio of $\mathrm{CTFE} / \mathrm{EVE}=3 / 2$.

\section{Experimental procedure:}

An oven-dried $10 \mathrm{~mL}$ Schlenck tube equipped with a stir bar was charged with CTA, catalyst and internal standard (1,4-difluorobenzene). The solution of CTFE and EVE in DEC $([\mathrm{CTFE}] /[\mathrm{EVE}] /[\mathrm{CTA}] /[\mathrm{F}-\mathrm{PTH}]=120 / 80 / 1 / 0.05)$ was added into the tube via a syringe. The solution was deoxygenated with three freeze-pump-thaw cycles under $\mathrm{N}_{2}$ atmosphere. Then, the tube was kept in front of a $30 \mathrm{~W}$ purple LED bulb at room temperature for 24-30 h, and blown with compressed air to avoid heating. At corresponding exposing time, a small aliquot was taken and diluted with solvent (particles were dissolved by solvent to give homogenous solutions) before analyzing by NMR and SEC measurements.

Table S1. Optimization of CTA for the photoredox copolymerization of CTFE and EVE. ${ }^{[a]}$

\begin{tabular}{ccccc}
\hline Entry & $\begin{array}{c}\text { Conv. } \\
(\%)\end{array}$ & $\begin{array}{c}M_{\mathrm{n}, \text { calc }} \\
(\mathrm{kDa}]\end{array}$ & $\begin{array}{c}M_{\mathrm{n}, \mathrm{SEC}} \\
(\mathrm{kDa})\end{array}$ & $Ð$ \\
\hline CTA 1a & 59 & 9.2 & 11.2 & 1.47 \\
CTA 1b & 75 & 11.6 & 9.6 & 1.45 \\
CTA 1c & 77 & 11.9 & 8.6 & 1.60 \\
CTA 1d & 95 & 14.6 & 12.1 & 1.42 \\
CTA 2a & 61 & 9.5 & 10.4 & 2.25 \\
CTA 2b & 60 & 9.3 & 12.1 & 1.61 \\
CTA 2c & 63 & 9.8 & 8.9 & 1.62 \\
CTA 2d & 93 & 14.3 & 12.9 & 1.47 \\
CTA 3a & 53 & 8.3 & 7.0 & 1.52 \\
CTA 3b & 81 & 12.5 & 11.7 & 1.52 \\
CTA 3c & 95 & 14.6 & 13.1 & 1.51 \\
CTA 3d & 98 & 15.1 & 16.8 & 1.39 \\
CTA 4 & $>99$ & 15.2 & 19.8 & 1.21 \\
\hline
\end{tabular}




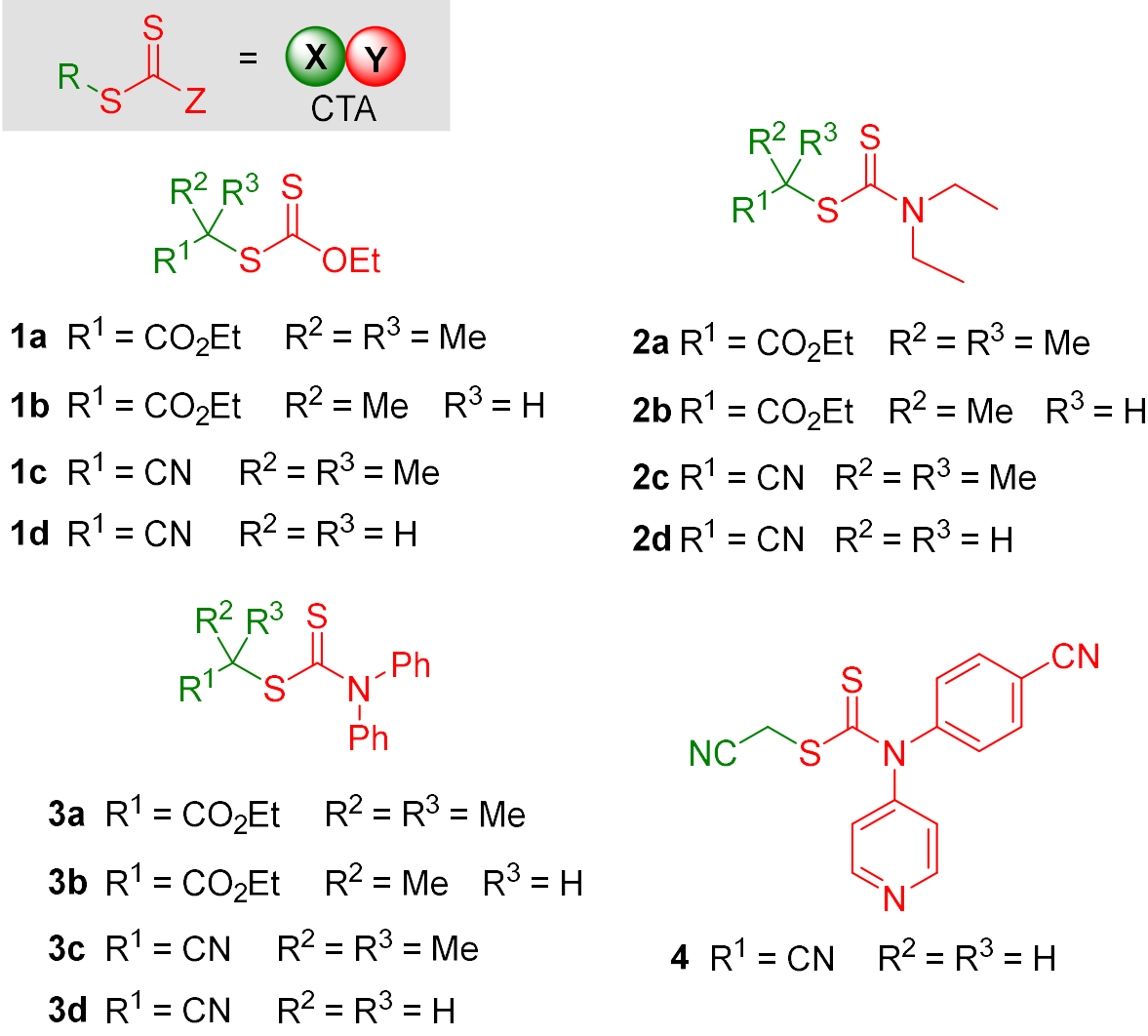

${ }^{[\mathrm{a}]}[\mathrm{M}]=[\mathrm{CTFE}]+[\mathrm{EVE}],[\mathrm{CTFE}] /[\mathrm{EVE}] /[\mathrm{CTA}] /[\mathrm{F}-\mathrm{PTH}]=120 / 80 / 1 / 0.05$, experiments were conducted at $25^{\circ} \mathrm{C}$ and ambient pressure in Schlenk glass tubes. A $30 \mathrm{~W}$ purple LED bulb was used as the light source, diethyl carbonate (DEC) as solvent. $M_{\mathrm{n} \text {,calc }}$ were determined based on VE conversions. Conversions are based on the ${ }^{1} \mathrm{H}$ NMR analysis of remaining VE after reactions. $M_{\mathrm{n}, \mathrm{SEC}}$ and $Ð$ were measured using SEC.

Table S2. Optimization of solvent for the photoredox copolymerization of CTFE and EVE. ${ }^{[a]}$

\begin{tabular}{cccccc}
\hline Entry & Solvent & $\begin{array}{c}\text { Conv. } \\
(\%)\end{array}$ & $\begin{array}{c}M_{\mathrm{n}, \text { calc }} \\
(\mathrm{kDa})\end{array}$ & $\begin{array}{c}M_{\mathrm{n}, \mathrm{SEC}} \\
(\mathrm{kDa})\end{array}$ & $Ð$ \\
\hline 1 & Anisole & 97 & 14.9 & 4.1 & 1.41 \\
2 & DMC & 88 & 13.6 & 18.1 & 1.70 \\
3 & DEC & $>99$ & 15.2 & 19.8 & 1.21 \\
4 & DMF & 43 & 6.8 & 2.6 & 1.77 \\
5 & $1,1,1,3,3-$ Pentafluorobutane & 37 & 5.9 & 6.6 & 1.35 \\
\hline
\end{tabular}

${ }^{[\mathrm{a}]}[\mathrm{M}]=[\mathrm{CTFE}]+[\mathrm{EVE}],[\mathrm{CTFE}] /[\mathrm{EVE}] /[\mathrm{CTA} 4] /[\mathrm{F}-\mathrm{PTH}]=120 / 80 / 1 / 0.05$, experiments were conducted at $25^{\circ} \mathrm{C}$ and ambient pressure in Schlenk glass tubes. A $30 \mathrm{~W}$ purple LED bulb was used as the light source. Conversions are based on the ${ }^{1} \mathrm{H}$ NMR analysis of remaining VE after reactions. 
Table S3. Optimization of light sources for the photoredox copolymerization of CTFE and EVE. ${ }^{[a]}$

\begin{tabular}{|c|c|c|c|c|c|}
\hline Entry & Light source & $\begin{array}{c}\text { Conv. } \\
(\%)\end{array}$ & $\begin{array}{c}M_{\mathrm{n}, \text { calc }} \\
(\mathrm{kDa})\end{array}$ & $\begin{array}{c}M_{\mathrm{n}, \mathrm{SEC}} \\
(\mathrm{kDa})\end{array}$ & $Ð$ \\
\hline 1 & White LED $^{[b]}$ & 72 & 11.2 & 12.0 & 1.26 \\
\hline 2 & Blue LED ${ }^{[\mathrm{b}]}$ & $>99$ & 15.2 & 16.7 & 1.69 \\
\hline
\end{tabular}

${ }^{[\mathrm{a}]}[\mathrm{M}]=[\mathrm{CTFE}]+[\mathrm{EVE}],[\mathrm{CTFE}] /[\mathrm{EVE}] /[\mathrm{CTA} 4] /[\mathrm{F}-\mathrm{PTH}]=120 / 80 / 1 / 0.05$, experiments were conducted at $25{ }^{\circ} \mathrm{C}$ and ambient pressure in Schlenk glass tubes using DEC as solvent. Conversions are based on the ${ }^{1} \mathrm{H}$ NMR analysis of remaining VE after reactions. ${ }^{[b]}$ Reaction time $=36-42 \mathrm{~h}$.

Table S4. Optimization of photocatalyst (PC) for the photoredox copolymerization of CTFE and EVE.

\begin{tabular}{cccccc}
\hline Entry & PC & $\begin{array}{c}\text { Conv. } \\
(\%)\end{array}$ & $M_{\mathrm{n}, \text { calc }}(\mathrm{kDa})$ & $\begin{array}{c}M_{\mathrm{n}, \mathrm{SEC}} \\
(\mathrm{kDa})\end{array}$ & $Ð^{[\mathrm{c}]}$ \\
\hline 1 & $\operatorname{Ir}(\mathrm{ppy}) 3$ & 97 & 14.9 & 24.6 & 1.49 \\
2 & PTH-1 & 96 & 14.8 & 24.8 & 1.77 \\
3 & Perylene & 88 & 13.6 & 14.3 & 1.53 \\
\hline
\end{tabular}

Chemical structures of PC<smiles>CCCCc1ccc(-c2ccc3c(c2)Sc2cc(-c4ccc(CCCC)cc4)ccc2N3c2ccc(-c3ccccc3)cc2)cc1</smiles>

PTH-1<smiles></smiles>

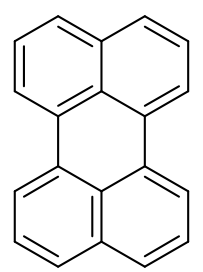

Perylene

${ }^{[\mathrm{a}]}[\mathrm{M}]=[\mathrm{CTFE}]+[\mathrm{EVE}],[\mathrm{CTFE}] /[\mathrm{EVE}] /[\mathrm{CTA} 4] /[\mathrm{PC}]=120 / 80 / 1 / 0.05$, experiments were conducted at $25{ }^{\circ} \mathrm{C}$ and ambient pressure in Schlenk glass tubes using DEC as solvent. A $30 \mathrm{~W}$ purple LED bulb was used as the light source. Conversions are based on the ${ }^{1} \mathrm{H}$ NMR analysis of remaining $\mathrm{VE}$ after reactions. 


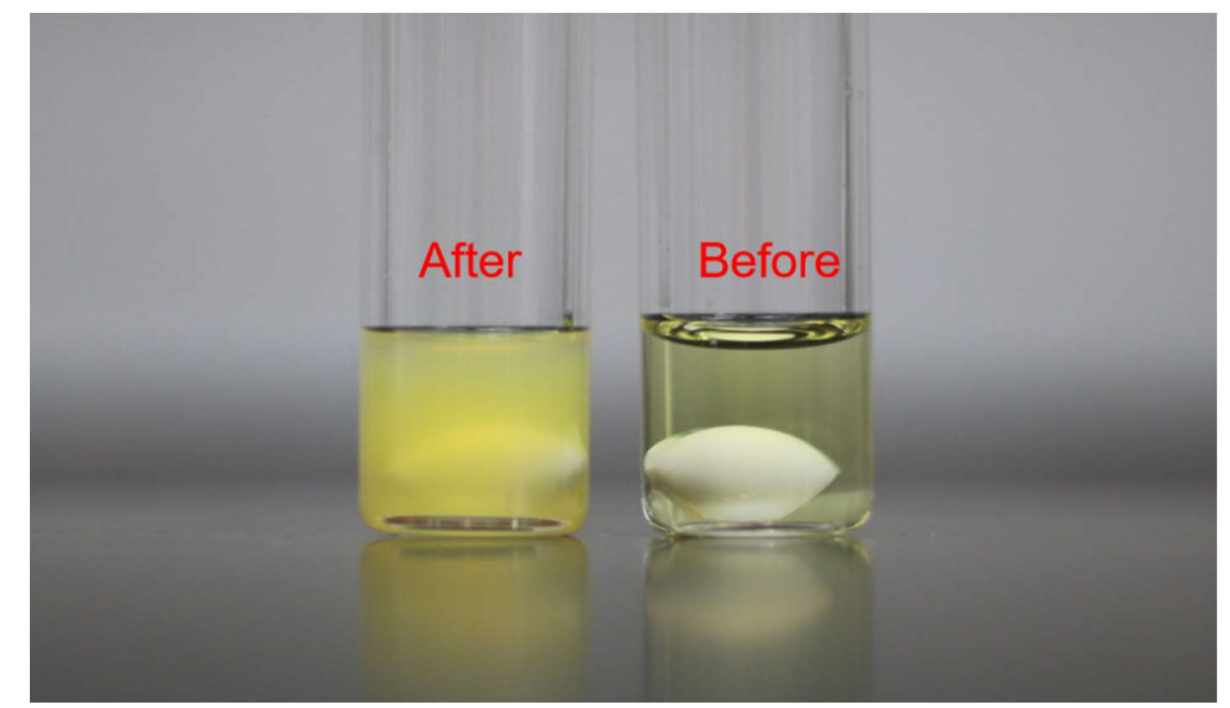

Figure S9. Optical images of reaction mixtures before and after polymerization.

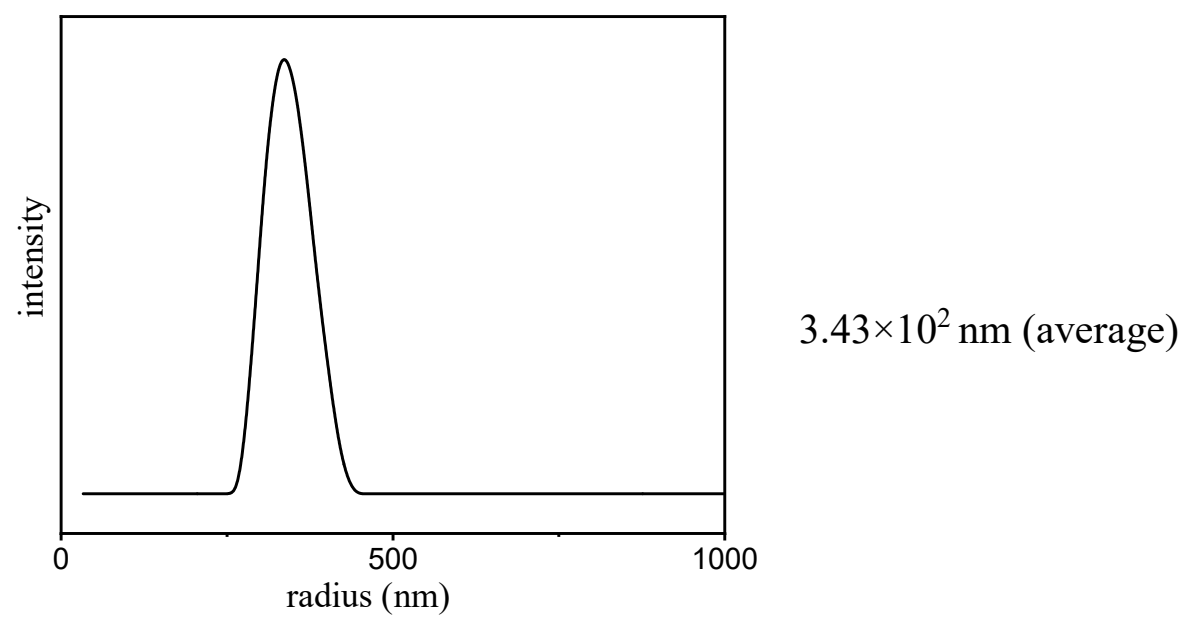

Figure S10. Dynamic light scattering (DLS) analysis of the reaction mixture after polymerization. DLS was measured with a 3D LS instrument (LS Instrument AG). The reaction mixture was directly diluted to $0.005 \mathrm{M}$ with diethyl carbonate, and measured at $25{ }^{\circ} \mathrm{C}$.

\section{Kinetic investigation for the alternating copolymerization in Figure 3}

General procedure for the polymerization:

An oven-dried $20 \mathrm{~mL}$ Schlenck tube equipped with a stir bar was charged with CTA 4, FPTH catalyst, a solution of CTFE and VE in DEC ([CTFE]/[VE]/[CTA 4]/[F-PTH] = 120/80/1/0.05) and internal standard (1,4-difluorobenzene, $0.5 \mathrm{mmol}$ ). The solution was deoxygenated with three freeze-pump-thaw cycles under $\mathrm{N}_{2}$ atmosphere. Then, the tube was kept in front of a $30 \mathrm{~W}$ purple LED bulb (1 cm distance) at room temperature, and blown with 
compressed air to avoid heating. At corresponding exposing time, a small aliquot was taken, diluted with solvent, and analyzed by NMR and SEC. The reaction mixture was concentrated under vacuum. Obtained compound was dried under vacuum at $60{ }^{\circ} \mathrm{C}$, and weighed to give the weight of copolymer [W(copolymer)]. See following parts for details.

Calculation method for degree of polymerization (DP):

Conv(VE) is the conversion of vinyl ether based the ${ }^{1} \mathrm{H}$ NMR analysis of remaining VE in the reaction mixure. $\mathrm{W}(\mathrm{CTFE})$ and $\mathrm{W}(\mathrm{VE})$ represent the weight of two monomers contained in the mixture before reaction. The molar ratio of $[\mathrm{CTFE}] /[\mathrm{VE}] /[\mathrm{CTA}]=120 / 80 / 1$. DP(VE) and DP(CTFE) are DP of two monomers contained in copolymers. DP of comonomers could be calculated by Equations S1 and S2.

$$
\begin{array}{cc}
\mathrm{DP}(\mathrm{VE})=80 \times \operatorname{Conv}(\mathrm{VE}) & \text { Equation S1 } \\
\mathrm{DP}(\mathrm{CTFE})=120 \times\{[\mathrm{W}(\text { copolymer })-\mathrm{W}(\mathrm{VE}) \times \operatorname{Conv}(\mathrm{VE})] / \mathrm{W}(\mathrm{CTFE})\} & \text { Equation S2 }
\end{array}
$$

\section{Alternating copolymerization of CTFE and SiBVE:}

The Schlenk tube equipped with a stir bar was charged with $3 \mathrm{~mL} \mathrm{DEC} \mathrm{solution} \mathrm{containing}$ monomers $(\mathrm{W}(\mathrm{CTFE})=698.1 \mathrm{mg}, \mathrm{W}(\mathrm{SiBVE})=912.8 \mathrm{mg})$, CTA $4(15.3 \mathrm{mg})$ and F-PTH

\begin{tabular}{|c|c|c|c|c|c|c|c|c|}
\hline Entry & $\begin{array}{l}\text { Time } \\
\text { (h) }\end{array}$ & $\begin{array}{c}\text { Conv } \\
\text { (SiBVE) } \\
(\%)\end{array}$ & $\begin{array}{c}M_{\mathrm{n}, \mathrm{calc}} \\
(\mathrm{kDa})^{[\mathrm{b}]}\end{array}$ & $\begin{array}{c}M_{\mathrm{n}, \mathrm{SEC}} \\
(\mathrm{kDa})^{[\mathrm{c}]}\end{array}$ & $\bigoplus^{[\mathrm{c}]}$ & $\ln \left([\mathrm{M}]_{0} /[\mathrm{M}]_{\mathrm{t}}\right)^{[\mathrm{b}]}$ & $\begin{array}{c}\mathrm{DP}^{[\mathrm{d}]} \\
(\mathrm{SiBVE})\end{array}$ & $\begin{array}{c}\mathrm{DP}^{[\mathrm{d}]} \\
(\mathrm{CTFE})\end{array}$ \\
\hline 1 & 2 & 28 & 8.1 & 7.3 & 1.26 & 0.3285 & 22.4 & 25.3 \\
\hline 2 & 4 & 57 & 16.1 & 19.5 & 1.22 & 0.8439 & 45.6 & 46.1 \\
\hline 3 & 7 & 77 & 21.7 & 25.7 & 1.26 & 1.4697 & 61.6 & 61.8 \\
\hline 4 & 10 & 90 & 25.3 & $\begin{array}{c}30.1 \\
(25.9)^{[\mathrm{e}]}\end{array}$ & 1.28 & 2.3026 & 72.0 & 74.6 \\
\hline
\end{tabular}
catalyst $\left(220 \mu \mathrm{L}, 11.2 \times 10^{-3} \mathrm{M}, 10.3 \mathrm{mg} / \mathrm{mL}\right.$ in DEC). For the experimental operation, see the general procedure for the copolymerization.

Table S5. Experimental results of alternating copolymerization of CTFE and SiBVE. 


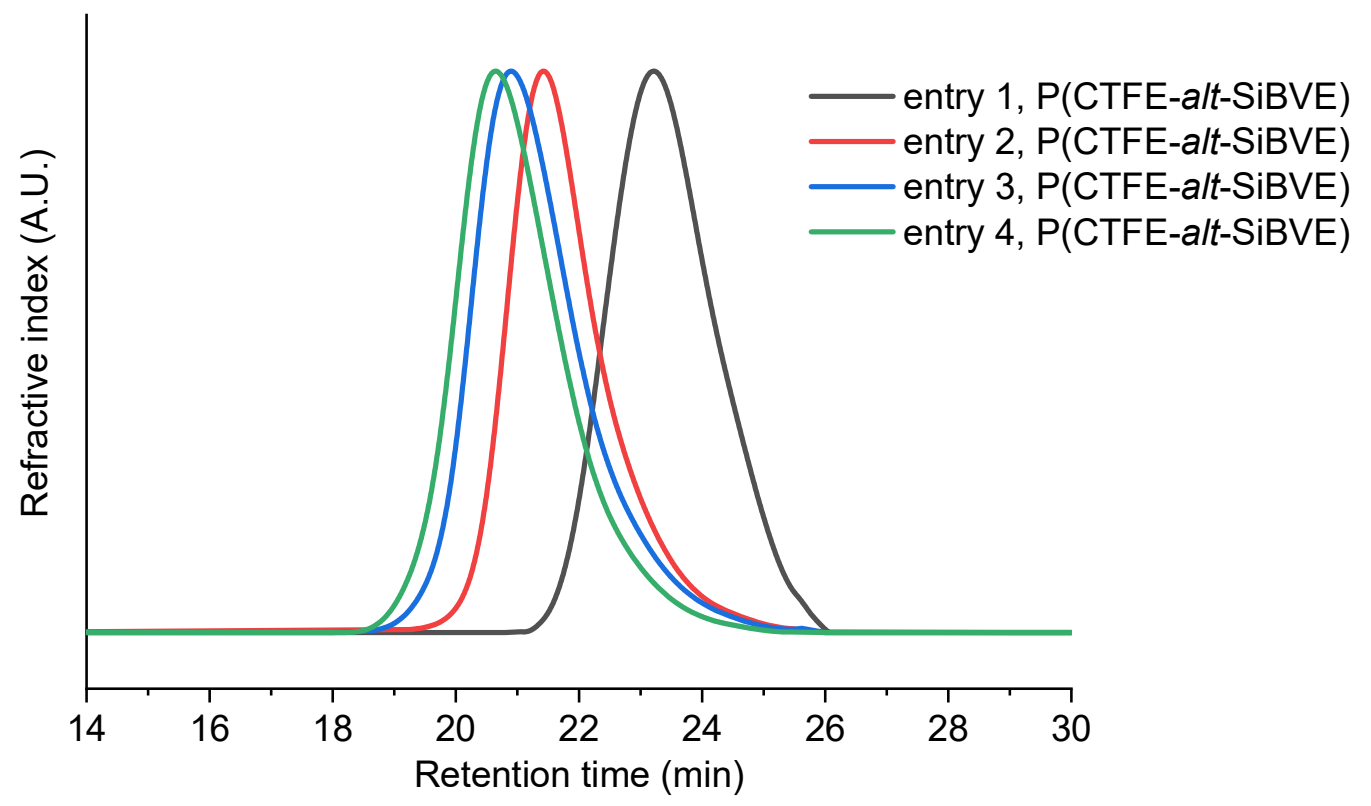

Figure S11. SEC profiles for alternating copolymerization of CTFE and SiBVE.

Alternating copolymerization of CTFE and EVE:

An oven-dried $20 \mathrm{~mL}$ Schlenk tube equipped with a stir bar was charged with $3 \mathrm{~mL}$ DEC solution containing monomers $(\mathrm{W}(\mathrm{CTFE})=698.1 \mathrm{mg}, \mathrm{W}(\mathrm{EVE})=285.8 \mathrm{mg}), \mathrm{CTA} 4(15.3 \mathrm{mg})$ and F-PTH catalyst $\left(220 \mu \mathrm{L}, 11.2 \times 10^{-3} \mathrm{M}\right.$ in DEC). For the experimental operation, see the general procedure for the polymerization.

Table S6. Experimental results of alternating copolymerization of CTFE and EVE.

\begin{tabular}{ccccccccc}
\hline Entry & $\begin{array}{c}\text { Time } \\
(\mathrm{h})^{[\mathrm{a}]}\end{array}$ & $\begin{array}{c}\text { Conv } \\
(\mathrm{EVE}) \\
(\%)\end{array}$ & $\begin{array}{c}M_{\mathrm{n}, \text { calc }} \\
(\mathrm{kDa})^{[\mathrm{b}]}\end{array}$ & $\begin{array}{c}M_{\mathrm{n}, \mathrm{SEC}} \\
(\mathrm{kDa})^{[\mathrm{c}]}\end{array}$ & $\begin{array}{c}\bigoplus^{[\mathrm{c}]} \\
\ln \left([\mathrm{M}]_{0} /[\mathrm{M}]_{\mathrm{t}}\right)^{[\mathrm{b}]}\end{array}$ & $\begin{array}{c}\mathrm{DP}^{[\mathrm{d}]} \\
(\mathrm{EVE})\end{array}$ & $\begin{array}{c}\mathrm{DP}^{[\mathrm{d}]} \\
(\mathrm{CTFE})\end{array}$ \\
\hline 1 & 2 & 20 & 2.8 & 3.7 & 1.19 & 0.2230 & 16.0 & 15.5 \\
2 & 9 & 71 & 11.0 & 14.3 & 1.19 & 1.2379 & 56.8 & 54.7 \\
3 & 13 & 85 & 13.1 & 18.0 & 1.12 & 1.8971 & 68.0 & 68.9 \\
4 & 18 & 93 & 14.4 & 22.9 & 1.17 & 2.6593 & 74.4 & 76.0 \\
& & & & $(14.3)^{[\mathrm{e}]}$ & & & &
\end{tabular}

${ }^{[\mathrm{a}]}$ Reaction time exposing to light irradiation. ${ }^{[\mathrm{b}]}$ Calculated based on conversions of SiBVE.

${ }^{[\mathrm{c}]} M_{\mathrm{n}, \mathrm{SEC}}$ and $\oslash$ were measured using SEC. ${ }^{[\mathrm{d}]}$ Determined by Equations $\mathrm{S} 1$ and $\mathrm{S} 2$. ${ }^{[\mathrm{e}]}$ Determined with a MALLS detector. 


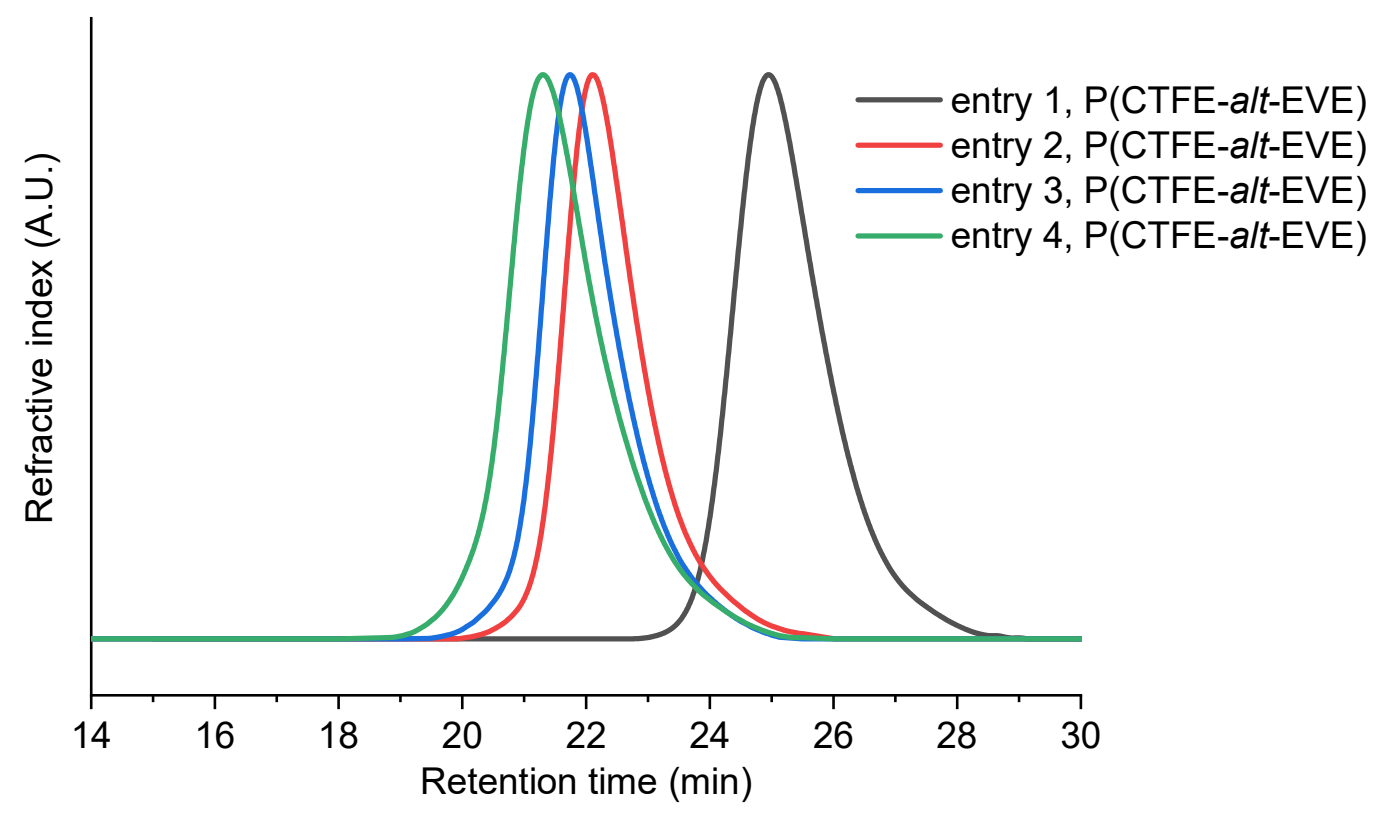

Figure S12. SEC profiles for alternating copolymerization of CTFE and EVE.

Alternating copolymerization of CTFE and IBVE:

An oven-dried $20 \mathrm{~mL}$ Schlenk tube equipped with a stir bar was charged with $3 \mathrm{~mL}$ DEC solution containing monomers $(\mathrm{W}(\mathrm{CTFE})=698.1 \mathrm{mg}, \mathrm{W}(\mathrm{IBVE})=396.8 \mathrm{mg})$, CTA 4 (15.3 $\mathrm{mg})$ and F-PTH catalyst $\left(220 \mu \mathrm{L}, 11.2 \times 10^{-3} \mathrm{M}\right.$ in DEC). For the experimental operation, see the general procedure for the polymerization.

Table S7. Experimental results of alternating copolymerization of CTFE and IBVE.

\begin{tabular}{ccccccccc}
\hline Entry & $\begin{array}{c}\text { Time } \\
(\mathrm{h})^{[\mathrm{a}]}\end{array}$ & $\begin{array}{c}\text { Conv } \\
(\mathrm{IBVE}) \\
(\%)\end{array}$ & $\begin{array}{c}M_{\mathrm{n}, \mathrm{calc}} \\
(\mathrm{kDa})^{[\mathrm{b}]}\end{array}$ & $\begin{array}{c}M_{\mathrm{n}, \mathrm{SEC}} \\
(\mathrm{kDa})^{[\mathrm{c}]}\end{array}$ & $\bigoplus^{[\mathrm{c}]}$ & $\ln \left([\mathrm{M}]_{0} /[\mathrm{M}]_{\mathrm{t}}\right)^{[\mathrm{b}]}$ & $\begin{array}{c}\mathrm{DP}^{[\mathrm{d}]} \\
(\mathrm{IBVE})\end{array}$ & $\begin{array}{c}\mathrm{DP}^{[\mathrm{d}]} \\
(\mathrm{CTFE})\end{array}$ \\
\hline 1 & 4 & 39 & 7.1 & 7.5 & 1.25 & 0.4943 & 31.2 & 29.8 \\
2 & 6 & 57 & 10.2 & 11.6 & 1.28 & 0.8439 & 45.6 & 47.6 \\
3 & 9 & 70 & 12.4 & 17.0 & 1.29 & 1.2039 & 56.0 & 57.6 \\
4 & 16 & 89 & 15.7 & 23.5 & 1.29 & 2.2072 & 71.2 & 72.8 \\
& & & & $(16.9)^{[\mathrm{e}]}$ & & & &
\end{tabular}

${ }^{[\mathrm{a}]}$ Reaction time exposing to light irradiation. ${ }^{[\mathrm{b}]}$ Calculated based on conversions of SiBVE. ${ }^{[\mathrm{c}]} M_{\mathrm{n}, \mathrm{SEC}}$ and $\oslash$ were measured using SEC. ${ }^{[\mathrm{d}]}$ Determined by Equations $\mathrm{S} 1$ and $\mathrm{S} 2$. ${ }^{[\mathrm{e}]}$ Determined with a MALLS detector. 


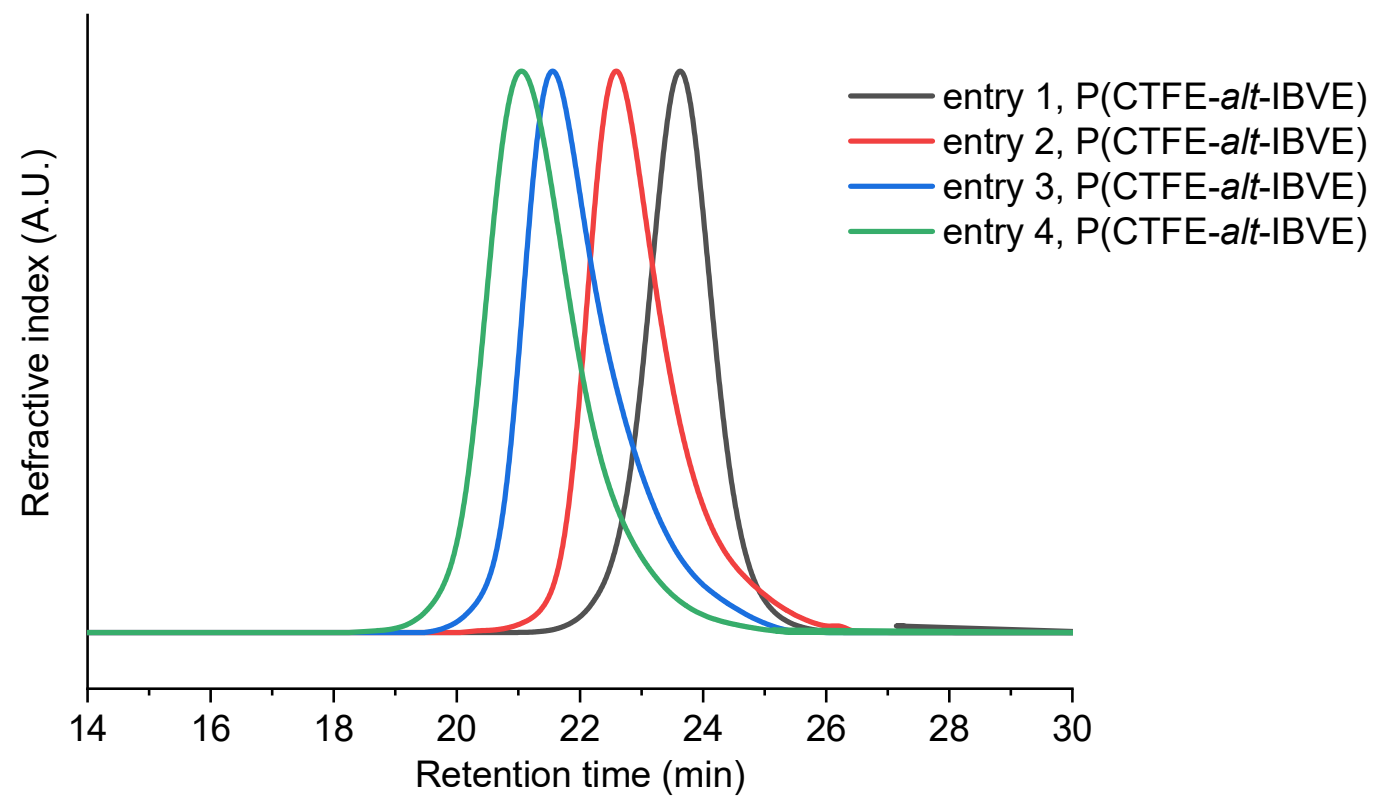

Figure S13. SEC profiles for alternating copolymerization of CTFE and IBVE.

Alternating copolymerization of CTFE and BVE:

An oven-dried $20 \mathrm{~mL}$ Schlenk tube equipped with a stir bar was charged with $3 \mathrm{~mL}$ DEC solution containing monomers $(\mathrm{W}(\mathrm{CTFE})=698.1 \mathrm{mg}, \mathrm{W}(\mathrm{BVE})=396.4 \mathrm{mg})$, CTA $4(15.3 \mathrm{mg})$ and F-PTH catalyst $\left(220 \mu \mathrm{L}, 11.2 \times 10^{-3} \mathrm{M}\right.$ in DEC). For the experimental operation, see the general procedure for the polymerization.

Table S8. Experimental results of alternating copolymerization of CTFE and BVE.

\begin{tabular}{ccccccccc}
\hline Entry & $\begin{array}{c}\text { Time } \\
(\mathrm{h})^{[\mathrm{a}]}\end{array}$ & $\begin{array}{c}\text { Conv } \\
(\mathrm{BVE}) \\
(\%)\end{array}$ & $\begin{array}{c}M_{\mathrm{n}, \mathrm{calc}} \\
(\mathrm{kDa})^{[\mathrm{b}]}\end{array}$ & $\begin{array}{c}M_{\mathrm{n}, \mathrm{SEC}} \\
(\mathrm{kDa})^{[\mathrm{c}]}\end{array}$ & $\bigoplus^{[\mathrm{c}]}$ & $\ln \left([\mathrm{M}]_{0} /[\mathrm{M}]_{\mathrm{t}}\right)^{[\mathrm{b}]}$ & $\begin{array}{c}\mathrm{DP}^{[\mathrm{d}]} \\
(\mathrm{BVE})\end{array}$ & $\begin{array}{c}\mathrm{DP}^{[\mathrm{d}]} \\
(\mathrm{CTFE})\end{array}$ \\
\hline 1 & 3 & 18 & 3.4 & 3.5 & 1.19 & 0.1984 & 14.4 & 17.8 \\
2 & 8 & 41 & 7.4 & 7.5 & 1.21 & 0.5978 & 36.0 & 35.1 \\
3 & 15 & 69 & 12.3 & 16.4 & 1.19 & 1.1712 & 56.0 & 59.4 \\
4 & 28 & 90 & 15.9 & 21.1 & 1.22 & 2.3025 & 72.0 & 74.0 \\
& & & & $(14.8)^{[\mathrm{e}]}$ & & & &
\end{tabular}

${ }^{[\mathrm{a}]}$ Reaction time exposing to light irradiation. ${ }^{[\mathrm{b}]}$ Calculated based on conversions of SiBVE. ${ }^{[\mathrm{c}]} M_{\mathrm{n}, \mathrm{SEC}}$ and $\oslash$ were measured using SEC. ${ }^{[\mathrm{d}]}$ Determined by Equations $\mathrm{S} 1$ and $\mathrm{S} 2$. ${ }^{[\mathrm{e}]}$ Determined with a MALLS detector. 


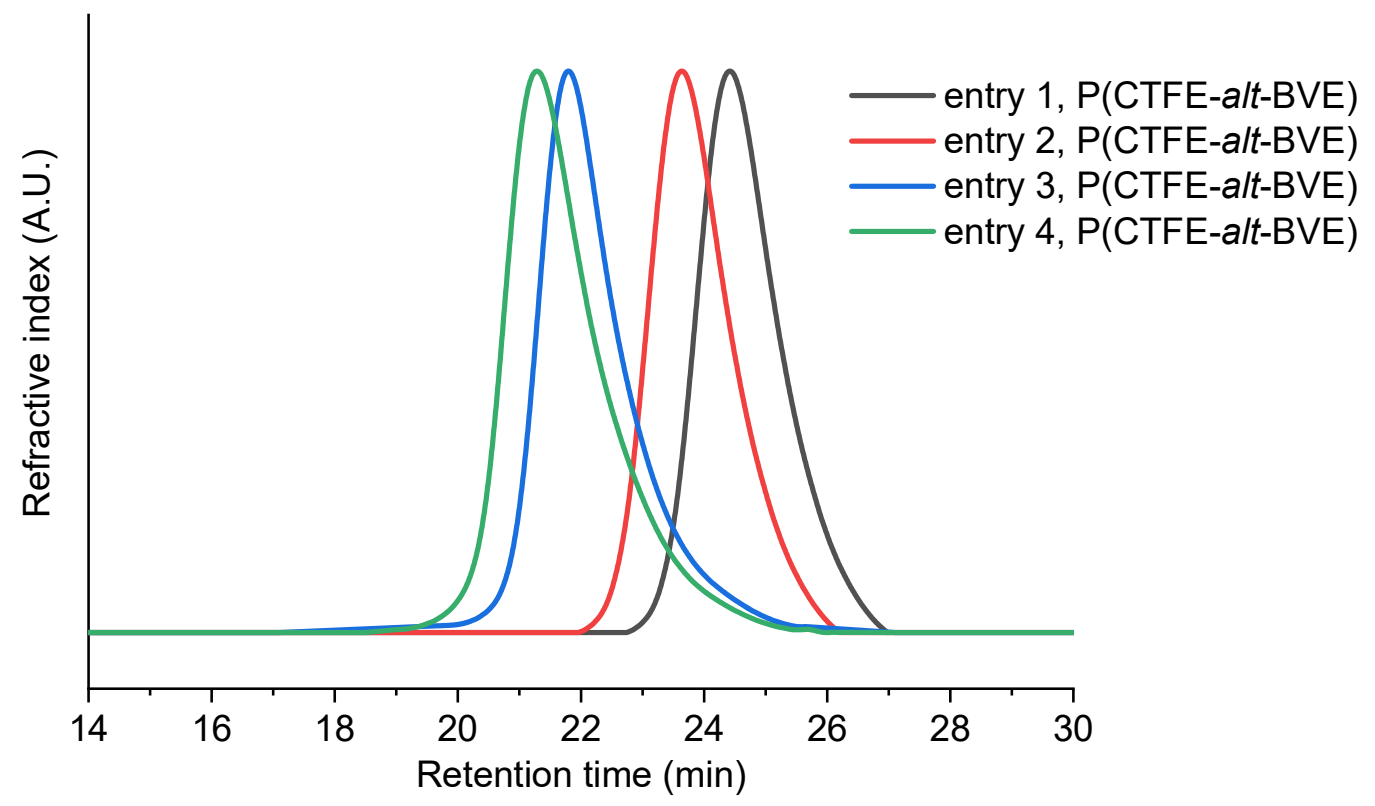

Figure S14. SEC profiles for alternating copolymerization of CTFE and BVE.

Alternating copolymerization of CTFE and CEVE:

An oven-dried $20 \mathrm{~mL}$ Schlenk tube equipped with a stir bar was charged with $3 \mathrm{~mL}$ DEC solution containing monomers $(\mathrm{W}(\mathrm{CTFE})=698.1 \mathrm{mg}, \mathrm{W}(\mathrm{CEVE})=421.9 \mathrm{mg})$, CTA $4(15.3$ $\mathrm{mg})$ and F-PTH catalyst $\left(220 \mu \mathrm{L}, 11.2 \times 10^{-3} \mathrm{M}\right.$ in DEC). For the experimental operation, see the general procedure for the polymerization.

Table S9. Experimental results of alternating copolymerization of CTFE and CEVE.

\begin{tabular}{ccccccccc}
\hline Entry & $\begin{array}{c}\text { Time } \\
(\mathrm{h})^{[\mathrm{a}]}\end{array}$ & $\begin{array}{c}\text { Conv } \\
(\mathrm{CEVE}) \\
(\%)\end{array}$ & $\begin{array}{c}M_{\mathrm{n}, \mathrm{calc}} \\
(\mathrm{kDa})^{[\mathrm{b}]}\end{array}$ & $\begin{array}{c}M_{\mathrm{n}, \mathrm{SEC}} \\
(\mathrm{kDa})^{[\mathrm{c}]}\end{array}$ & $\bigoplus^{[\mathrm{c}]}$ & & & \\
$\ln \left([\mathrm{M}]_{0} /[\mathrm{M}]_{\mathrm{t}}\right)^{[\mathrm{b}]}$ & $\begin{array}{c}\mathrm{DP}^{[\mathrm{d}]} \\
(\mathrm{CEVE})\end{array}$ & $\begin{array}{c}\mathrm{DP}^{[\mathrm{d}]} \\
(\mathrm{CTFE})\end{array}$ \\
\hline 1 & 10 & 28 & 5.3 & 5.5 & 1.17 & 0.3285 & 22.4 & 22.9 \\
2 & 14 & 40 & 7.4 & 7.7 & 1.18 & 0.5108 & 32.0 & 33.5 \\
3 & 20 & 53 & 9.8 & 9.9 & 1.18 & 0.7550 & 42.4 & 44.2 \\
4 & 23 & 60 & 11.0 & 11.4 & 1.21 & 0.9162 & 48.0 & 49.8 \\
\hline
\end{tabular}

${ }^{[\mathrm{a}]}$ Reaction time exposing to light irradiation. ${ }^{[\mathrm{b}]}$ Calculated based on conversions of SiBVE.

${ }^{[\mathrm{c}]} M_{\mathrm{n}, \mathrm{SEC}}$ and $Ð$ were measured using SEC. ${ }^{[\mathrm{d}]}$ Determined by Equations S1 and S2. 


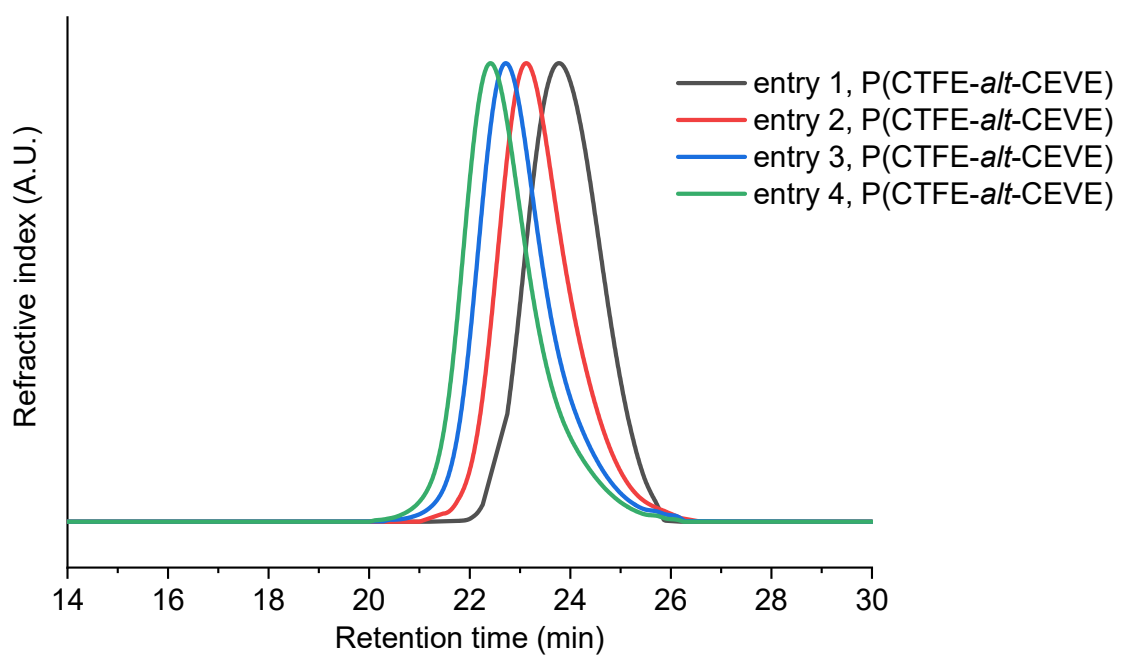

Figure S15. SEC profiles for alternating copolymerization of CTFE and CEVE.

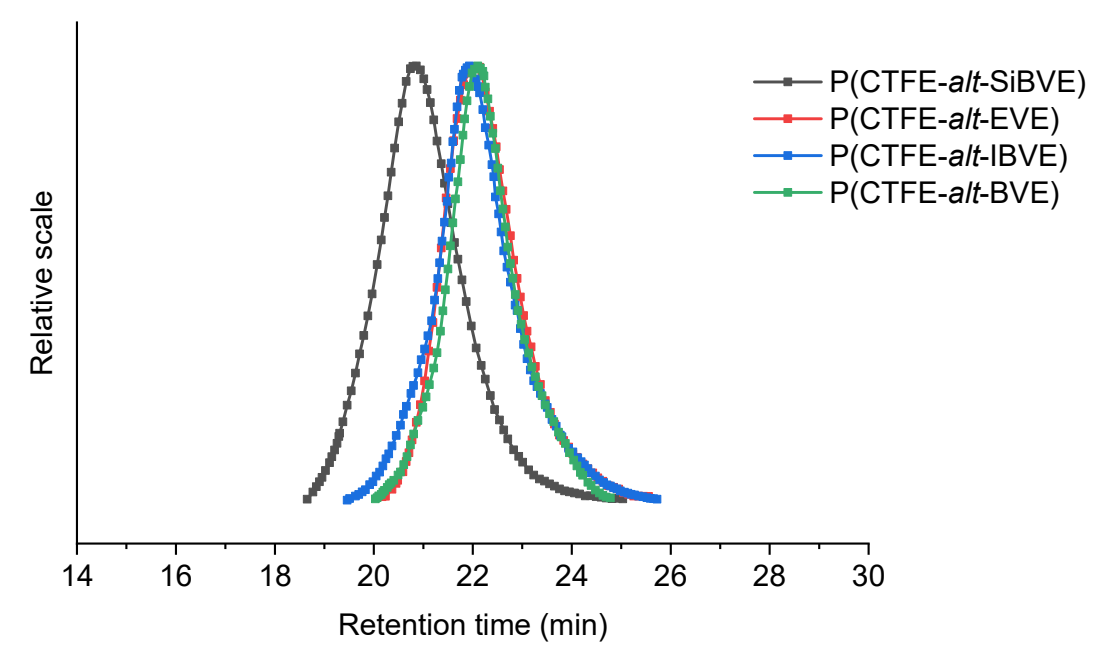

Figure S16. SEC-MALLS profiles for alternating copolymerization of CTFE and VEs.

\section{Experimental procedure and results for experiments in Table 1}

General procedure for the polymerization:

An oven-dried $10 \mathrm{~mL}$ Schlenck glass tube equipped with a stir bar was charged with $3 \mathrm{~mL}$ DEC solution containing CTFE (W(CTFE) $=462.0 \mathrm{mg})$, CTA 4 (10.1 mg) F-PTH catalyst (150 $\mu \mathrm{L}, 11.2 \times 10^{-3} \mathrm{M}$ in DEC). Corresponding amount of $\mathrm{VE}$ comonomer (molar ratio of $[\mathrm{CTFE}] /[\mathrm{VE}]=3 / 2$, molar ratio of $([\mathrm{CTFE}]+[\mathrm{VE}]) /[\mathrm{CTA}] /[\mathrm{F}-\mathrm{PTH}]$ is shown in Table 1$)$ was added into the tube via a syringe. The solution was deoxygenated with three freeze-pump-thaw cycles under $\mathrm{N}_{2}$ atmosphere. Then, the tube was kept in front of a $30 \mathrm{~W}$ purple LED bulb (1 cm distance) at room temperature for 24-32 h, and blown with compressed air to avoid heating. 
At corresponding exposing time, a small aliquot was taken, diluted with solvent, and analyzed by NMR and SEC. The reaction mixture was dropwisely added into methanol with vigorous stirring to give precipitate. The precipitate was collected and dried under vacuum at $60{ }^{\circ} \mathrm{C}$ to give target copolymer.
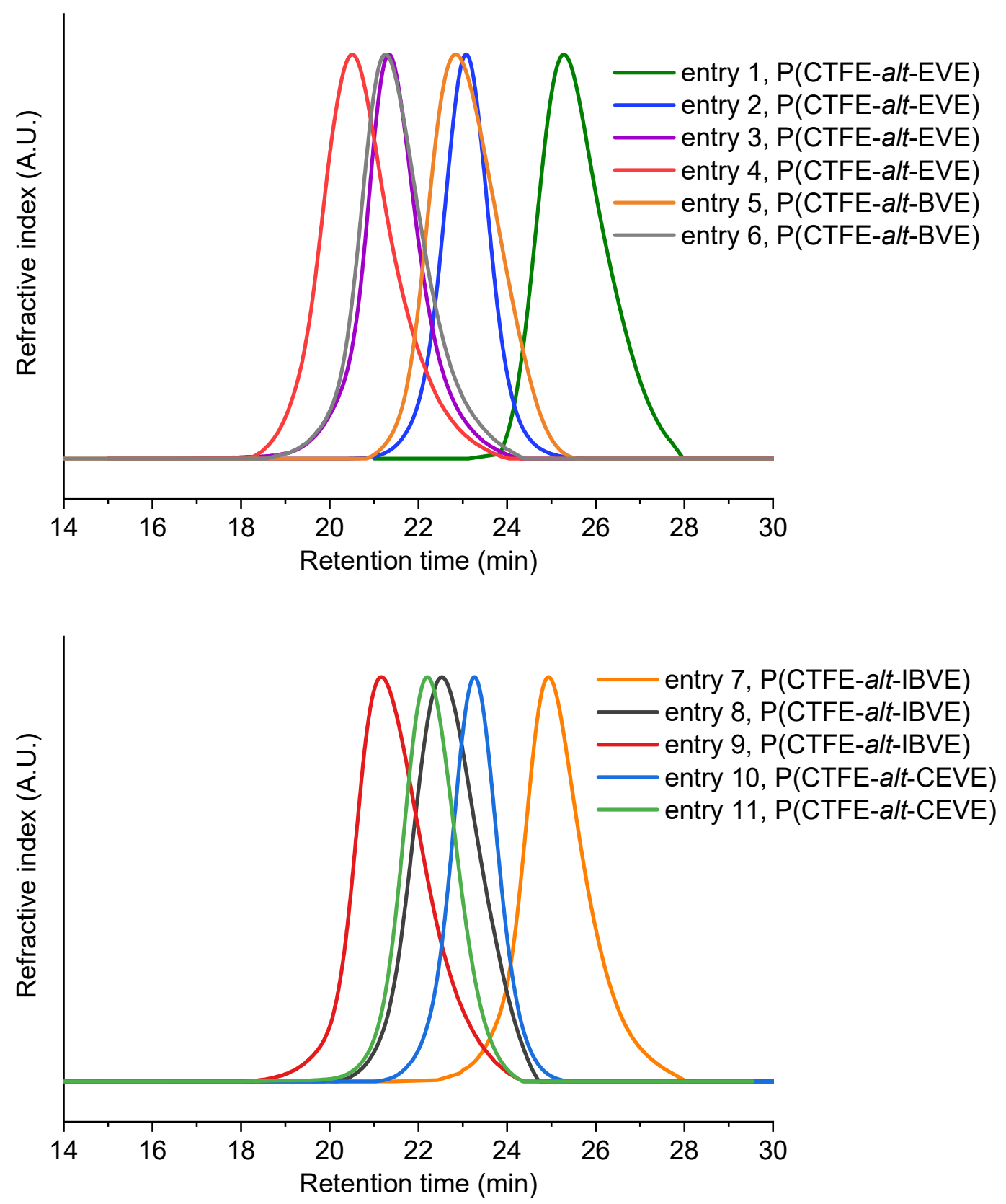


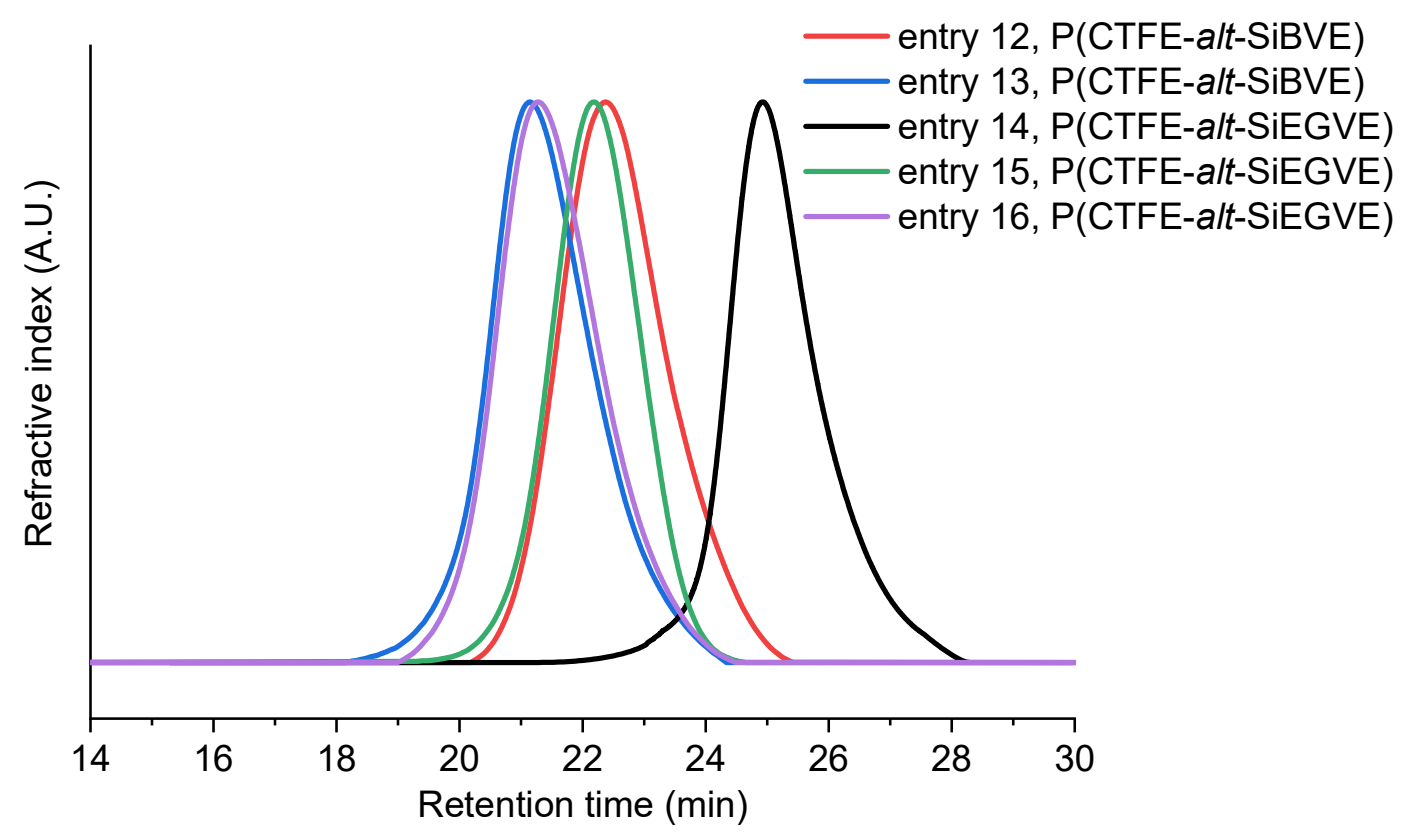

Figure S17. SEC profiles for alternating copolymerization in Table 1.

Table S10. Experimental results of copolymerization of CTFE and VEs using CTA 3d. ${ }^{[a]}$

\begin{tabular}{ccccccc}
\hline Entry & VE & {$[\mathrm{CTFE}] /[\mathrm{VE}] /[\mathrm{CTA} 3 \mathrm{~d}]$} & $\begin{array}{c}\text { Conv. } \\
(\%)\end{array}$ & $\begin{array}{c}M_{\mathrm{n}, \text { calc }} \\
(\mathrm{kDa})\end{array}$ & $\begin{array}{c}M_{\mathrm{n}, \mathrm{SEC}} \\
(\mathrm{kDa})\end{array}$ & $Ð$ \\
\hline 1 & EVE & $120 / 80 / 1$ & 98 & 15.1 & 16.8 & 1.39 \\
2 & BVE & $120 / 80 / 1$ & 95 & 16.8 & 35.2 & 1.50 \\
3 & IBVE & $120 / 80 / 1$ & 92 & 16.2 & 30.9 & 1.51 \\
4 & CEVE & $120 / 80 / 1$ & 70 & 12.8 & 18.5 & 1.33 \\
5 & SiBVE & $120 / 80 / 1$ & 90 & 25.3 & 33.6 & 1.38 \\
6 & SiEGVE & $120 / 80 / 1$ & 72 & 21.2 & 28.7 & 1.43 \\
\hline
\end{tabular}

[a] $[\mathrm{CTA}] /[\mathrm{F}-\mathrm{PTH}]=1 / 0.05$, experiments were conducted at $25{ }^{\circ} \mathrm{C}$ and ambient pressure in Schlenk glass tubes. A $30 \mathrm{~W}$ purple LED bulb was used as the light source, diethyl carbonate (DEC) as solvent. $M_{\mathrm{n} \text {,calc }}$ were determined based on VE conversions. Conversions are based on the ${ }^{1} \mathrm{H}$ NMR analysis of remaining VE after reactions. $M_{\mathrm{n}, \mathrm{SEC}}$ and $Ð$ were measured using SEC.

\section{UV-vis analysis and ${ }^{1} \mathrm{H}$ NMR spectra for alternating copolymers}


A)

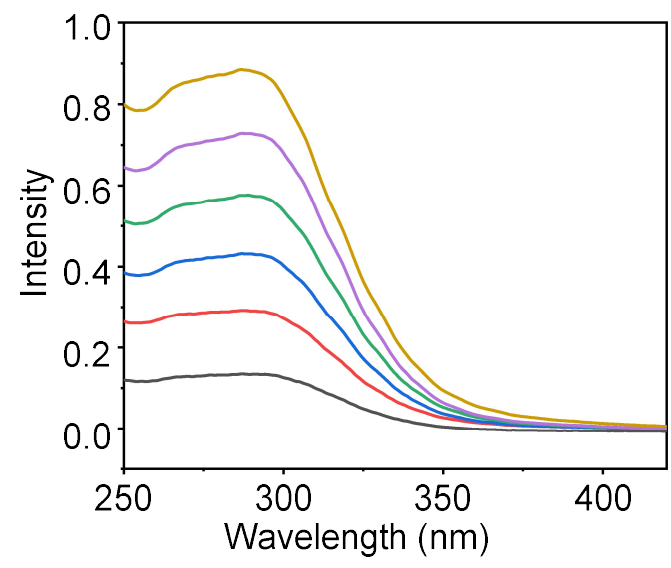

B)

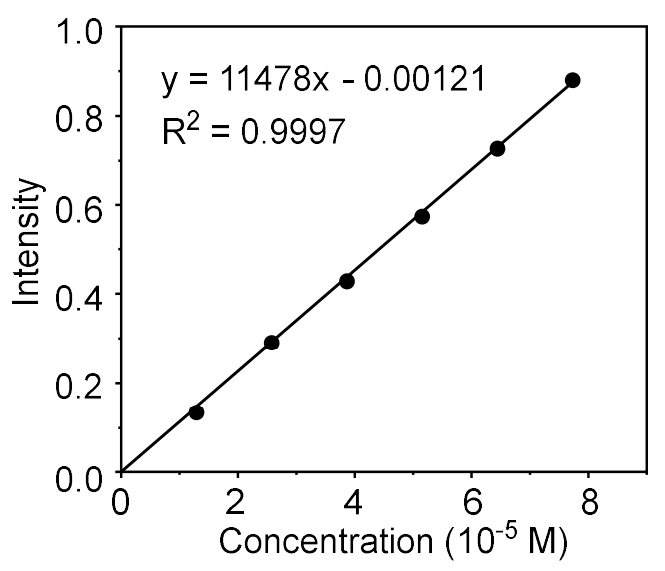

Figure S18. A) UV-Vis absorption of CTA 4 (in $\mathrm{CHCl}_{3}$ ) at room temperature. Concentration of CTA 4 ranges from $1.29 \times 10^{-5} \mathrm{M}$ to $7.73 \times 10^{-5} \mathrm{M}$. B) Intensity $v$ CTA 4 concentration, which gives the extinction coefficient of $\varepsilon=1.167 \times 10^{4} \mathrm{~L} \cdot \mathrm{mol}^{-1} \mathrm{~cm}^{-1}$ at $296 \mathrm{~nm}$ according to the Beer-Lambert Law.

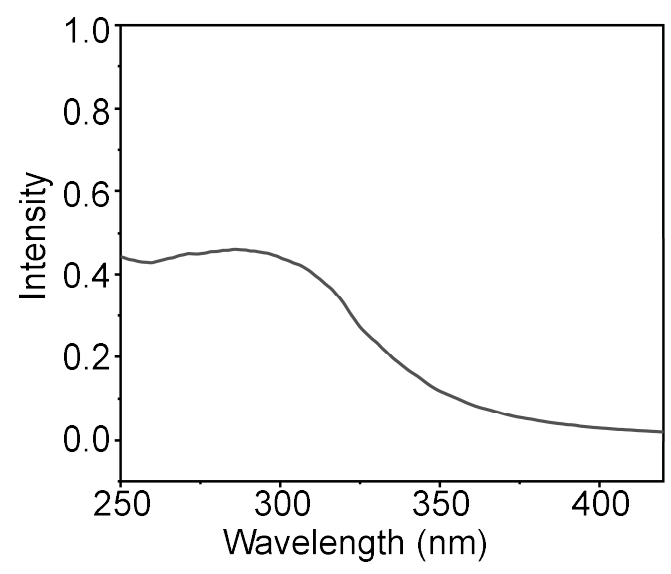

Figure S19. UV-vis absorption of $\mathrm{P}\left(\mathrm{CTFE}-\right.$ alt-CEVE) $\left(\mathrm{CHCl}_{3}\right)$ at room temperature.

Because CTA 4 exhibits a strong UV-vis absorption at $296 \mathrm{~nm}$, it is possible to analyze the degree of chain-end functionality as well as to estimate the molecular weights of fluoropolymers by UV-vis spectroscopy. ${ }^{[3]} \mathrm{P}\left(\mathrm{CTFE}\right.$-alt-CEVE) $\left(M_{\mathrm{n}, \mathrm{NMR}}=24.8 \mathrm{kDa}, M_{\mathrm{n}, \mathrm{MALLS}}\right.$ $=24.2 \mathrm{kDa}, M_{\mathrm{n}, \text { calc }}=23.9 \mathrm{kDa}$ ) was dissolved in $\mathrm{CHCl}_{3}$ and absorbance at $296 \mathrm{~nm}$ (A) was obtained by UV-vis. $M_{\mathrm{n}, \mathrm{UV}-\mathrm{vis}}$ of fluoropolymer was estimated according to Equation $\mathrm{S} 3,{ }^{[3]}$ where $w$ is the mass $(\mathrm{g})$ of polymer, $l(\mathrm{~cm})$ is the optical path length of the light inside the sample cell, $\varepsilon$ is the molar extinction coefficient of CTA 4 in $\mathrm{CHCl}_{3}\left(\mathrm{~L} \cdot \mathrm{mol}^{-1} \mathrm{~cm}^{-1}\right)$, and $V$ is 
the volume of the sample (L). According to this method, $M_{\mathrm{n}, \mathrm{UV} \text {-vis }}=25.1 \mathrm{kDa}$ is obtained. This method was also applied to $\mathrm{P}(\mathrm{CTFE}-$ alt $-\mathrm{BVE})\left(M_{\mathrm{n}, \mathrm{NMR}}=17.8 \mathrm{kDa}, M_{\mathrm{n} \text {,calc }}=16.8 \mathrm{kDa}\right)$ and the obtained result is $M_{\mathrm{n}, \mathrm{UV} \text {-vis }}=17.6 \mathrm{kDa}$. For both polymers, when compared to values of $M_{\mathrm{n} \text {,calc }}$ or $M_{\mathrm{n}, \mathrm{MALLS}}$, the degree of end group functionality are above $95 \%$.

$$
M_{\mathrm{n}, \mathrm{UV} \text {-vis }}=w \varepsilon l / A V
$$

Equation S3
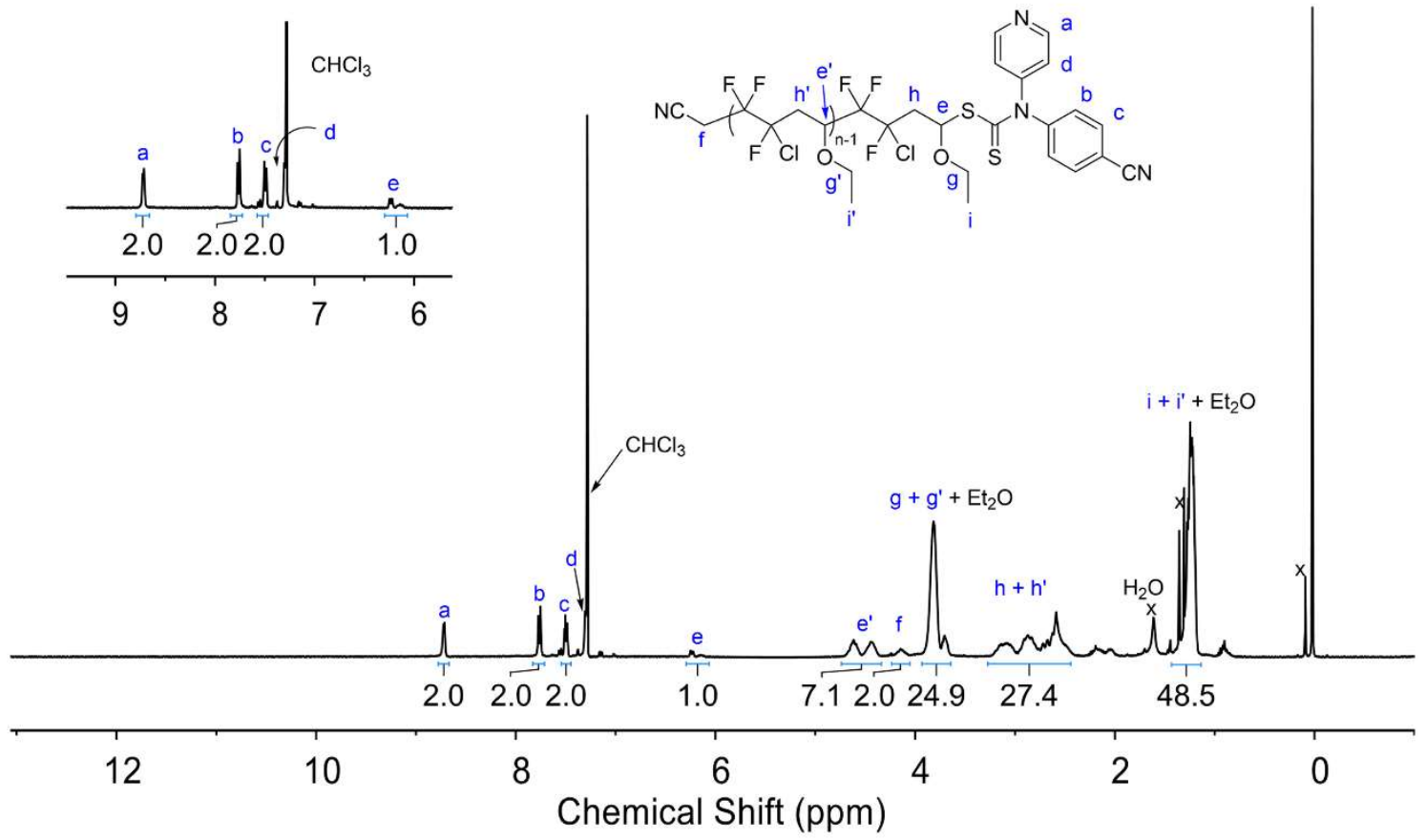

Figure S20. ${ }^{1} \mathrm{H}$ NMR spectrum of $\mathrm{P}\left(\mathrm{CTFE}-\right.$ alt-EVE). $M_{\mathrm{n}, \mathrm{NMR}}=1.8 \mathrm{kDa}$. The $M_{\mathrm{n}, \mathrm{NMR}}$ was calculated by $\left(M_{\mathrm{w}, \mathrm{CTFE}}+M_{\mathrm{w}, \mathrm{EVE}}\right) *\left(\mathrm{e}+\mathrm{e}^{\prime}\right)+M_{\mathrm{w}, \mathrm{CTA}} \cdot M_{\mathrm{w}, \mathrm{CTFE}}$ is the molecular weight of CTFE, $M_{\mathrm{w}, \mathrm{EVE}}$ is the molecular weight of EVE, $M_{\mathrm{w}, \mathrm{CTA}}$ is the molecular weight of CTA. 

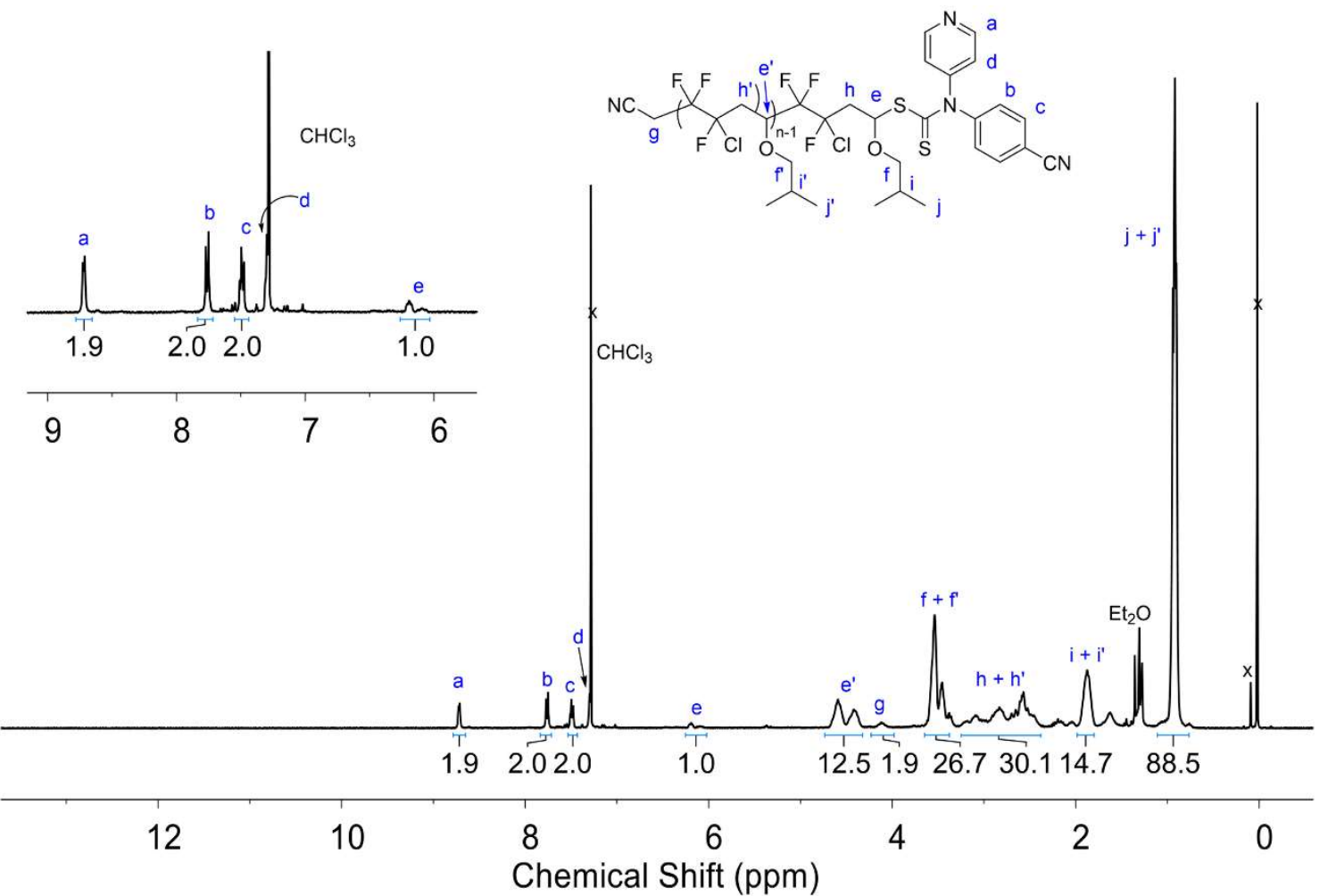

Figure S21. ${ }^{1} \mathrm{H}$ NMR spectrum of $\mathrm{P}\left(\mathrm{CTFE}-\right.$ alt-IBVE). $M_{\mathrm{n}, \mathrm{NMR}}=3.2 \mathrm{kDa}$. The $M_{\mathrm{n}, \mathrm{NMR}}$ was calculated by $\left(M_{\mathrm{w}, \mathrm{CTFE}}+M_{\mathrm{w}, \mathrm{IBVE}}\right) *\left(\mathrm{e}+\mathrm{e}^{\prime}\right)+M_{\mathrm{w}, \mathrm{CTA}} \cdot M_{\mathrm{w}, \mathrm{CTFE}}$ is the molecular weight of CTFE, $M_{\mathrm{w}, \mathrm{IBVE}}$ is the molecular weight of IBVE, $M_{\mathrm{w}, \mathrm{CTA}}$ is the molecular weight of CTA.
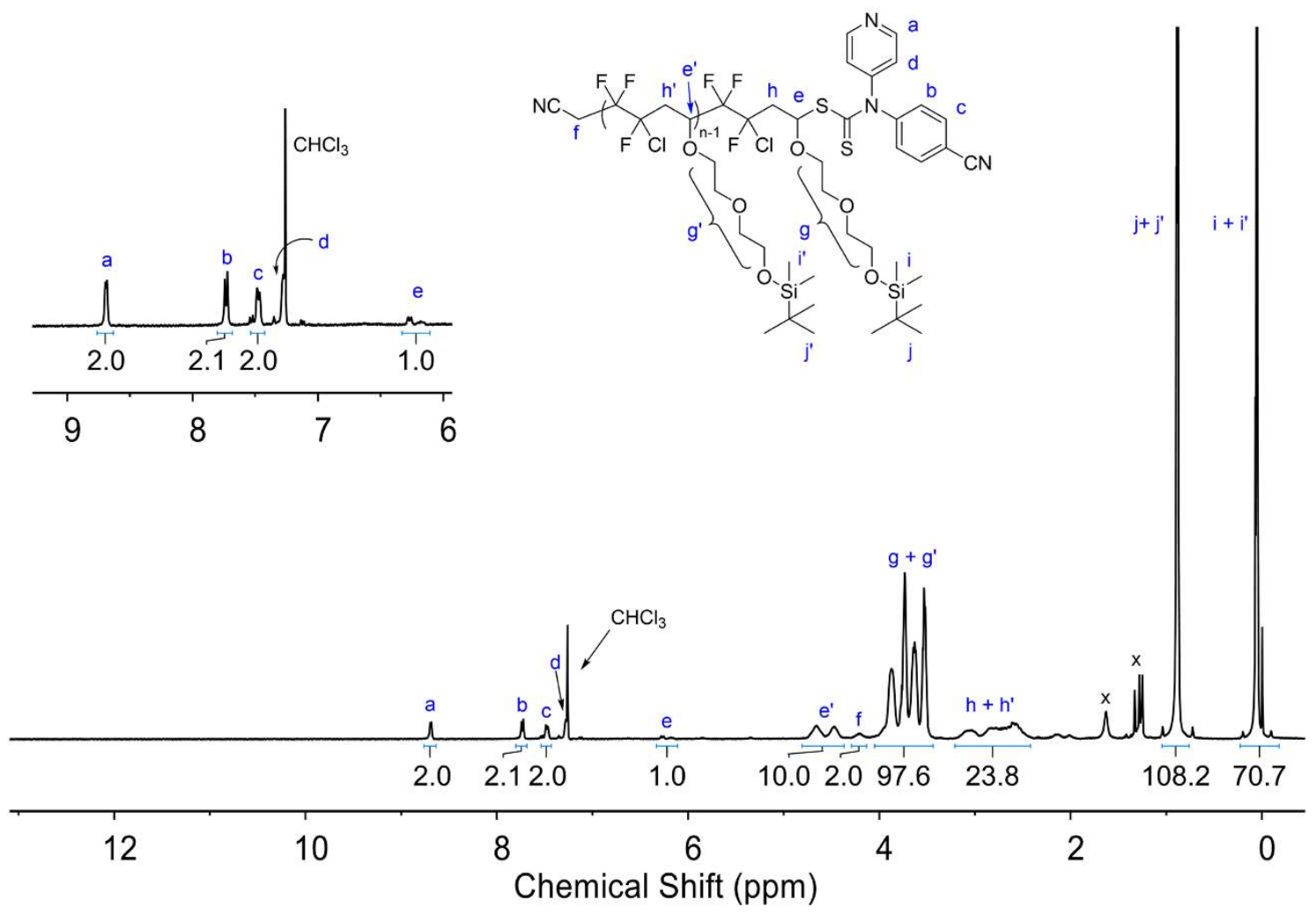

Figure S22. ${ }^{1} \mathrm{H}$ NMR spectrum of $\mathrm{P}\left(\mathrm{CTFE}-\right.$ alt-SiEGVE). $M_{\mathrm{n}, \mathrm{NMR}}=4.3 \mathrm{kDa}$. The $M_{\mathrm{n}, \mathrm{NMR}}$ was 
calculated by $\left(M_{\mathrm{w}, \mathrm{CTFE}}+M_{\mathrm{w}, \mathrm{SiEGVE}}\right) *\left(\mathrm{e}+\mathrm{e}^{`}\right)+M_{\mathrm{w}, \mathrm{CTA}} \cdot M_{\mathrm{w}, \mathrm{CTFE}}$ is the molecular weight of CTFE, $M_{\mathrm{w}, \mathrm{SiEGVE}}$ is the molecular weight of SiEGVE, $M_{\mathrm{w}, \mathrm{CTA}}$ is the molecular weight of CTA.
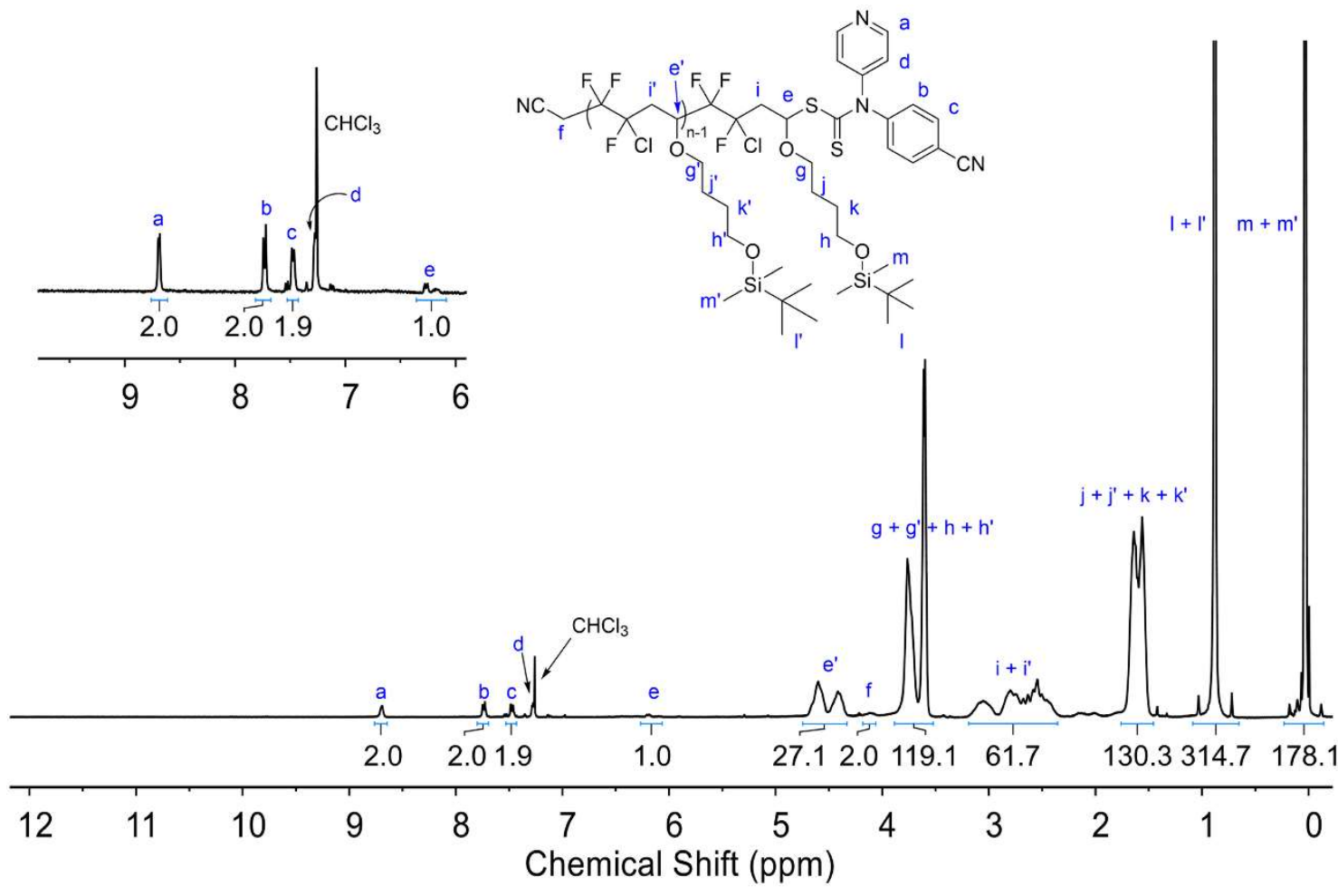

Figure S23. ${ }^{1} \mathrm{H}$ NMR spectrum of $\mathrm{P}(\mathrm{CTFE}-$ alt-SiBVE $) . M_{\mathrm{n}, \mathrm{NMR}}=9.7 \mathrm{kDa}$. The $M_{\mathrm{n}, \mathrm{NMR}}$ was calculated by $\left(M_{\mathrm{w}, \mathrm{CTFE}}+M_{\mathrm{w}, \mathrm{SiBVE}}\right) *\left(\mathrm{e}+\mathrm{e}^{\prime}\right)+M_{\mathrm{w}, \mathrm{CTA}} \cdot M_{\mathrm{w}, \mathrm{CTFE}}$ is the molecular weight of CTFE, $M_{\mathrm{w}, \mathrm{SiBVE}}$ is the molecular weight of $\mathrm{SiBVE}, M_{\mathrm{w}, \mathrm{CTA}}$ is the molecular weight of CTA.
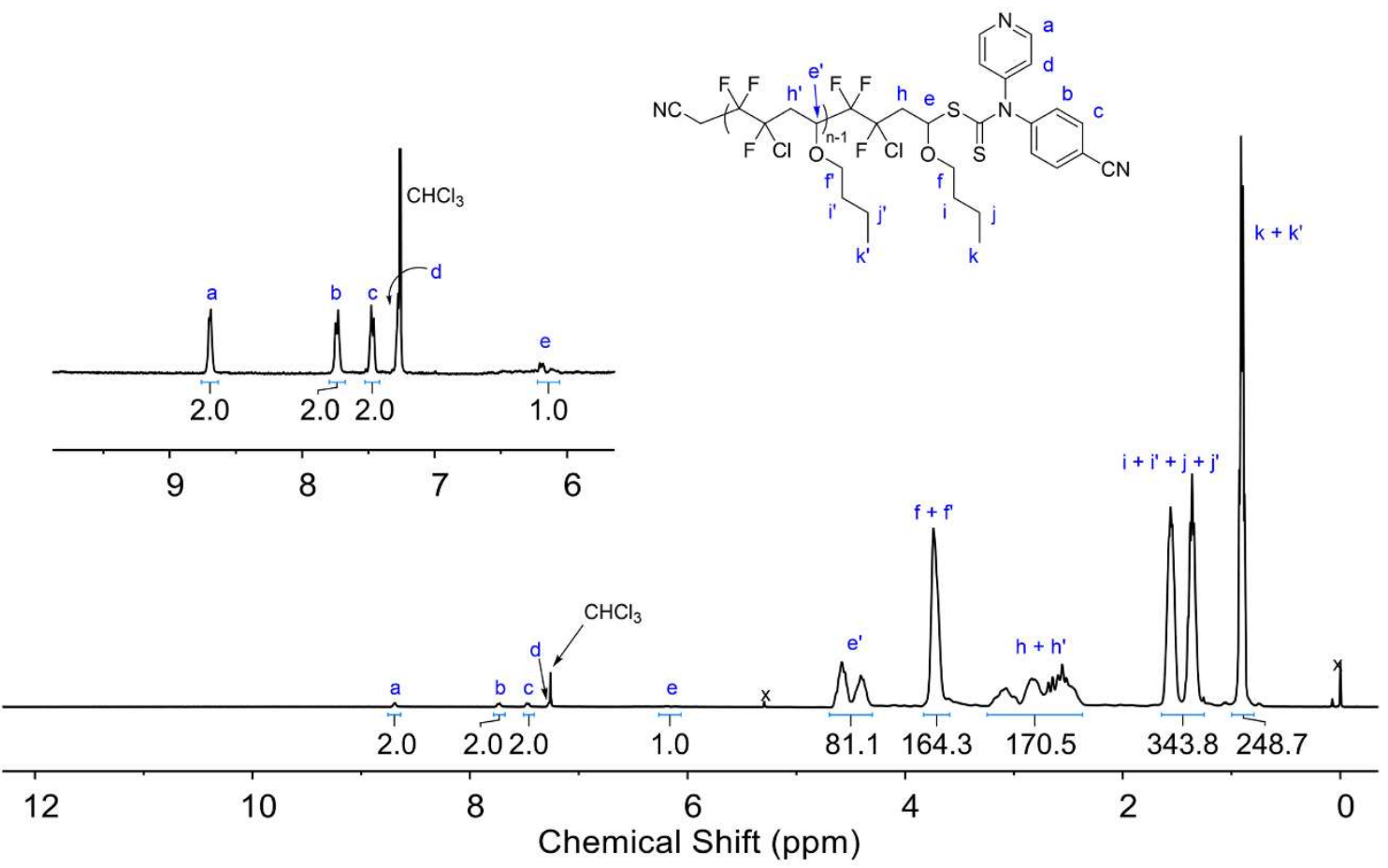
Figure S24. ${ }^{1} \mathrm{H}$ NMR spectrum of $\mathrm{P}\left(\mathrm{CTFE}-\right.$ alt-BVE). $M_{\mathrm{n}, \mathrm{NMR}}=17.8 \mathrm{kDa}$. The $M_{\mathrm{n}, \mathrm{NMR}}$ was calculated by $\left(M_{\mathrm{w}, \mathrm{CTFE}}+M_{\mathrm{w}, \mathrm{BVE}}\right) *\left(\mathrm{e}+\mathrm{e}^{\prime}\right)+M_{\mathrm{w}, \mathrm{CTA}} M_{\mathrm{w}, \mathrm{CTFE}}$ is the molecular weight of CTFE, $M_{\mathrm{w}, \mathrm{SiBVE}}$ is the molecular weight of BVE, $M_{\mathrm{w}, \mathrm{CTA}}$ is the molecular weight of CTA.

\section{Light controlled "ON/OFF" experiments in Figures 4 and 5}

Experimental procedure for copolymerization of CTFE and IBVE in Figure 4: An ovendried $20 \mathrm{~mL}$ Schlenk tube equipped with a stir bar was charged with $6 \mathrm{~mL}$ DEC solution containing monomers $(\mathrm{W}(\mathrm{CTFE})=1.39 \mathrm{~g}, \mathrm{~W}(\mathrm{IBVE})=793.0 \mathrm{mg})$, CTA 4 (30.5 mg), F-PTH catalyst $\left(440 \mu \mathrm{L}, 11.2 \times 10^{-3} \mathrm{M}\right.$ in DEC) $([\mathrm{CTFE}] /[\mathrm{IBVE}] /[\mathrm{CTA}] /[\mathrm{F}-\mathrm{PTH}]=120 / 80 / 1 / 0.05)$ and internal standard (1,4-difluorobenzene, $0.5 \mathrm{mmol})$. The solution was deoxygenated with three freeze-pump-thaw cycles under $\mathrm{N}_{2}$ atmosphere. Then, the tube was kept in front of a $30 \mathrm{~W}$ purple LED bulb (1 cm distance) at room temperature, and blown with compressed air to avoid heating. At corresponding time, a small aliquot was taken, and the light irradiation was turned "ON" or "OFF" as indicated in Figure 5. The obtained sample was diluted with solvent before analyzing with NMR and SEC instruments.

Table S11. "ON/OFF" experiments for the photoredox copolymerization of CTFE and IBVE in Figure 4.

\begin{tabular}{cccccc}
\hline Entry & $\begin{array}{c}\text { Light } \\
\text { irradiation }\end{array}$ & $\begin{array}{c}\text { Time } \\
(\mathrm{h})^{[\mathrm{a}]}\end{array}$ & $\begin{array}{c}\text { Conv } \\
(\%)^{[\mathrm{b}]}\end{array}$ & $\begin{array}{c}M_{\mathrm{n}, \text { SEC }} \\
(\mathrm{kDa})^{[\mathrm{c}]}\end{array}$ & $\bigoplus^{[\mathrm{c}]}$ \\
\hline 1 & ON & 0 & 0 & - & - \\
2 & OFF & 2 & 20 & 2.8 & 1.24 \\
3 & ON & 3 & 20 & 2.9 & 1.24 \\
4 & OFF & 5 & 36 & 5.8 & 1.22 \\
5 & ON & 6 & 36 & 5.8 & 1.22 \\
6 & OFF & 13 & 72 & 18.8 & 1.25 \\
7 & ON & 14 & 72 & 19.0 & 1.25 \\
8 & OFF & 22 & 94 & 26.7 & 1.26 \\
9 & - & 23 & 94 & 26.8 & 1.26
\end{tabular}

${ }^{[\mathrm{a}]}$ Reaction time. ${ }^{[\mathrm{b}]}$ Calculated based on conversions of IBVE. ${ }^{[\mathrm{c}]} M_{\mathrm{n}, \mathrm{SEC}}$ and $\oslash$ were measured using SEC.

Experimental procedure for copolymerization of CTFE and IBVE in Figure 5: An oven- 
dried $25 \mathrm{~mL}$ Schlenk tube equipped with a stir bar was charged with $15 \mathrm{~mL}$ DEC solution containing monomers $(\mathrm{W}(\mathrm{CTFE})=3.48 \mathrm{~g}, \mathrm{~W}(\mathrm{IBVE})=1.98 \mathrm{~g})$, CTA 4 (76.3 mg), F-PTH catalyst $\left(1.1 \mathrm{~mL}, 11.2 \times 10^{-3} \mathrm{M}\right.$ in DEC) $([\mathrm{CTFE}] /[\mathrm{IBVE}] /[\mathrm{CTA}] /[\mathrm{F}-\mathrm{PTH}]=120 / 80 / 1 / 0.05)$ and internal standard (1,4-difluorobenzene). The solution was deoxygenated with three freezepump-thaw cycles under $\mathrm{N}_{2}$ atmosphere. Then, the tube was kept in front of $30 \mathrm{~W}$ purple LED bulbs ( $1 \mathrm{~cm}$ distance) at room temperature, and blown with compressed air to avoid heating. At corresponding time, a small aliquot was taken, and the light irradiation was turned "ON" or "OFF" as indicated in Figure 5. The obtained sample was diluted with solvent before analyzing with NMR and SEC instruments.

Table S12. "ON/OFF” experiments for the photoredox copolymerization of CTFE and IBVE in Figure 5.

\begin{tabular}{cccccc}
\hline Entry & $\begin{array}{c}\text { Light } \\
\text { irradiation }\end{array}$ & $\begin{array}{c}\text { Time } \\
(\mathrm{h})^{[\mathrm{a}]}\end{array}$ & $\begin{array}{c}\text { Conv } \\
(\%)^{[\mathrm{b}]}\end{array}$ & $\begin{array}{c}M_{\mathrm{n}, \mathrm{SEC}} \\
(\mathrm{kDa})^{[\mathrm{c}]}\end{array}$ & $\Xi^{[\mathrm{c}]}$ \\
\hline 1 & OFF & 0 & 0 & - & - \\
$\ldots$ & $\ldots$ & $\ldots$ & $\ldots$ & $\ldots$ & $\ldots$ \\
2 & ON & 2 & 0 & - & - \\
4 & ON & 3 & 9 & - & - \\
5 & ON & 4 & 22 & 4.6 & 1.22 \\
6 & OFF & 5 & 32 & 6.2 & 1.25 \\
$\ldots$ & $\ldots$ & $\ldots$ & $\ldots$ & $\ldots$ & $\ldots$ \\
7 & ON & 15 & 32 & 6.2 & 1.25 \\
8 & ON & 17 & 49 & 9.5 & 1.23 \\
9 & ON & 19 & 60 & 13.3 & 1.26 \\
10 & ON & 21 & 66 & 15.7 & 1.27 \\
\hline
\end{tabular}

${ }^{[\mathrm{a}]}$ Reaction time. ${ }^{[\mathrm{b}]}$ Calculated based on conversions of IBVE. ${ }^{[\mathrm{c}]} M_{\mathrm{n}, \mathrm{SEC}}$ and $\oslash$ were measured using SEC.

\section{Experiments and characterization for Figure 6}

\subsection{Synthesis of $\mathrm{P}(\mathrm{CTFE}-a \mathrm{lt}-\mathrm{EVE})-\mathrm{b}-\mathrm{P}(\mathrm{CTFE}-a l t-\mathrm{CEVE})$ via in situ chain-extension alternating copolymerization}




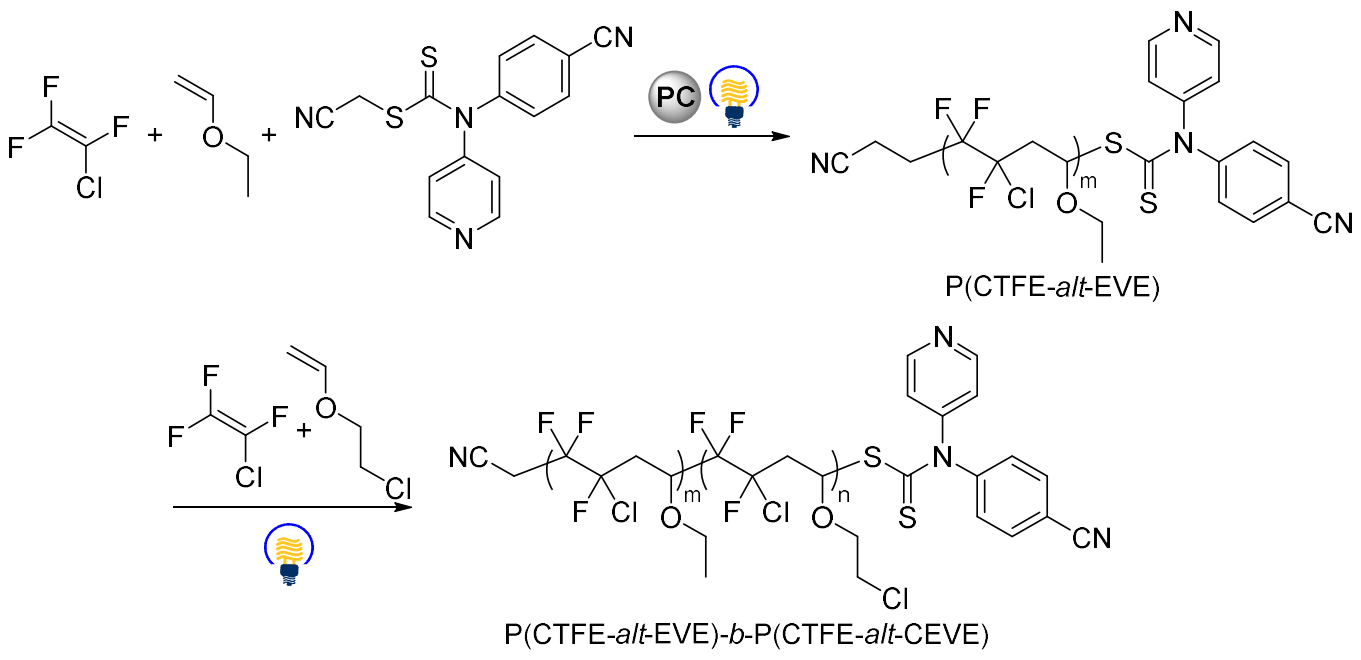

Scheme S2. Synthetic route to P(CTFE-alt-EVE)-b-P(CTFE-alt-CEVE).

An oven-dried $10 \mathrm{~mL}$ Schlenk tube equipped with a stir bar was charged with $2 \mathrm{~mL}$ DEC solution containing monomers $(\mathrm{W}(\mathrm{CTFE}=279.7 \mathrm{mg}, \mathrm{W}(\mathrm{EVE})=115.2 \mathrm{mg}), \mathrm{CTA} 4(12.5 \mathrm{mg})$ and F-PTH catalyst $\left(150 \mu \mathrm{L}, 13.6 \times 10^{-3} \mathrm{M}\right.$ in DEC). The solution ([CTFE + EVE]/[CTA]/[F$\mathrm{PTH}]=100 / 1 / 0.05)$ was deoxygenated with three freeze-pump-thaw cycles under $\mathrm{N}_{2}$ atmosphere. Then, the mixture was stirred for $12 \mathrm{~h}$ in front of a purple LED light bulb. After reaction, the mixture was concentrated under vacuum to remove all monomers left and solvent. Then, $2 \mathrm{~mL}$ DEC solution containing monomers ( $\mathrm{W}(\mathrm{CTFE}=279.7 \mathrm{mg}, \mathrm{W}(\mathrm{CEVE})=170.2 \mathrm{mg})$ were added via a syringe into the tube under $\mathrm{N}_{2}$ atmosphere. The mixture was stirred for $24 \mathrm{~h}$ under the LED light irradiation. A small aliquot was taken and directly analyzed using the SEC instrument. The reaction mixture was dropwisely added into methanol with vigorous stirring to give precipitate. The precipitate was collected and dried under vacuum to give P(CTFE-altEVE)- $b$ - P(CTFE-alt-CEVE). 

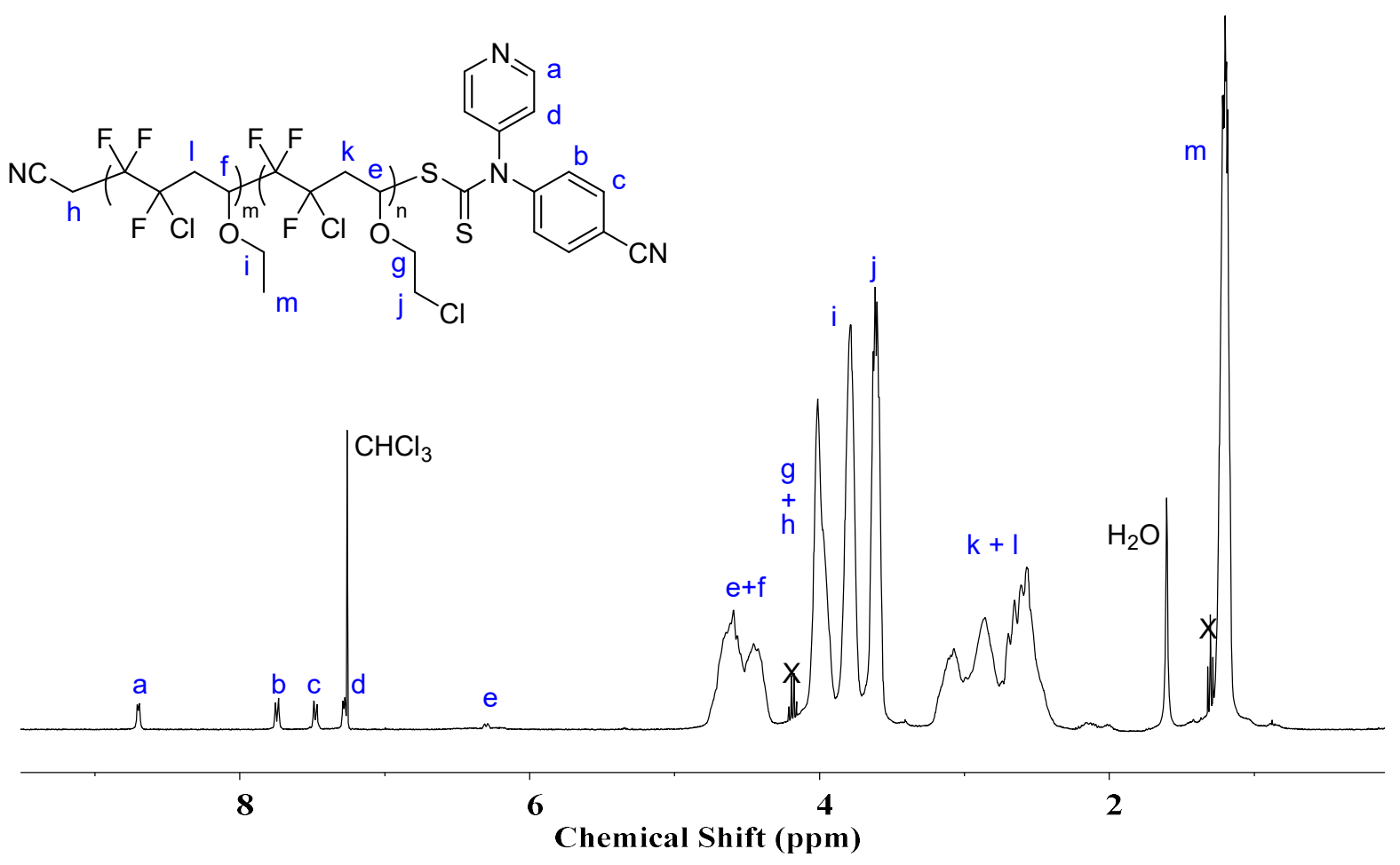

Figure S25. ${ }^{1} \mathrm{H}$ NMR spectrum of $\mathrm{P}(\mathrm{CTFE}-$ alt-EVE)- $b$ - $\mathrm{P}(\mathrm{CTFE}-$ alt-CEVE).

8.2 Post-synthetic modification from P(CTFE-alt-EVE)-b-P(CTFE-alt-CEVE)
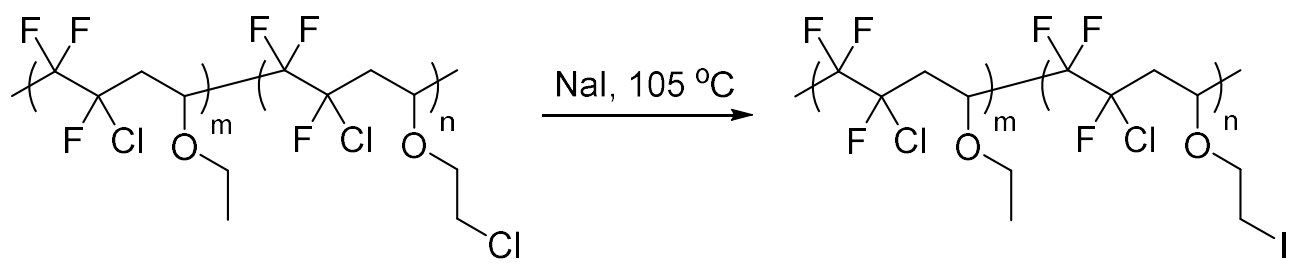

Scheme S3. The synthetic route for P(CTFE-alt-EVE)- $b$-P(CTFE-alt-IEVE).

An oven-dried round-bottomed flask equipped with a stir bar was charged with P(CTFE$a l t$-EVE)- $b$-P(CTFE-alt-CEVE) (500.0 mg), NaI (2.0 g) and $10 \mathrm{~mL}$ cyclohexanone. Then, the mixture was stirred at $105{ }^{\circ} \mathrm{C}$ overnight. After reaction, the mixture was cooled down, and concentrated under vacuum. The residue was treated with DCM and brine. The DCM layer was dried over $\mathrm{Na}_{2} \mathrm{SO}_{4}$, concentrated under vacuum to give $\mathrm{P}(\mathrm{CTFE}-$ alt-EVE)- $b$-P(CTFE-altIEVE). The polymer was dissolved in minimal amount of DCM, and added into methanol to give precipitate. The solid was collected and dried under vacuum to give target polymer. 

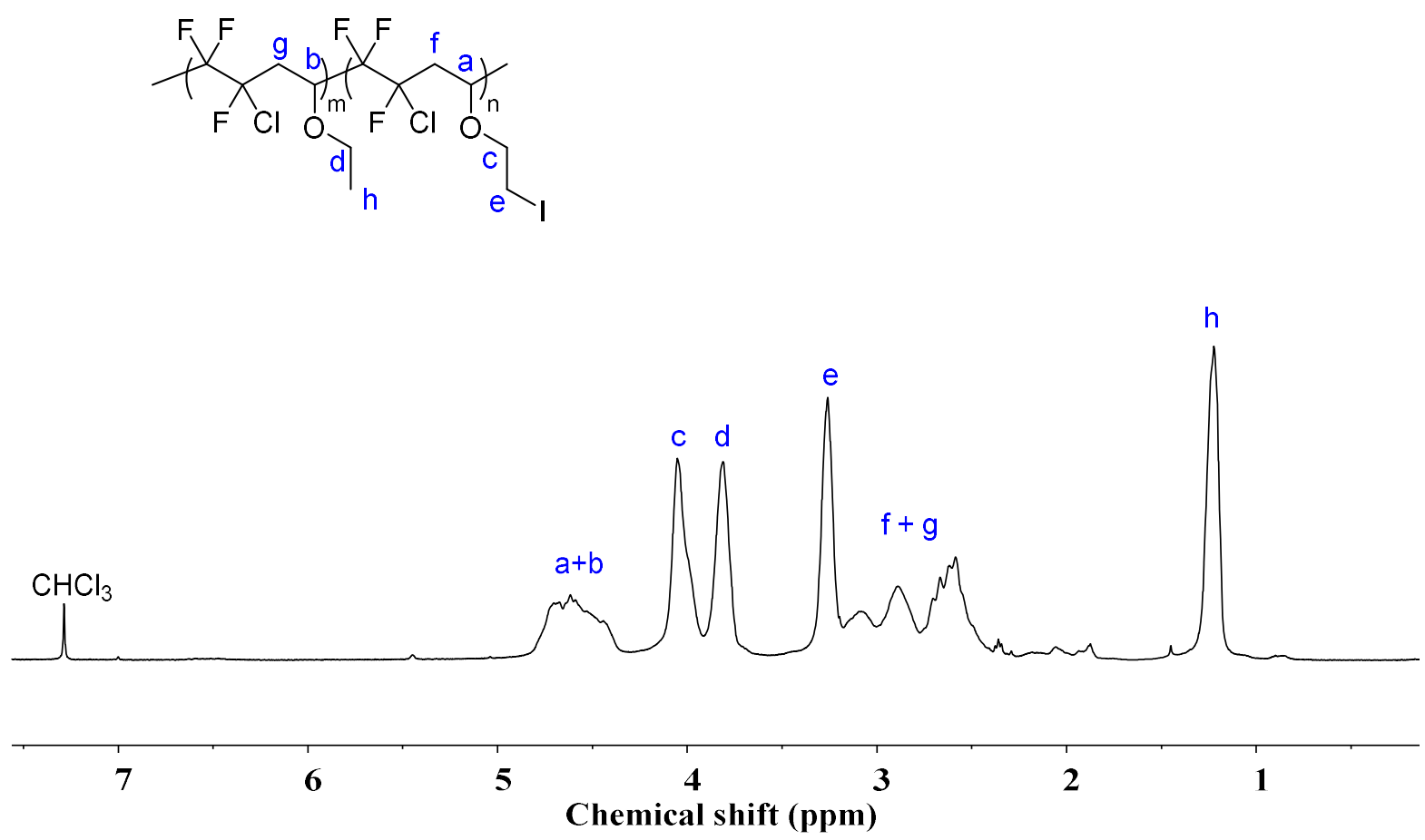

Figure S26. ${ }^{1} \mathrm{H}$ NMR spectrum of $\mathrm{P}(\mathrm{CTFE}-$ alt-EVE)- $b$-P(CTFE-alt-IEVE). NOTE: During the post-synthetic modificatioin, terminally functional group from CTA was cleavged in the presence of the nucleophilc agent under thermal conditions.

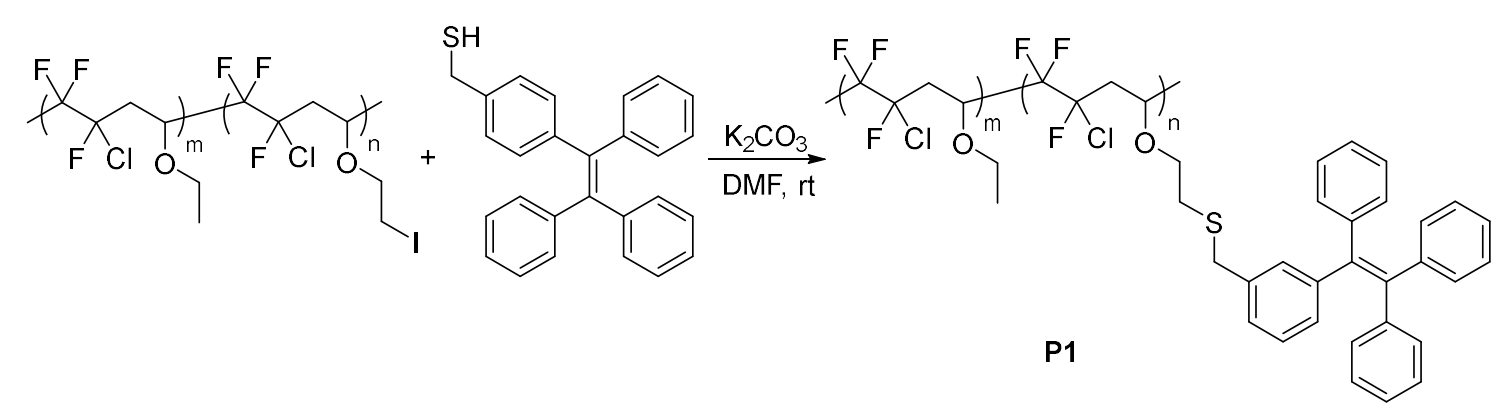

Scheme S4. The synthetic route for P1. 

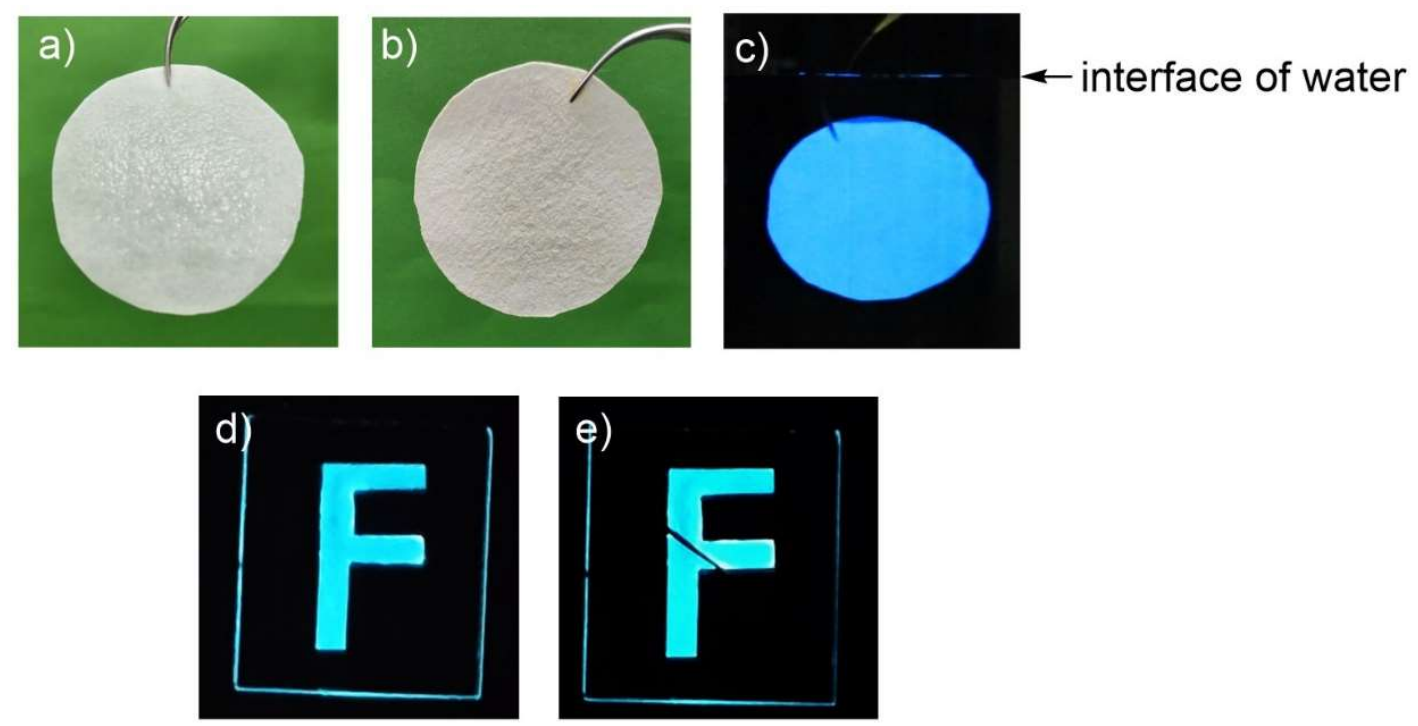

Figure S27. a) and b) Images of filter papers taken out from a water bath. The paper in b) was treated with compound $\mathbf{P 1}$ before submerging in water. c) Image of the light-emission behavior of the filter paper in b), when submerged under water. d) and e) Paintings with P1 on a surface, without and with scratch, respectively. These results indicated that when utilized as a coating material, P1 provided excellent waterproof ability for the filter paper as indicated by the different wetting behaviors between the treated and untreated samples after submerging under water ( $\mathrm{a}$ and $\mathrm{b}$ ). Meanwhile, the modified paper displayed apparent light emission exposing to UV irradiation (c), which could facilitate the detection of crack or scratch for a hydrophobic painting ( $\mathrm{d}$ and $\mathrm{e}$ ). 


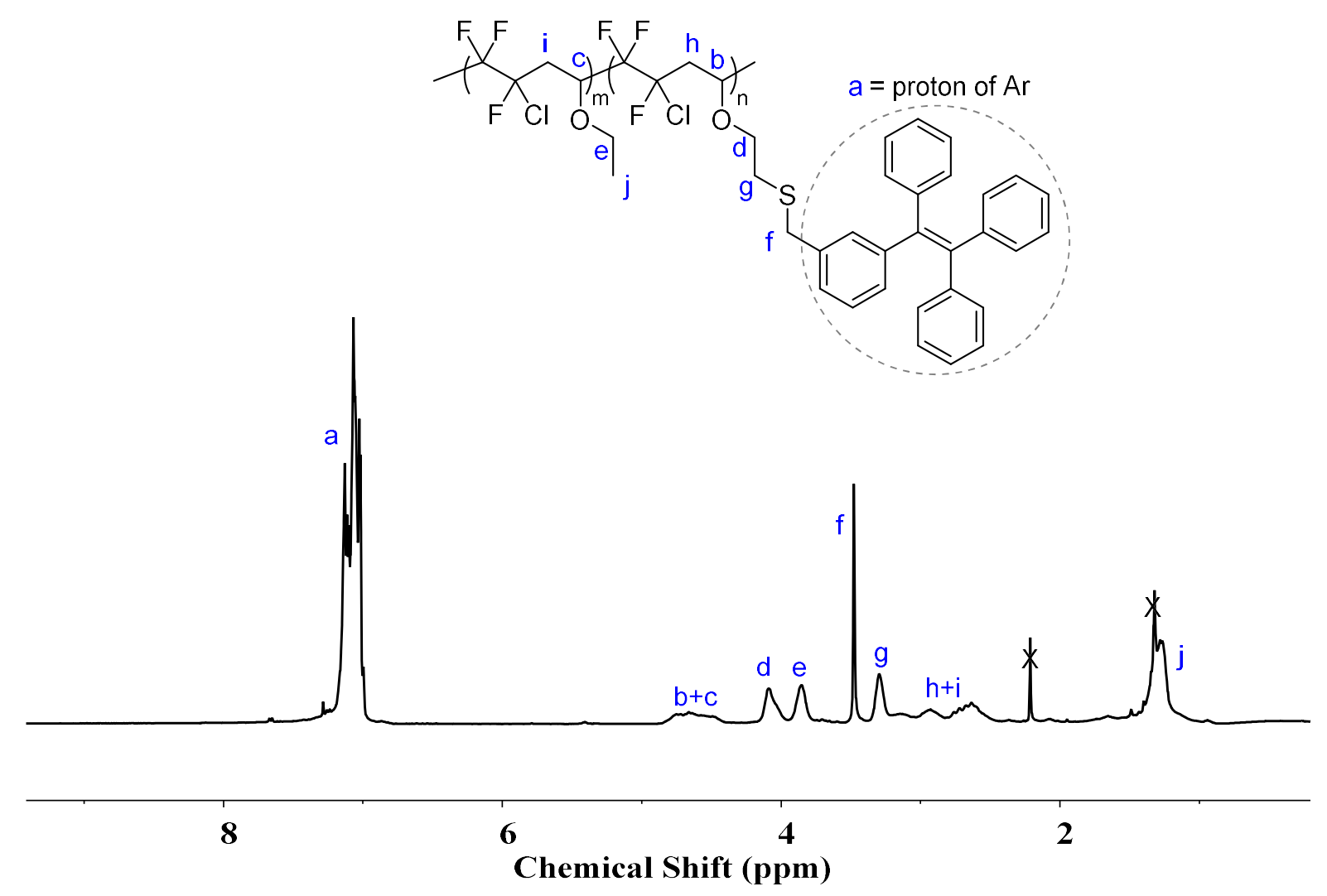

Figure S28. ${ }^{1} \mathrm{H}$ NMR spectrum of $\mathbf{P 1}$.

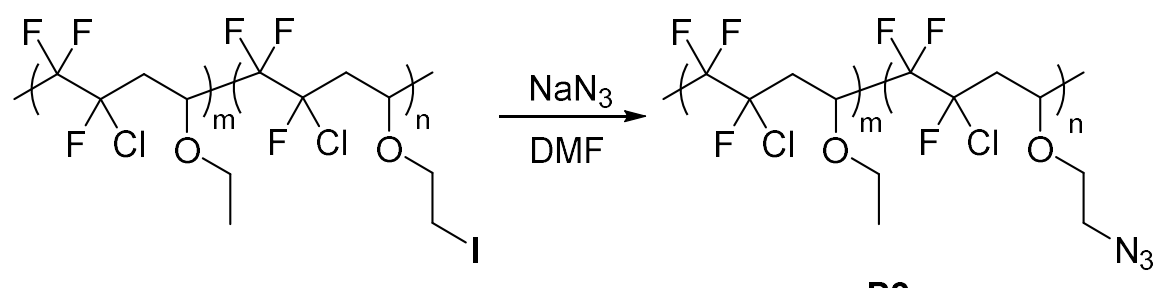

P2

Scheme S5. The synthetic route for $\mathbf{P 2}$.

A round-bottom flask equipped with a stir bar was charged with P(CTFE-alt-EVE)- $b$ $\mathrm{P}\left(\mathrm{CTFE}-\right.$ alt-IEVE) $(350.0 \mathrm{mg}), \mathrm{NaN}_{3}(300 \mathrm{mg}), 5 \mathrm{~mL} \mathrm{DMF}$ and $200 \mu \mathrm{L}$ water. Then, the mixture was stirred at $55^{\circ} \mathrm{C}$ overnight. After reaction, the mixture was treated with DCM and brine. The seperated organic layer was dried over $\mathrm{Na}_{2} \mathrm{SO}_{4}$, concentrated under vacuum. The obtained residue was dissolved in minimal amount of DCM, and dropwisely added into methanol to give precipitate. The collected solid was dried under vacuum to give target polymer P2. 

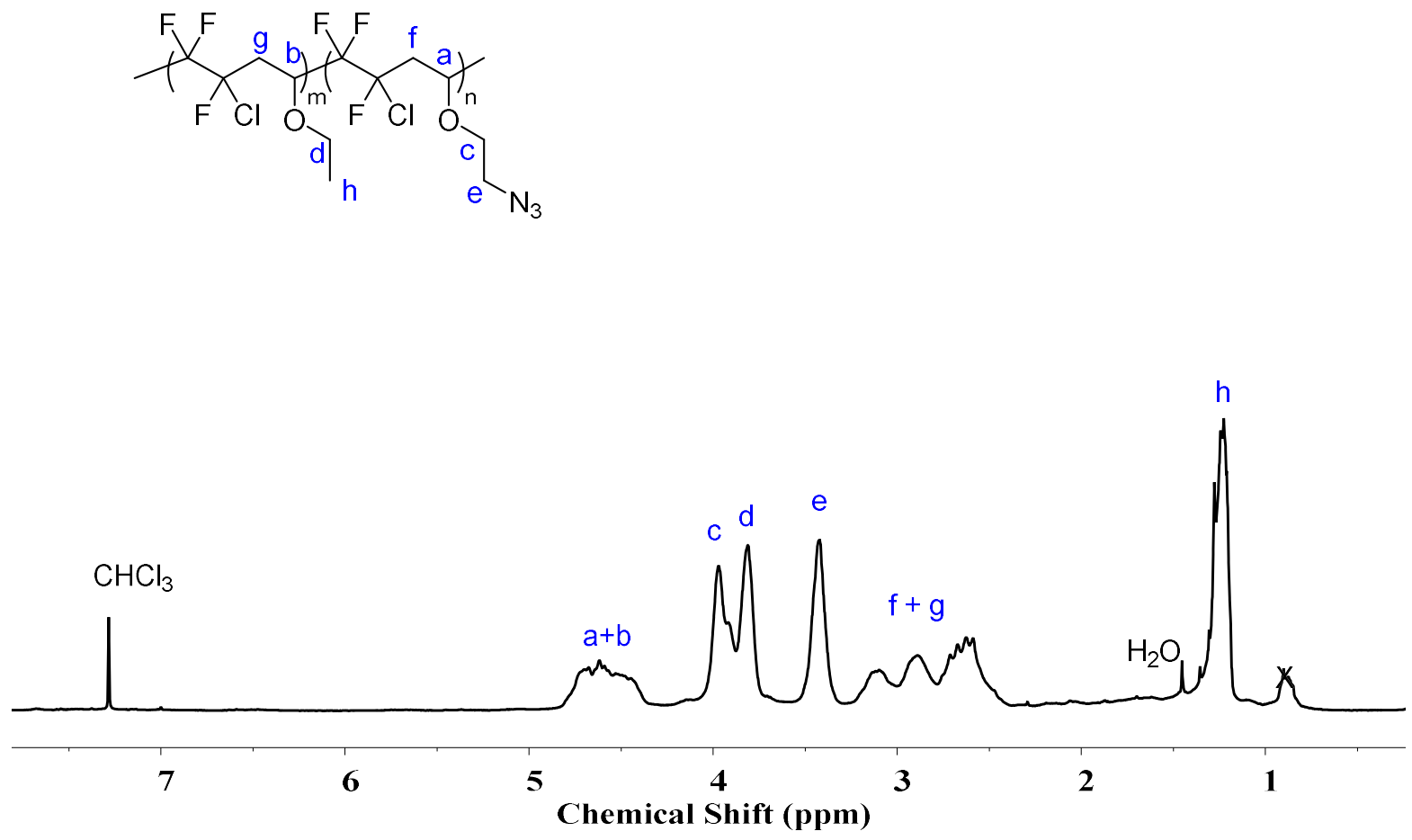

Figure S29. ${ }^{1} \mathrm{H}$ NMR spectrum of $\mathbf{P 2}$.

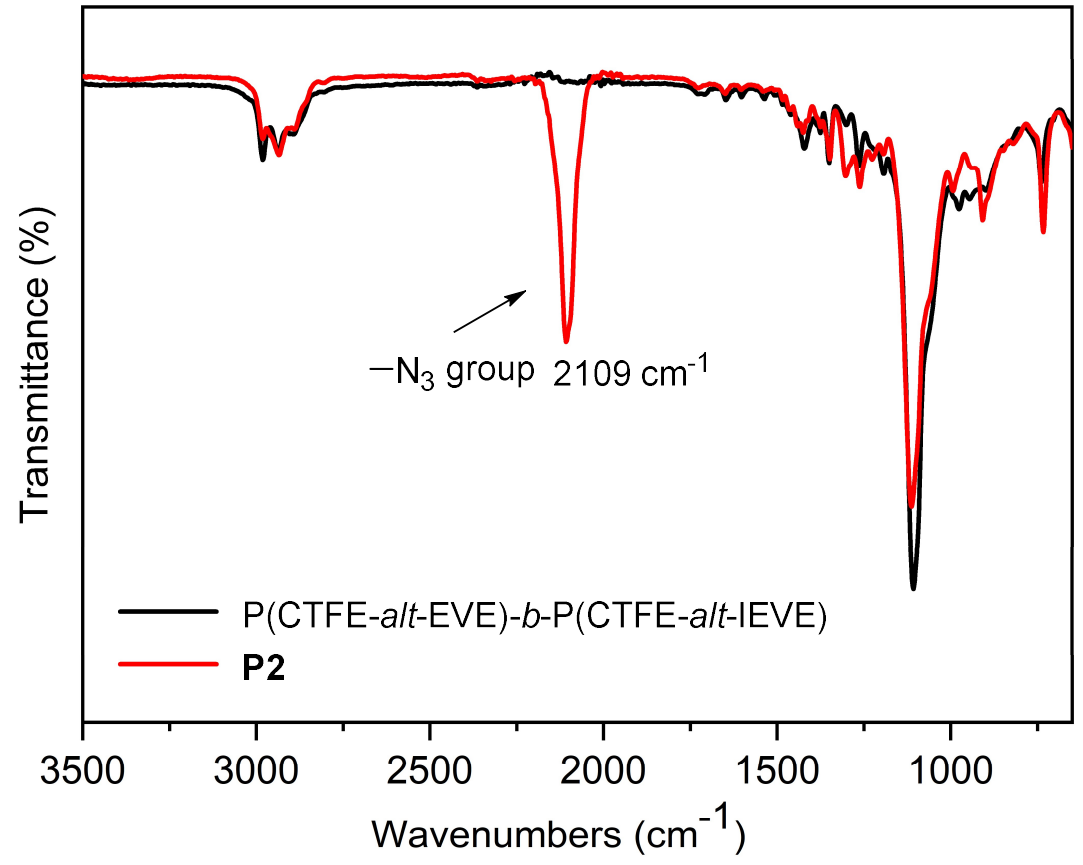

Figure S30. FT-IR of $\mathrm{P}(\mathrm{CTFE}-$ alt-EVE)- $b$-P(CTFE-alt-IEVE) and P2. 


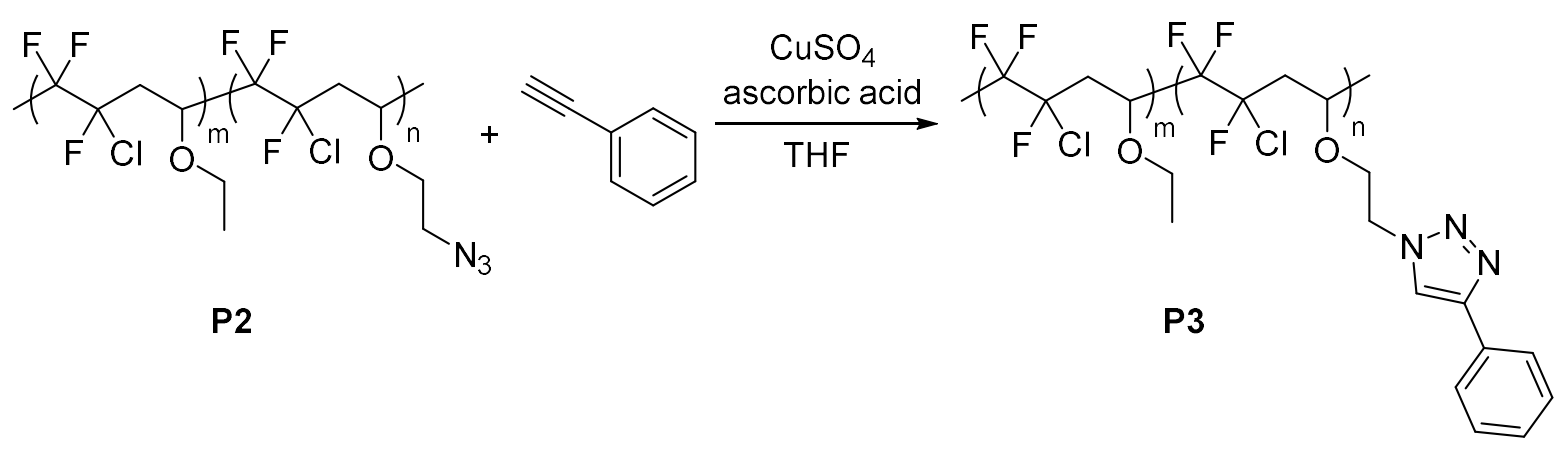

Scheme S6. Preparation of P3 via the "Click" reaction of $\mathbf{P 2}$.

An oven-dried round-bottomed flask equipped with a stir bar was charged with P2 (200 $\mathrm{mg}), 200 \mu \mathrm{L}$ phenylacetylene, $\mathrm{CuSO}_{4} \cdot 5 \mathrm{H}_{2} \mathrm{O}(8.1 \mathrm{mg})$, L-ascorbic acid $(20.5 \mathrm{mg})$ and $5 \mathrm{~mL}$ THF. Then, the mixture was stirred at room temperature overnight. After reaction, reaction mixture was concentrated under vacuum. The residue was diluted with DCM, washed with ammonium hydroxide and brine. The DCM layer was concentrated under vacuum. The crude compound was purified by precipitation from $\mathrm{MeOH} / \mathrm{H}_{2} \mathrm{O}$.

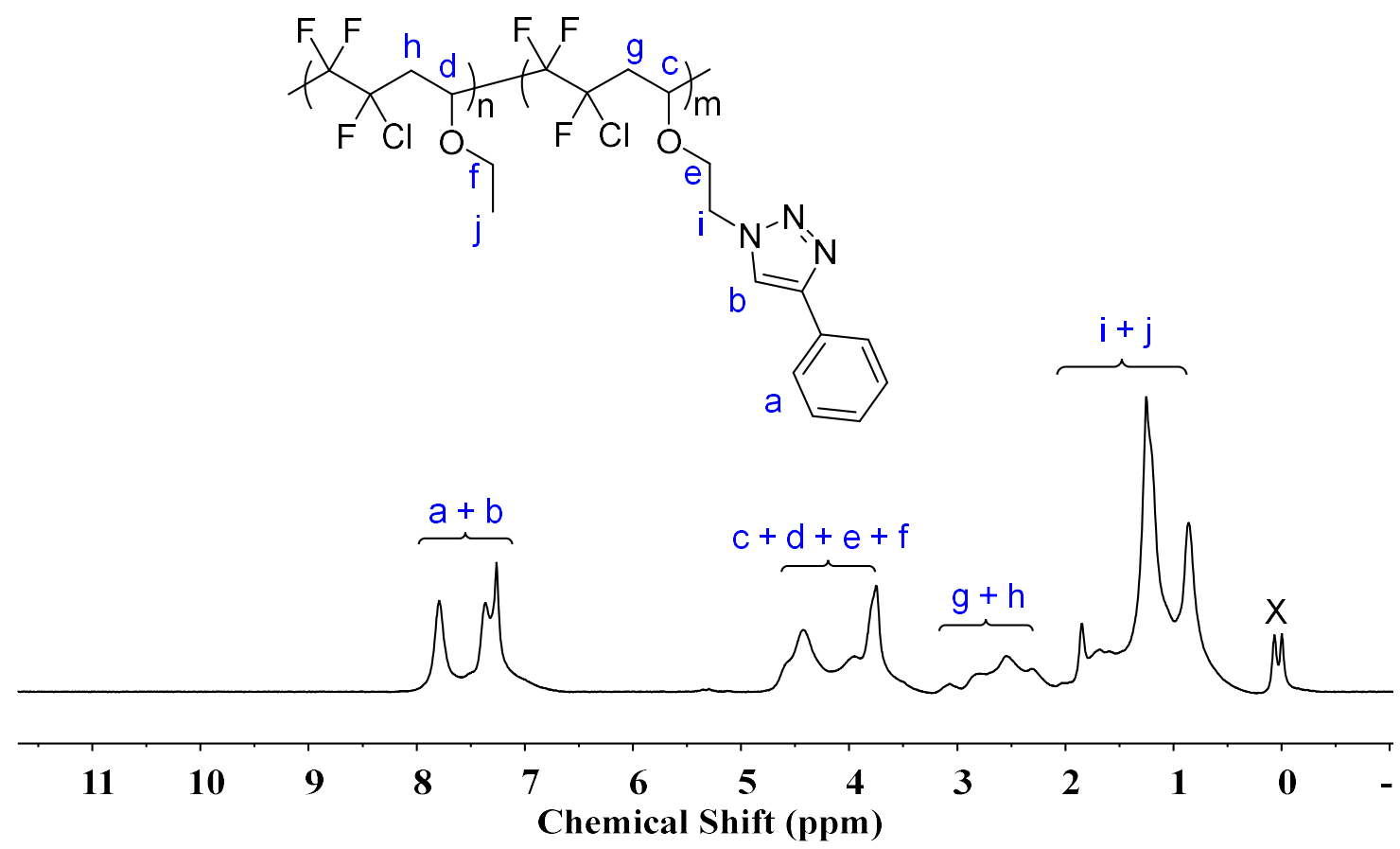

Figure S31. ${ }^{1} \mathrm{H}$ NMR spectrum of $\mathbf{P 3}$.

The differential scanning calorimetry (DSC) was carried out on a DSC Q2000 thermal analysis system (Shimadzu, Japan). The sample was first heated from $-40{ }^{\circ} \mathrm{C}$ to $150{ }^{\circ} \mathrm{C}$ at a heating rate of $10{ }^{\circ} \mathrm{C} \mathrm{min}-1$ under nitrogen atmosphere, followed by cooling to $-40{ }^{\circ} \mathrm{C}$ at $10{ }^{\circ} \mathrm{C} \mathrm{min}^{-1}$ after stopping at $150{ }^{\circ} \mathrm{C}$ for 3 minutes. 


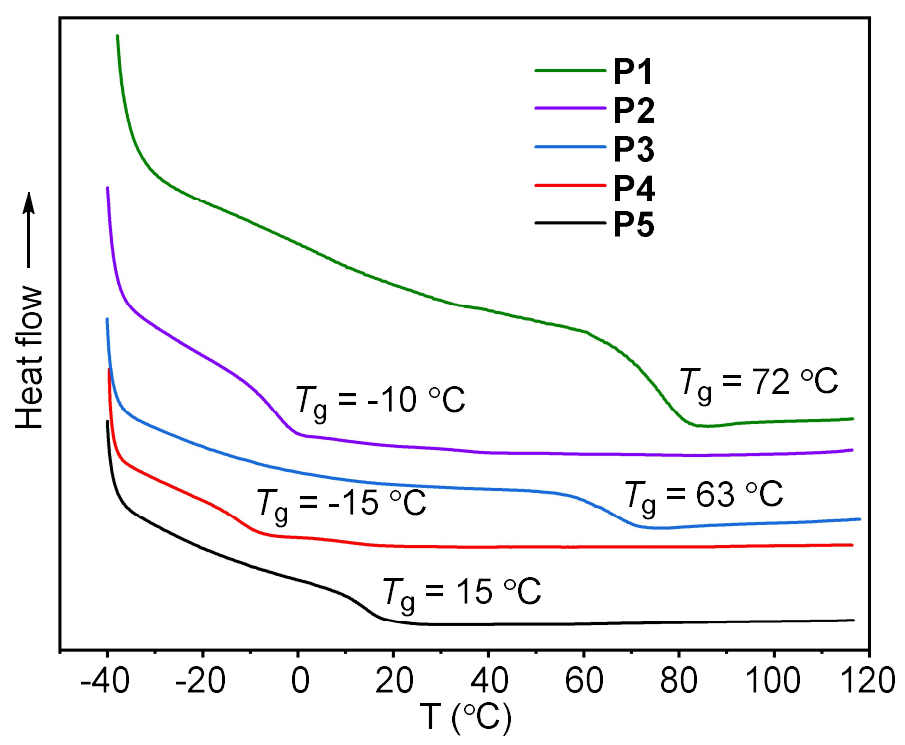

Figure S32. DSC curves of block alternating copolymers. For structures of $\mathbf{P 1}$ and P2, see Figure 5 in the manuscript. For structure of P3, see Figure S31. For structures of P4 [P(CTFE$a l t-\mathrm{EVE})-b-\mathrm{P}(\mathrm{CTFE}-a l t-\mathrm{CEVE})]$ and $\quad \mathbf{P 5}$ [P(CTFE-alt-EVE)- $b$-P(CTFE-alt-IEVE)], see Schemes S2 and S3, respectively.

\section{Synthesis and characterization of CTAs}

CTA 1a,${ }^{[4]}$ CTA 1b,${ }^{[5]}$ CTA 1c,${ }^{[6]}$ CTA 1d,,${ }^{[7]}$ CTA 2a, ${ }^{[8]}$ CTA 2b,${ }^{[9]}$ CTA 2c,,${ }^{[9]}$ CTA 2d ${ }^{[7]}$ and CTA $3^{\left[{ }^{[9]}\right.}$ were synthesized according to litetures or procedures modified from litetures.<smiles>N#CCSC(=S)N(c1ccc(C#N)cc1)c1ccc(Nc2ccncc2)cc1</smiles>

Scheme S7. The synthetic route for CTA 4 (modified from ref ${ }^{[4]}$ ).

A Schlenk tube equipped with a stir bar was charged with 4-aminobenzonitrile (5.19 g, $44 \mathrm{mmol})$, 4-chloropyridine hydrochloride (6.00 g, $40 \mathrm{mmol}), \mathrm{Pd}_{2}(\mathrm{dba})_{3}(733.1 \mathrm{mg}, 0.8 \mathrm{mmol})$, 1,3-bis(2,6-diisopropylphenyl)imidazolium chloride $(273.0 \mathrm{mg}, 0.8 \mathrm{mmol})$ and $\mathrm{KO} t \mathrm{Bu}(11.2 \mathrm{~g}$, $100 \mathrm{mmol}$ ) under $\mathrm{N}_{2}$ atmosphere. $120 \mathrm{~mL}$ Anhydrous dioxane was added into the tube via a sypringe. Then, the reaction mixture was stirred at $110^{\circ} \mathrm{C}$ for $20 \mathrm{~h}$. After reaction, the mixture was cooled to room temperature, treated with $\mathrm{HCl}(250 \mathrm{~mL}, 1.0 \mathrm{M})$ and $\mathrm{Et}_{2} \mathrm{O}(3 \times 100 \mathrm{~mL})$. 
After the orgainic layer was removed, the water phase was subsequently treated with $\mathrm{NaOH}$ $(6.0 \mathrm{M})$ until $\mathrm{pH} \sim 14$. The mixture was extracted with DCM $(3 \times 120 \mathrm{~mL})$, washed with brine, dried with anhydrous $\mathrm{Na}_{2} \mathrm{SO}_{4}$, concentrated under vacuum. The residue was purified with silica gel column chromatography $(0-10 \%$ methanol in EtOAc) to afford 4-(pyridin-4ylamino)benzonitrile as a yellowish-brown solid (3.83 g, 49\% yield). ${ }^{[4]}$

A Schenk flask equipped with a stir bar was charged with 4-(pyridin-4ylamino)benzonitrile $(2.93 \mathrm{~g}, 15 \mathrm{mmol})$ and $60 \mathrm{~mL}$ anhydrous THF under vacuum. Sodium bis(trimethylsilyl)amide (NaHMDS) in anhydrous THF (2.0 M, 7.5 mL) was dropwisely added into the flask at $0{ }^{\circ} \mathrm{C}$ with vigorous stirring. The mixture was stirred at room temperature for 1 h. Then, $\mathrm{CS}_{2}$ (3.43 g, $\left.45 \mathrm{mmol}\right)$ was added into the mixture, stirred for another $18 \mathrm{~h}$ at room temperature. Afterwards, bromoacetonitrile $(1.80 \mathrm{~g}, 15 \mathrm{mmol})$ was added into the flask at $0{ }^{\circ} \mathrm{C}$ with vigorous stirring. The reaction mixture was stirred at room temperature for $24 \mathrm{~h}$. After reaction, the mixture was concentrated under vacuum, treated with water and DCM. The combined organic layers were washed with brine, dried with $\mathrm{Na}_{2} \mathrm{SO}_{4}$ and concentrated under vacuum. The residue was purified with silica gel column chromatography $(50 \%$ EtOAc in petroleum ether) to afford CTA 1 as an orange solid (1.96 g, 42\% yield). ${ }^{1} \mathrm{H}$ NMR (400 MHz, $\left.\mathrm{CDCl}_{3}\right) \delta: 8.74(\mathrm{~d}, J=6.0 \mathrm{~Hz}, 2 \mathrm{H}), 7.79(\mathrm{~d}, J=8.8 \mathrm{~Hz}, 2 \mathrm{H}), 7.52(\mathrm{~d}, J=8.8 \mathrm{~Hz}, 2 \mathrm{H}), 7.32$

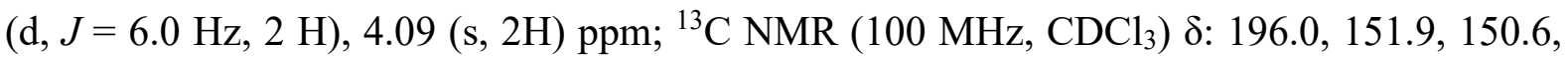
$146.7,134.0,129.3,122.3,117.5,115.2,113.3,23.4$ ppm.

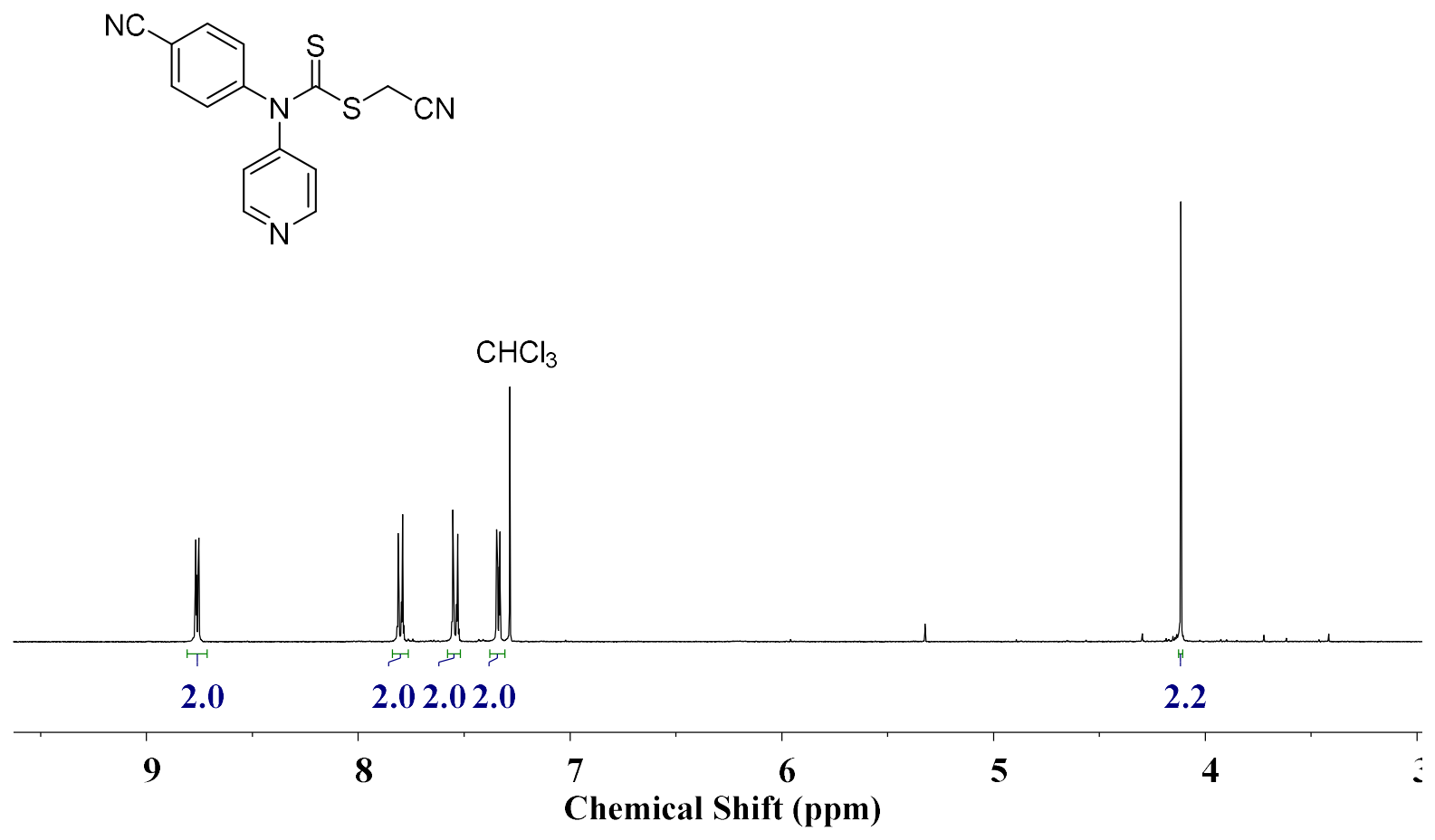


Figure S33. ${ }^{1} \mathrm{H}$ NMR spectrum of CTA 4.

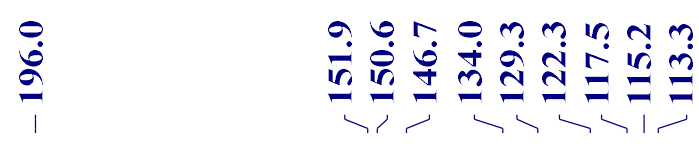<smiles>N#CCSC(=S)N(c1ccncc1)c1ccc(C#N)cc1</smiles>

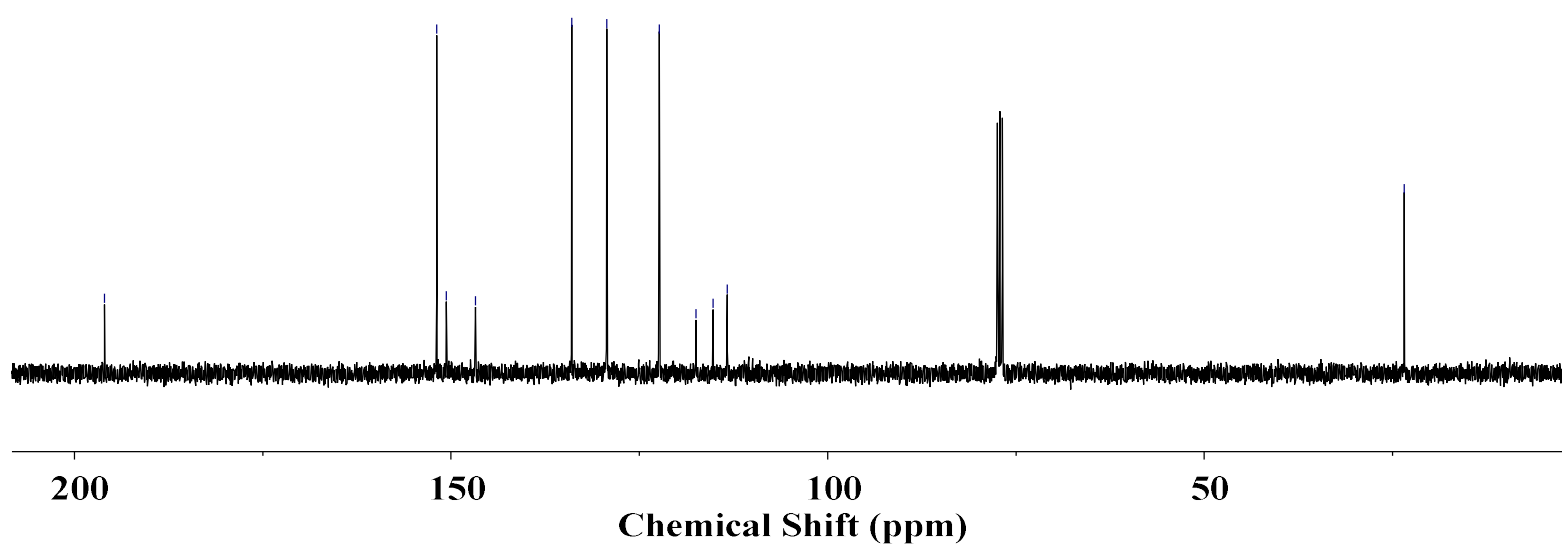

Figure S34. ${ }^{13} \mathrm{C}$ NMR spectrum of CTA 4.<smiles>CC#CC(C)(C)C(O)(O)C#N</smiles><smiles>S=C([Sn])N(c1ccccc1)c1ccccc1</smiles>
$\mathrm{Na-DTC}$<smiles>CC(C)(C)N=NC(C)(C)C</smiles><smiles>CC(C)(C#N)SC(=S)N(c1ccccc1)c1ccccc1</smiles>

Scheme S8. The synthetic route for CTA 3a.

An oven-dried round-bottom flask equipped with a magnetic stir bar was charged with diphenylamine $(845.0 \mathrm{mg}, 5.0 \mathrm{mmol})$ and $10 \mathrm{~mL}$ anhydrous tetrahydrofuran. $\mathrm{NaH}(120.0 \mathrm{mg})$ was added into the flaks at $0{ }^{\circ} \mathrm{C}$ with vigorous stirring. The mixture was stirred at room 
temperature overnight to give the solution of sodium diphenyl dithiocarbamate (Na-DTC). The solution was concentrated under vacuum to give Na-DTC solid, which was directly used without further purification.

A round-bottom flask equipped with a magnetic stir bar was charged with Na-DTC (534.5 $\mathrm{mg}, 2.0 \mathrm{mmol})$. A aqueous solution of $\mathrm{K}_{3} \mathrm{Fe}(\mathrm{CN})_{6}(987.5 \mathrm{mg})$ as added into the flask at $0{ }^{\circ} \mathrm{C}$ with vigorous stirring. After stirring at room temperature overnight, the mixture was extracted with ethyl acetate for several times. Combined organic layers were washed with brine, dried with anhydrous $\mathrm{Na}_{2} \mathrm{SO}_{4}$, concentrated under vacuum. Obtained residue was purified with flash column chromatography (eluting with $0-5 \%$ EtOAc in hexanes) to afford bis(diphenyl dithiocarbamate) (bis-DTC) as a light yellow solid (425.5 mg, 87\% yield).

A round-bottom flask equipped with a magnetic stir bar was charged with bis-DTC $(244.2$ $\mathrm{mg}$ ), azodiisobutyronitrile (AIBN, $835.5 \mathrm{mg}$ ) and degassed ethyl acetate $(3 \mathrm{~mL})$. The mixture was reflux overnight under $\mathrm{N}_{2}$ atmosphere. After reaction, the mixture was cooled down, and concentrated under vacuum. The obtained residue was purified with flash column chromatography (eluting with $0-5 \%$ EtOAc in hexanes) to afford CTA 3a as a light yellow solid (174.8 mg, 56\% yield). ${ }^{1} \mathrm{H}$ NMR (400 MHz, $\left.\mathrm{CDCl}_{3}\right) \delta: 7.44-7.30(\mathrm{~m}, 10 \mathrm{H}), 1.84(\mathrm{~s}, 6 \mathrm{H})$ ppm.

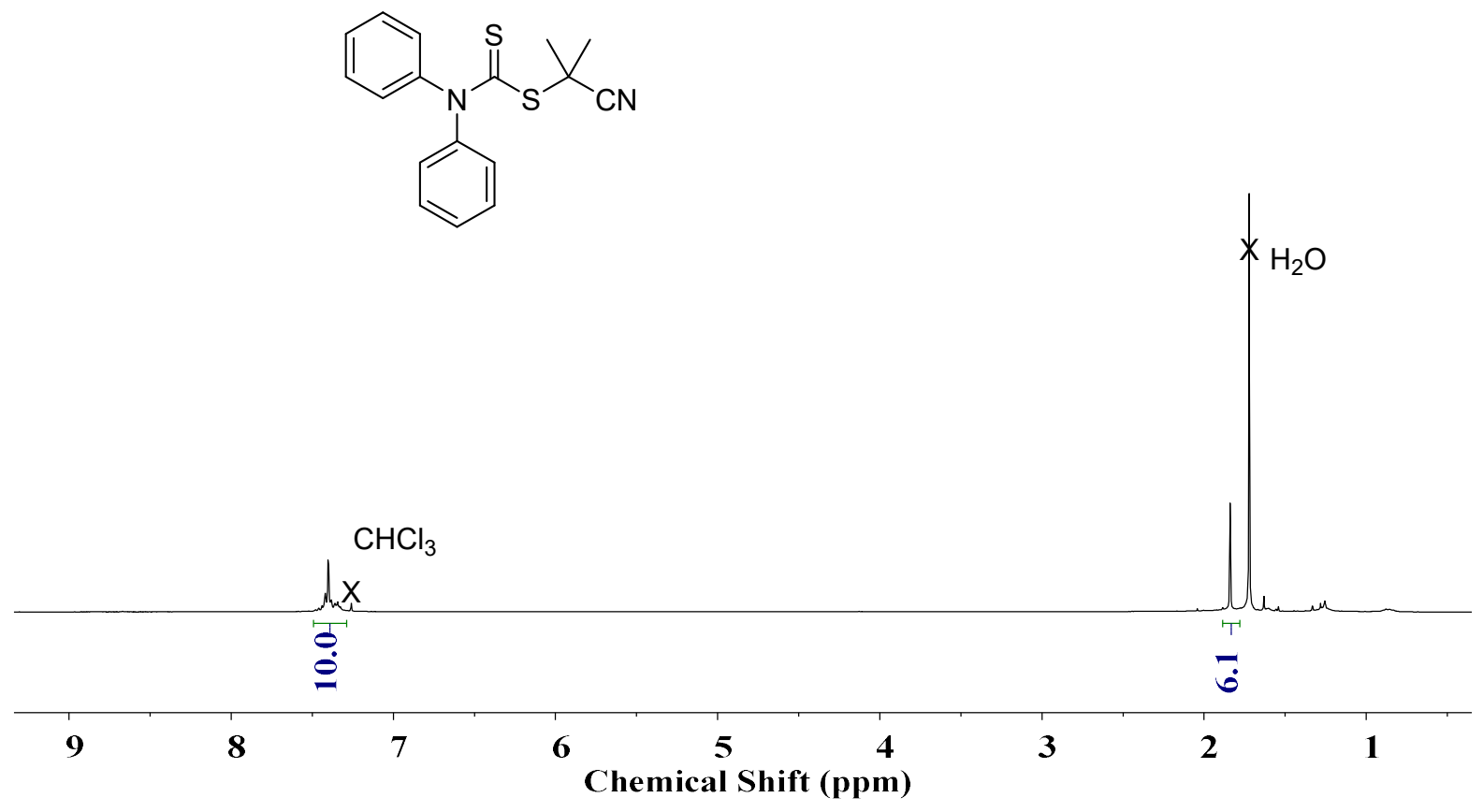

Figure S35. ${ }^{1} \mathrm{H}$ NMR spectrum of CTA 3a. 
<smiles>S=C(S)N(c1ccccc1)c1ccccc1</smiles>

$\mathrm{Na}-\mathrm{DTC}$

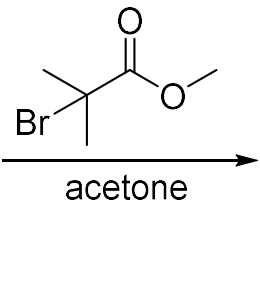<smiles>CC(=O)C(C)(C)SC(=S)N(c1ccccc1)c1ccccc1</smiles>

CTA 3b

Scheme S9. The synthetic route for CTA $\mathbf{3 b}$.

A round-bottom flask equipped with a magnetic stir bar was charged with a solution of Na-DTC (267.2 mg, $1.0 \mathrm{mmol})$ in acetone. Methyl 2-bromoisobutyrate (181.2, $1.0 \mathrm{mmol})$ was added into the flask with stirring. The mixture was stirred at room temperature overnight. After reaction, the mixture was extracted with DCM for three times. Combined organic layers were dried with anhydrous $\mathrm{Na}_{2} \mathrm{SO}_{4}$, concentrated under vacuum. The obtained residue was purified with flash column chromatography (eluting with 0-10\% EtOAc in hexanes) to afford CTA 3b as a light-yellow solid (293.5 mg, 85\% yield). ${ }^{1} \mathrm{H}$ NMR (400 MHz, $\left.\mathrm{CDCl}_{3}\right) \delta: 7.45-7.37$ (m, $8 \mathrm{H}), 7.37-7.28$ (m, 2H), 3.73 (m, 3H), 1.67 (s, 6H) ppm; $\left.{ }^{13} \mathrm{C} \mathrm{NMR} \mathrm{(100} \mathrm{MHz,} \mathrm{CDCl}_{3}\right) \delta: 198.8$, $174.4,145.0,129.6,128.2,128.0,55.4,52.9,25.9 \mathrm{ppm}$.
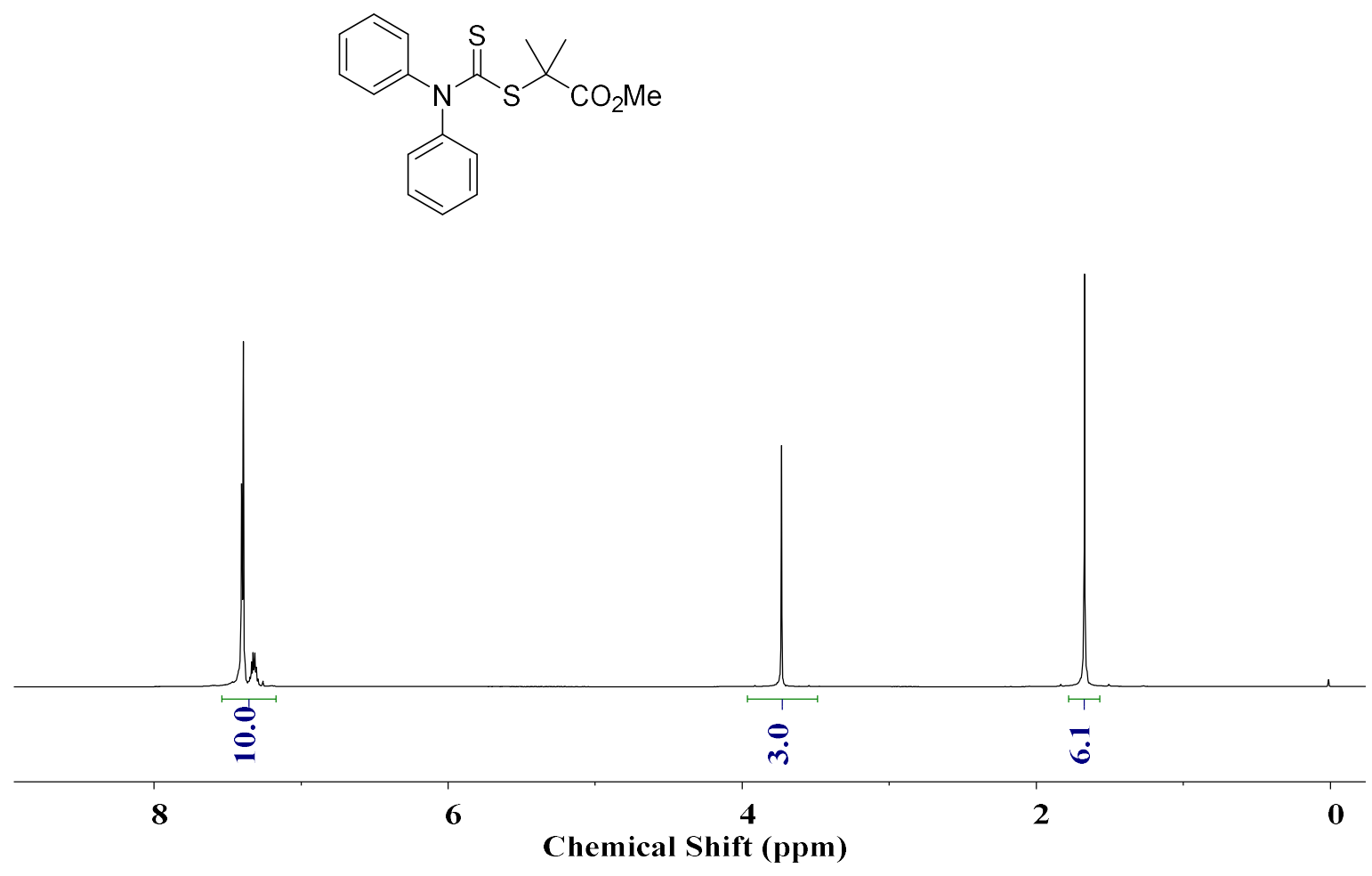

Figure S36. ${ }^{1} \mathrm{H}$ NMR spectrum of CTA $\mathbf{3 b}$. 


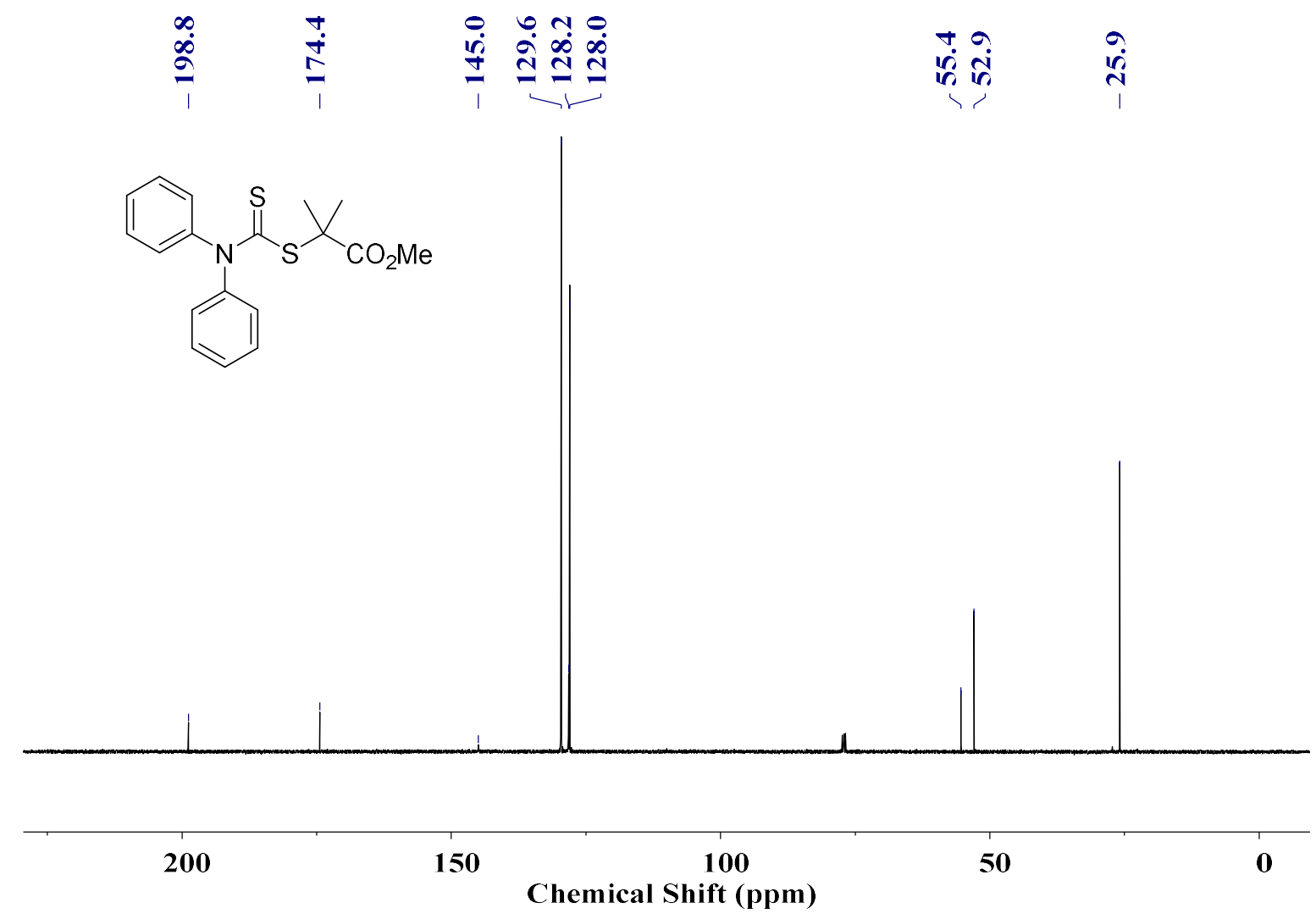

Figure S37. ${ }^{13} \mathrm{C}$ NMR spectrum of CTA $\mathbf{3 b}$.<smiles>[N+]#[S-]C(=S)N(c1ccccc1)c1ccccc1</smiles>

Na-DTC

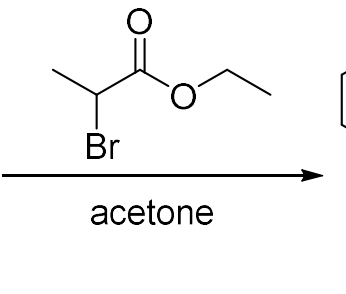

acetone<smiles>CCOC(C)C(=O)SC(=S)N(c1ccccc1)c1ccccc1</smiles>

CTA 3c

Scheme S10. The synthetic route for CTA 3c.

A round-bottom flask equipped with a magnetic stir bar was charged with a solution of Na-DTC (267.0 mg, $1.0 \mathrm{mmol})$ in acetone. Ethyl 2-bromopropionate $(181.1 \mathrm{mg}, 1.0 \mathrm{mmol})$ was added into the flask with stirring. The mixture was stirred at room temperature overnight. After reaction, the mixture was extracted with DCM for three times. Combined organic layers were dried with anhydrous $\mathrm{Na}_{2} \mathrm{SO}_{4}$, concentrated under vacuum. The obtained residue was purified with flash column chromatography (eluting with 0-10\% EtOAc in hexanes) to afford CTA 3c as a light-yellow solid (317.9 mg, 92\% yield). ${ }^{1} \mathrm{H}$ NMR (400 MHz, $\left.\mathrm{CDCl}_{3}\right) \delta:$ 7.46$7.37(\mathrm{~m}, 8 \mathrm{H}), 7.37-7.27(\mathrm{~m}, 2 \mathrm{H}), 4.65$ (q, $J=8.0 \mathrm{~Hz}, 1 \mathrm{H}), 4.24-4.16(\mathrm{~m}, 2 \mathrm{H}), 1.52(\mathrm{~d}, J=8.0$ $\mathrm{Hz}, 3 \mathrm{H}), 1.29$ (t, $J=8.0 \mathrm{~Hz}, 3 \mathrm{H}) \mathrm{ppm} ;{ }^{13} \mathrm{C} \mathrm{NMR}\left(100 \mathrm{MHz}, \mathrm{CDCl}_{3}\right) \delta: 199.7,172.1,129.7$, 
$129.7,128.4,128.0,61.6,50.0,17.1,14.2 \mathrm{ppm}$.

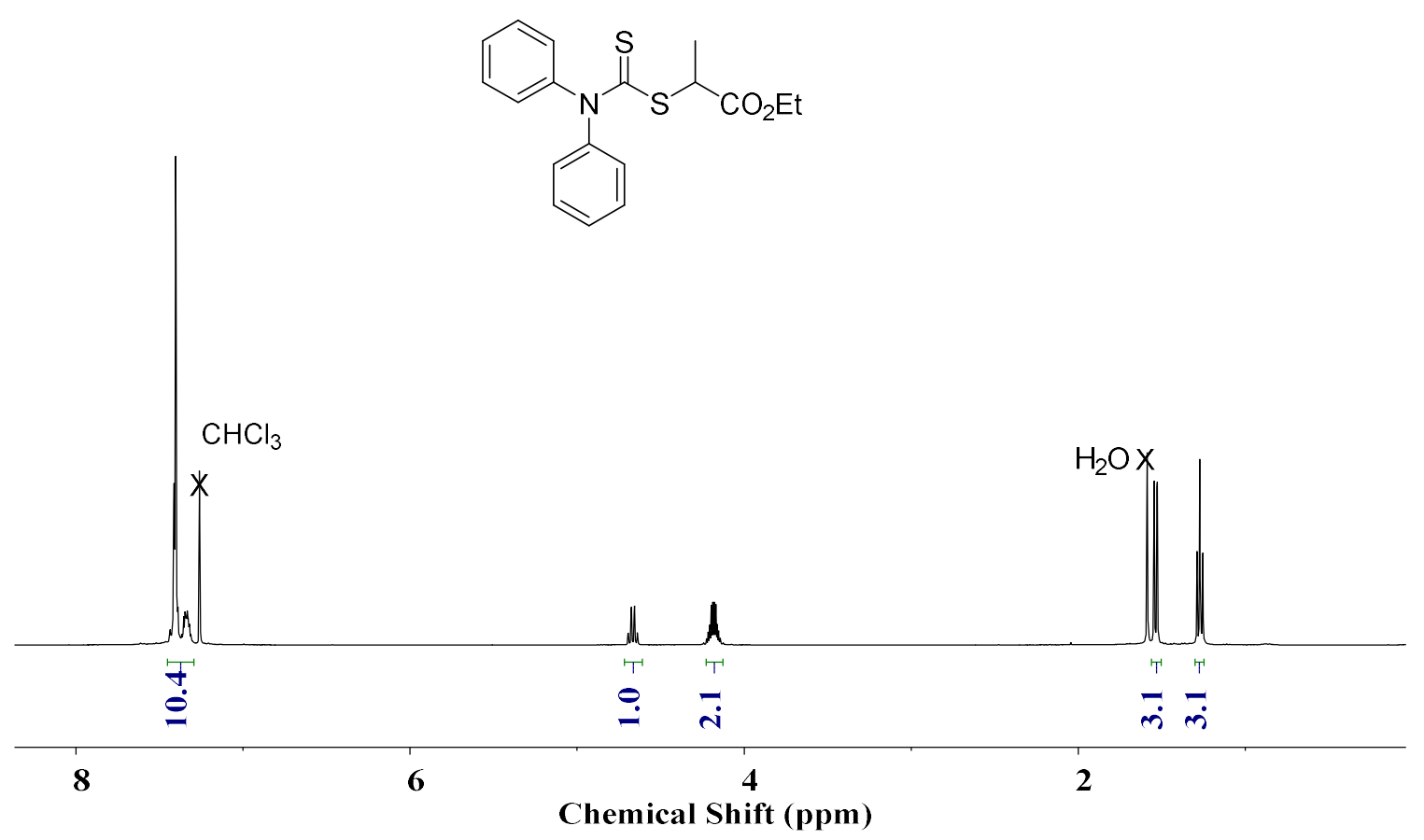

Figure S38. ${ }^{1} \mathrm{H}$ NMR spectrum of CTA 3c.
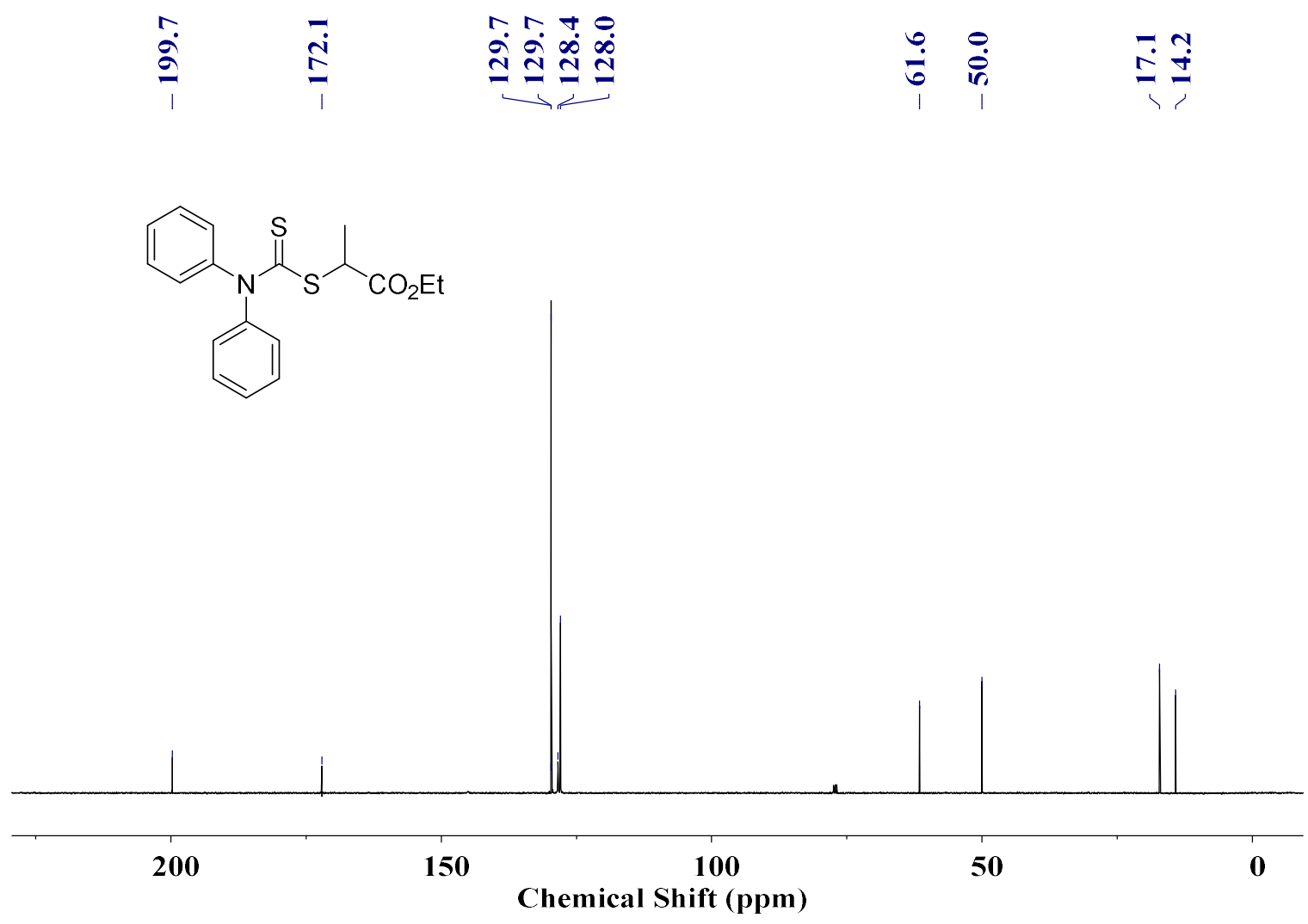

Figure S39. ${ }^{13} \mathrm{C}$ NMR spectrum of CTA 3c. 
<smiles>N#CCC([AsH2])C(=O)O</smiles>

Na-DTC<smiles>N#CCSC(=S)N(c1ccccc1)c1ccccc1</smiles>

CTA 3d

Scheme S11. The synthetic route for CTA 3d.

A Schlenk tube equipped with a magnetic stir bar was charged with a solution of Na-DTC $(267.0 \mathrm{mg}, 1.0 \mathrm{mmol})$ in acetone. Bromoacetonitrile $(120.4 \mathrm{mg}, 1.0 \mathrm{mmol})$ was added into the flask with stirring. The mixture was stirred at room temperature overnight. After reaction, the mixture was extracted with DCM for three times. Combined organic layers were dried with anhydrous $\mathrm{Na}_{2} \mathrm{SO}_{4}$, concentrated under vacuum. The obtained residue was purified with flash column chromatography (eluting with $0-10 \%$ EtOAc in hexanes) to afford CTA 3d as a light yellow solid (268.8 mg, 95\% yield). ${ }^{1} \mathrm{H}$ NMR (400 MHz, $\left.\mathrm{CDCl}_{3}\right) \delta: 7.46-7.38(\mathrm{~m}, 10 \mathrm{H}), 4.09$ (s, 2H) ppm; ${ }^{13} \mathrm{C}$ NMR (100 MHz, $\left.\mathrm{CDCl}_{3}\right) \delta: 196.3,129.9,129.7,129.0,127.8,115.9,23.4$ ppm.<smiles>N#CCSC(=S)N(c1ccccc1)c1ccccc1</smiles>

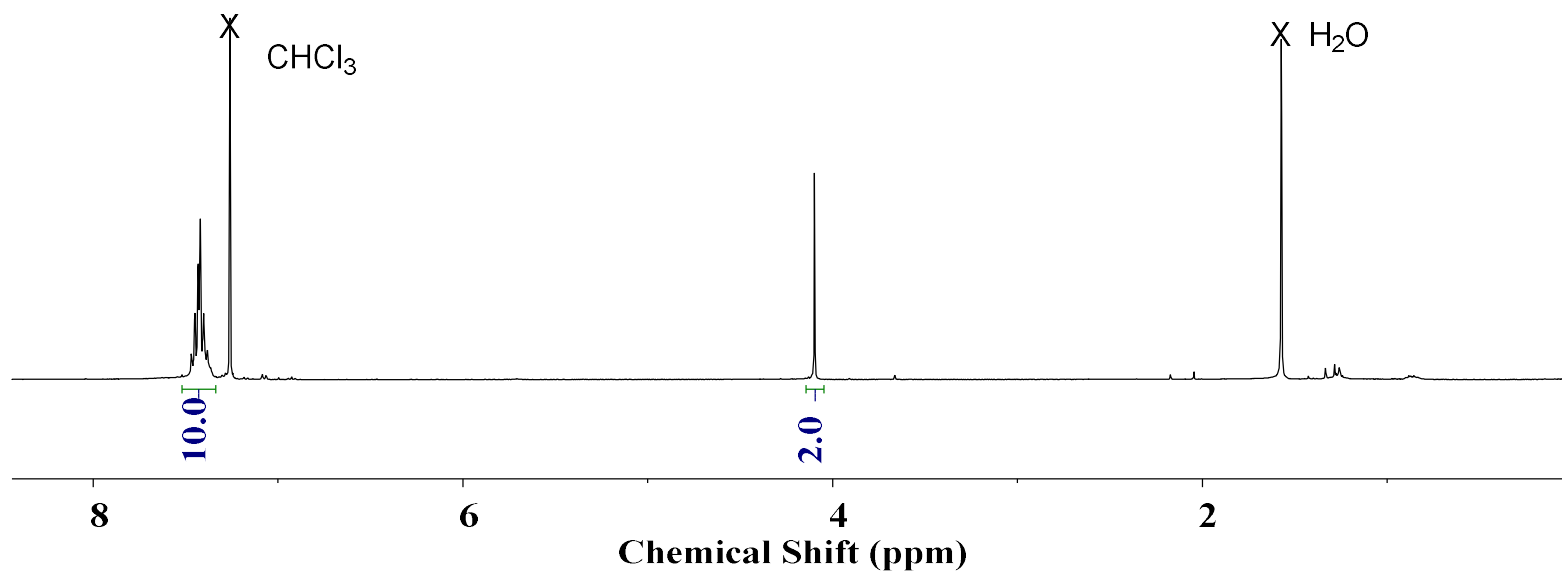

Figure S40. ${ }^{1} \mathrm{H}$ NMR spectrum of CTA 3d. 

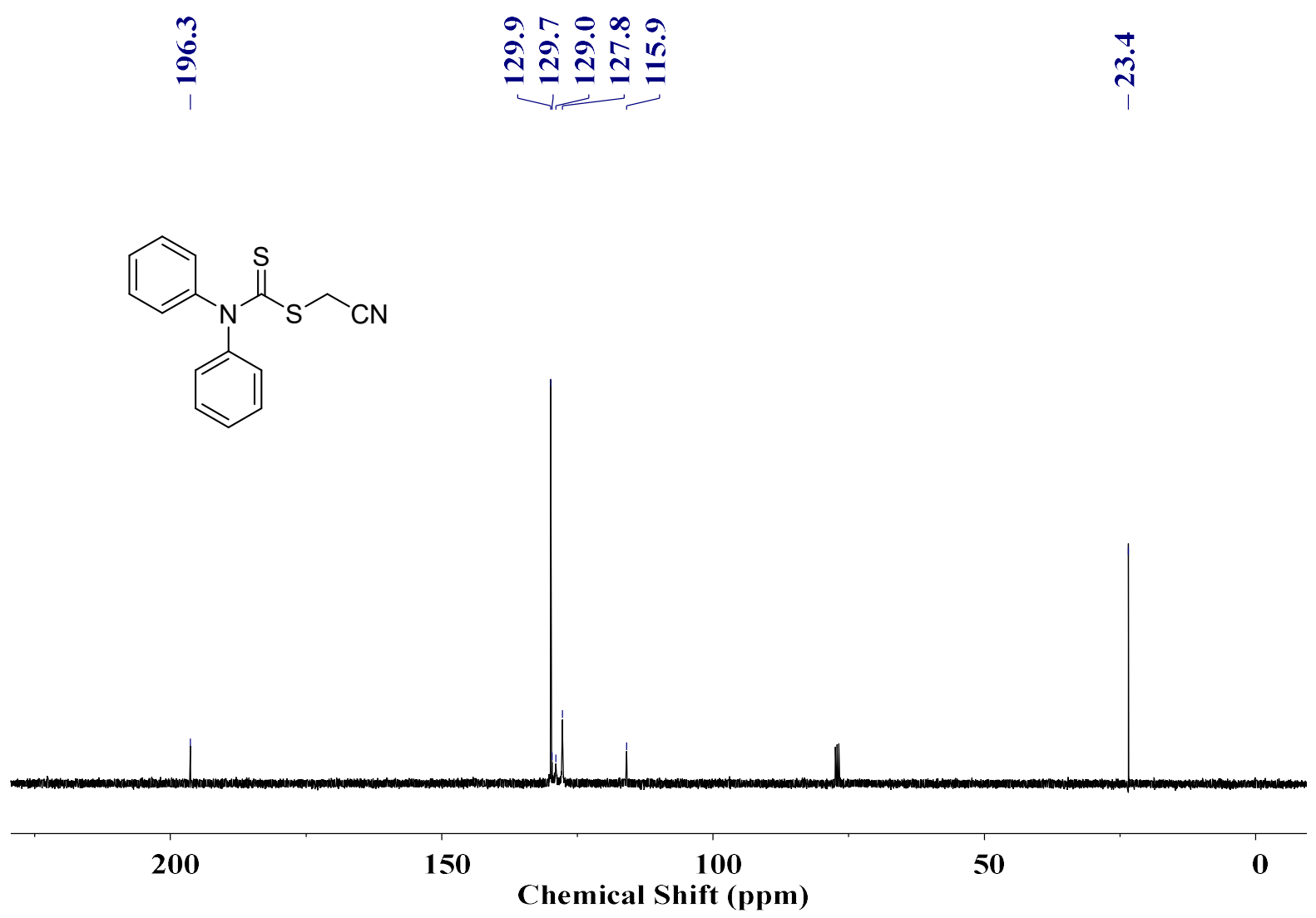

Figure S41. ${ }^{13} \mathrm{C}$ NMR spectrum of CTA 3d.

\section{Information of global CTFE Market}

The Chlorotrifluoroethylene (CTFE) industry "maintained a relatively optimistic growth in the past four years. Chlorotrifluoroethylene (CTFE) market size to maintain the average annual growth rate of 0.024 from $\$ 160.0$ million in 2014 to $\$ 180.0$ million in 2019 . Our analysts believe that in the next few years, Chlorotrifluoroethylene (CTFE) market size will be further expanded. We expect that by 2024, the market size of the Chlorotrifluoroethylene (CTFE) will reach \$200.0 million." Quoted from: Acquire Market Research, “Global Chlorotrifluoroethylene (CTFE) Market Report 2020" (Report Code: AMR-18-278933), Jan. 2020.

\section{Reference}

[1] Y. Zhao, H. Gong, K. Jiang, S. Yan, J. Lin, M. Chen, Macromolecules 2018, 51, 938946.

[2] D. S. Surry, S. L. Buchwald, Chem. Sci. 2011, 2, $27-50$. 
[3] a) K. Skrabania, A. Miasnikova, A. M. Bivigou-Koumba, D. Zehm, A. Laschewsky, Polym. Chem. 2011, 2, 2074-2083; b) C. Herfurth, P. Malo de Molina, C. Wieland, S. Rogers, M. Gradzielski, A. Laschewsky, Polym. Chem. 2012, 3, 1606-1617.

[4] D. J. Keddie, C. Guerrero-Sanchez, G. Moad, R. J. Mulder, E. Rizzardo, S. H. Thang, Macromolecules 2012, 45, 4205-4215.

[5] M. Y. Khan, M.-S. Cho, Y.-J. Kwark, Macromolecules 2014, 47, 1929-1934.

[6] J. Chen, X. Zhao, L. Zhang, Z. Cheng, X. Zhu, J. Polym. Sci., Part A: Polym. Chem. 2015, 53, 1430-1436.

[7] Y. Kwak, R. Nicolaÿ, K. Matyjaszewski, Macromolecules 2009, 42, 3738-3742.

[8] K. Nakabayashi, A. Umeda, Y. Sato, H. Mori, Polymer 2016, 96, 81-93.

[9] Y. Kwak, K. Matyjaszewski, Macromolecules 2008, 41, 6627-6635. 